\title{
Investigation into gas production from natural gas hydrate: A review
}

\author{
Xiao-Sen Li ${ }^{\text {a,b, }}$, Chun-Gang Xu ${ }^{\mathrm{a}, \mathrm{b}}$, Yu Zhang ${ }^{\mathrm{a}, \mathrm{b}}$, Xu-Ke Ruan ${ }^{\mathrm{a}, \mathrm{b}}$, Gang Li ${ }^{\mathrm{a}, \mathrm{b}}$, Yi Wang ${ }^{\mathrm{a}, \mathrm{b}}$ \\ ${ }^{a}$ Key Laboratory of Gas Hydrate, Guangzhou Institute of Energy Conversion, Chinese Academy of \\ Sciences, Guangzhou 510640, P. R. China., \\ ${ }^{b}$ Guangzhou Center for Gas Hydrate Research, Chinese Academy of Sciences, Guangzhou 510640, P. \\ R. China.
}

\begin{abstract}
Natural gas hydrates (NGHs), which extensively exist in sea-floor and permafrost regions, are considered as an alternative energy in the future for the fossil fuels approaching depletion with the gradually increasing energy consumption. Because of the particularity of NGH stabilizing only in the conditions of the high pressure and the low temperature, the exploitation of $\mathrm{NGH}$ is distinguished from those of petroleum and natural gas. Researchers over the world are devoting themselves to developing the technologies of NGH exploitation. However, till now, few NGH exploitation technology is identified and employed to exploit commercially NGH. Although there do be two cases of short-term NGH exploitation in Mackenzie Delta (CAN), Alaska North Slope (USA) and Nankai Trough (JAP) in the past 10 years. It is mainly because some characteristics of the flow (gas, water, gas-hydrate slurry, quicksand, etc.), the issues of heat and mass transfer, the risk assessment and the economic evaluation are still not comprehensively recognized. Presently, the researches of NGH exploitation are mainly carried out from three aspects, numerical simulation and analysis, experimental simulation and field trial exploitation for the different technologies. In this paper, we comprehensively review the relevant studies of NGHs and propose our comments. We not only represent the achievements for the NGH exploitation researches, but also discuss the limitations and challenges, raise some questions and put forward some suggestions from our points of view.
\end{abstract}

Keyword: Natural gas hydrate; production technique; experiment; numerical simulation; field tests

\section{Contents}

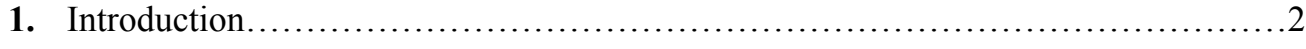

2. Natural gas hydrate resources...............................................

2.1. Distribution of gas hydrates.......................................... 3

2.2. Geologic characterization of gas hydrates................................ 4

2.3. Classification of gas hydrate reservoirs...................................5

3. Fundamental investigations of gas hydrates.................................. 6

3.1. Equilibrium of gas hydrates............................................ 6

3.2. Gas hydrate formation and decomposition............................... 8

3.3. Heat and mass transfers...............................................11

* Corresponding author. Tel: +86-20-87057037; Fax: +86-20-87034664.
E-mail address: lixs@ms.giec.ac.cn (X.-S. Li) 
3.4. Multiphase flow. . .13

3.5. Mechanic characterization................................................ 16

4. Laboratory investigations into gas production from NGHs.....................18

4.1. Techniques of gas production............................................. 18

4.2. Apparatuses of laboratory investigations...................................22

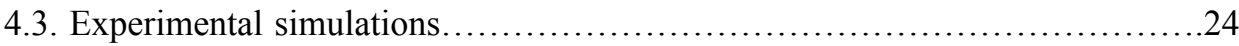

4.4. Numerical simulations....................................................... 34

4.5. Comments and suggestions ............................................ 41

5. Field production test from hydrate deposits...................................42

5.1. Field test from onshore and offshore gas hydrate deposits.....................42

5.2. Problems and comments................................................ 47

6. Environmental challenges for gas production from hydrates......................48

7. Economic analysis on gas production from hydrates................................49

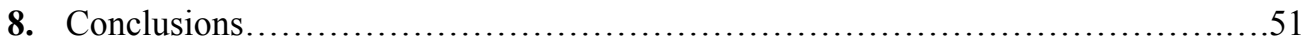

\section{Introduction}

Energy demand is expected to increase continuously in the coming years for meeting the human society's grows. In contrast, the ever-scarcer fossil energies including petroleum, coal and natural gas impede human society's continuous development. Therefore, it is essential and urgent to develop new alternative energy sources. Solar energy, wind energy, ocean energy, biomass energy and nuclear energy have undergone profoundly the development of the different levels in the different countries. However, the developments of all these new energies are limited by the geographical conditions, technique factor and political environment. And more importantly, the energy coming from these new energy resources could still not meet the demand of human society development according to the report submitted by the International Energy Agency (IEA).[1]

Natural gas hydrate $(\mathrm{NGH})$ is an ice-like crystalline compound formed by natural gas molecules and water molecules.[2] From the 1960's, the researchers gradually discovered that a large number of NGHs distributes in the sediments in seafloor and permafrost. There are two important reasons that the NGH attracts the world's eyes. On one hand, a cubic NGH can contain approximately 180 cubic natural gas at standard temperature and pressure; on the other hand, it is estimated that the amount of carbon in NGHs over the world is twice the total amount of carbon in the proved fossil fuels on the earth.[3, 4] Thus, NGH is considered as an alternative energy, which is widespread in seafloor and permafrost zones. Natural gas production from NGHs, thereby, attracts many attentions. By shifting the equilibrium condition of the NGH reservoir, the NGH dissociates and natural gas releases from the reservoir. Consequently, gas production is a process containing thermodynamics, kinetics, engineering technology, geology, etc. Moreover, due to the difference of the geological conditions and temperatures, deeply recognizing the characteristics of the NGH reservoirs and systematically simulating natural gas production from the different reservoirs in the laboratory are necessary and quite significant before natural gas production field tests. Around the topic of gas production from NGH, numerous studies on NGH, gas production methods, numerical and experimental simulation of gas production, and field trials have been carried out by the research groups over the world. All these studies were conducted on a very specific 
aspect of interest. For example, Collett et al.[5-7] put a lot of energy into investigating the physical and chemical characteristics of NGH reservoir, Li et al.[8-35] did numerous experiments to understand the mechanism of gas production and develop effective gas production methods, Moridis et al.[36-40] devoted themselves to developing the simulator for numerical simulation of gas production. Objectively, in the past three decades, a lot of excellent achievements were obtained. However, the fundamental issues such as gas production mechanism from NGH, governing factors, efficiency and economic evaluation are still not solved.

Previously, there are many reviews on the specific areas of hydrates conducted by many excellent scientists and groups from the different perspectives over the world,[41-51], such as the funmeantal research, hydrate application and production from NGH, etc. A comprehensive review of the current state of the research of hydrogen hydrates for gas storage and future directions has been conducted recently.[52] A recent review has summarized the research process on NGH production like production technique, environmental impact, strategy, and also the field test done.[53] In this review, we strive to review holistically the studies on gas production from NGH from the following aspects, including the NGH resources, fundamental investigation of $\mathrm{NGH}$, laboratory investigations into gas production from $\mathrm{NGH}$, field production tests from $\mathrm{NGH}$, environmental challenges for gas production from $\mathrm{NGH}$, economic evaluation, and novel techniques of gas production from NGHs, etc. In addition, we make a comment on the studies of the field tests and real drillings from the public reports. We hope to give more information of relationship and deficiency between the current studies and the final NGH production technology. From the review, we not only comprehensively state the studies of gas production from NGH, but also make the comments on the studies in our point of view, as well as put forward some suggestions.

\section{Natural Gas Hydrate Resources}

\subsection{Distribution of gas hydrates}

Natural gas hydrates (NGHs) are formed under a certain condition of the low temperature and high pressure. The chemical characteristics and stability of NGH have been widely investigated since 1930's.[4, 54-56] In general, three main structures of gas hydrates, structural I (sI), structural II (sII) and structure $\mathrm{H}(\mathrm{sH})$ are identified, and among them, sI and sII are cubic, $\mathrm{sH}$ is hexagonal. In sI hydrate, water molecules are automatically arranged to form cavities with $5^{12}$ cages (diameter about $7.90 \AA$ ) and $5^{12} 6^{2}$ cages (diameter about 8.67 $\AA$ ), and the ratio of the two cages is about 1:3. In sII hydrate, $5^{12}$ cages (diameter about $7.82 \AA$ ) and $5^{12} 6^{4}$ (diameter about $9.46 \AA$ ) cages coexist and the ratio is about $2: 1$. In sH hydrate, cages of $5^{12}$ (diameter about $7.82 \AA$ ), $4^{3} 5^{6} 6^{3}$ (diameter about $8.12 \AA$ ) and $5^{12} 6^{8}$ (diameter about $11.58 \AA$ ) coexist, and ratio is about $3: 2: 1$.[2] The hydrate structure is determined by the size of gas and condition of temperature and pressure.[3, 57] For instance, pure $\mathrm{CH}_{4}$ forms sI gas hydrate under a certain condition. $\mathrm{CH}_{4}$ gas molecules occupy these cages and are stabilized in the gas hydrate under Van der Waals forces. In nature, natural gases, which form NGHs, mainly originate from two aspects, thermogenic or/and biogenic.[58-63] Thermogenic natural gases come from the decomposition of organics from fossil matters, which include large amounts of $\mathrm{CH}_{4}$ and other balance hydrocarbons with longer chains such as ethane $\left(\mathrm{C}_{2} \mathrm{H}_{6}\right)$ and propane $\left(\mathrm{C}_{3} \mathrm{H}_{8}\right)$. Biogenic natural gases are generated from methanogens, and biogenic natural 
gases are nearly pure $\mathrm{CH}_{4}$.

The currently explored and proved NGH reservoirs mainly distribute in the sea regions of Japan Sea, India Ocean, Gulf of Mexico, South China Sea, Bearing Strait, Seas of Korea, Trinida and Tobago, and in the permafrost regions of Alaska (USA), Mackenzie Delta (CAN), Siberia (RUS) and Qinghai-Tibet Plateau (China) etc.[64] The most important ways to explore or evaluate NGH reservoir are analyzing systematically the characteristics of bottom simulating reflector (BSR) of NGH from the collected seismic lines for sea floor regions and investigating directly the drilled cores for permafrost regions.[65-67] For BSR, gas hydrate presents a sharp seismic velocity decrease along the interface between hydrate bearing sediment (HBS) with anomalously high seismic velocity and free gas with low seismic velocity. Nevertheless, for the regions with low hydrate saturation in the sediments or without free gas, there might be no sharp decrease in seismic velocity, which makes the BSR detecting no sense in these regions. Therefore, relative to NGH reservoir exploration in sea floor regions, it is more accurate to explore NGH reservoir in permafrost regions by the BSR.[65-67] Objectively, BSR might not be perfect for its limitations as mentioned above, but it should say, till now, BSR is the one available way to explore and prove NGH reservoirs.

\subsection{Geologic characterization of gas hydrates}

Most NGHs are proved to be sI hydrates, like those observed in the Ulleung Basin, [39, 68, 69] Gulf of Mexico,[50, 70-78] Nankai Trough,[79-83] South China Sea,[84-96] and so on. However, in some areas, where the conditions are too mild to form pure $\mathrm{CH}_{4}$ hydrates, sII or $\mathrm{sH}$ hydrates are observed and these hydrates are classified as thermogenic natural gas hydrates. The sII or sH thermogenic NGHs have been confirmed in the Gulf of Mexico,[75] Northern Cascadia Margin,[97-100] Caspian Sea,[101, 102] Chinese Qilian Mountain,[103] etc.

As a kind of energy resource, NGHs are systematically evaluated from the aspects of (1) how large the region ranges of stable NGHs is, (2) what the structure of the sediments containing NGHs is, (3) what the characteristics of NGHs in the sediments are, (4) whether the NGHs are suitable for production or not, (5) how much $\mathrm{CH}_{4}$ is contained in the region. NGHs together with free water or/and free gases distribute in the sediments of the seafloor and permafrost areas in the different forms and a range of geologic system.

Sediments containing NGHs with the different morphologies are classified as three types, pore filling, naturally fractured and massive/noddle, as shown in Figure 1.[104] For the first type, NGHs typically accumulate in pore spaces of porous sediments such as sandstones or carbonate rocks, as conventional gas or oil. [104] NGHs belonging to the first type have been proven in almost all the NGH reservoir sites. In the marine environments, this type of NGHs has been found in the Eastern Nankai Trough offshore Japan [104] and the Shenhu area of South of China Sea, [105] etc. In the permafrost environments, gas hydrates have been commonly documented to be the first type[106], such as those presented in the North Slope of Alaska, in the Canadian arctic, in northern Siberia, and in Qilian Mountain permafrost. For the second type, NGHs exist in fractures or/and veins of the sediments, and this type of NGHs have been discovered in the offshores in India and Korea. NGHs for the third type accumulates in fine grained muds in the form of lumps or/and nodules on the surface of seafloor, which are proven to locate in Gulf of Mexico and Japan Sea. Due to the considerably 
low energy efficiency, it is quite difficult to produce natural gases from the second and third types NHG reservoirs.[104]

Boswell and Collett [107] described the potential global gas hydrate occurrence by using a gas hydrate resource pyramid. The apex of the gas hydrate resource pyramid shows that the smallest but the most promising gas hydrate resource is the sand-dominated gas hydrate reservoirs, which may hold 10 to 100 of trillion cubic feet (TCF). The sand-dominated hydrate reservoirs are potentially high quality natural gas source, which have good porosity and good gas saturation, and thus, have high intrinsic permeability in coarse-grained sediments. The overlying hydrate layer may provide a low-permeability barrier to prevent gas leakage.[108] These factors are favorable for gas production from hydrate reservoirs. In addition, the fractured reservoirs involving massive hydrate are also interesting and may be common in certain areas [72], with thick sections presenting massive vein fills, high concentrations of small hydrate nodules, small vein fills, or massive layers parallel to bedding planes.[109] However, unlike the sand-dominated gas hydrate reservoirs with high permeability, gas extraction from these fractured hydrate reservoirs may be complex because of significant geomechanical issues to the integrity of the hydrate-bearing formation [110], the exploitation of gas from these fractured hydrate reservoirs will require the further studies and the improved gas production technologies.

\subsection{Classification of gas hydrate reservoirs}

NGHs are generally coexist with free water or/and free gases. Based on the difference of coexistence of NGHs, free water or/and free gases, the NGHs reservoirs are generally divided into three classes.[111] Figure 2 gives Sketch diagram of Classes 1, 2, and 3 hydrate reservoirs. As shown in Figure 2, Class 1 is that one hydrate bearing layer (HBL) covers on a two-phase fluid zone with free gas. In Class 1, the saturation of hydrates distributing in pore spaces is high enough, making the effective permeability of HBL relatively low. From the point of overall construct, the bottom of HBL is generally also the bottom of the hydrate stability zone. Because the thermodynamics of Class 1 is quite close to the equilibrium of $\mathrm{NGH}$, it is considered to be the most suitable NGH reservoir for natural gas production because only quite small energy is needed for the NGHs dissociation. The typical Class 1 NGHs are proven in Messoyakha Field in Russia, Sagavanirktok Formation in Alaska.[112] Class 2 is that one HBL covers on a mobile water zone, while Class 3 is that there is only one HBL. A part of NGH reservoirs in the Eastern Nankai Trough and Mallik sites are Class 2,[113-115] and most of the reservoirs in Eastern Nankai Trough, Mallik sites and Mt. Elbert sites are labelled as Class 3.[116-120] In Classes 2 and 3, the hydrate interval might be rich in the range of the hydrate stability zone, and the bottom of hydrate interval does not mean the bottom of the hydrate stability zone. In fact, compared to Class 1 NGH reservoirs, Classes 2 and 3 NGH reservoirs are still not well defined as gas production targets for the reasons of initial conditions, environmental protection, economic consideration and the thermodynamic conditions of the NGH reservoirs. Besides, other one NGH reservoir with low hydrate saturation and unconfined geological strata is defined as Class 4 , which specially and widely distributes in oceanic floor. Class 4 NGH reservoirs usually appear as nodules with very low saturation. Therefore, Moridis et al.[111] regarded them as sparse NGHs in muds. Because of the low NGH saturation and unconfined geological strata, Class 4 is not a target for natural 
gas production till now.

\section{Fundamental Investigations of Gas Hydrates}

\subsection{Equilibrium of Gas Hydrates}

The temperature and pressure conditions of the gas hydrate formation and decomposition is the initial issue of the investigation into the natural gas production, hydrate applications, and other areas where gas hydrate is encountered. A significant number of publications are devoted to the measurement of the equilibrium conditions of gas hydrates. [2] Because NGH mainly exists in the sediments, phase equilibrium studies of natural gas hydrate systems in porous media are of significance for understanding the characteristics of the hydrate in marine deposits and permafrost regions, and providing the data and theoretical reliability for the future hydrate exploitation. Many recent studies have focused on the equilibrium hydrate conditions in porous media. Handa and Stupin [121] first measured the equilibrium dissociation conditions of methane hydrate and propane hydrate in porous media. After that, the researchers have carried out many investigations into the hydrate equilibrium dissociation conditions for the different porous media, and obtained many experimental data. Most of the experiments were carried out in the artificial materials, such as silica glass, silica gels, etc.[122-130] The experimental results have revealed that the hydrate decomposition pressure increases with the decrease of the pore size of the porous media due to the effect of the capillary pressure.

All these study results show the thermodynamic characterization of simulated NGHs in different media, however, the simulated NGHs are not the real NGHs in natural conditions at all, i.e., these results could not be the equilibrium data for the real NGHs because the field conditions have more direct effect on the thermodynamic conditions. Therefore, several experiments were carried out in natural materials. Uchida et al.[131] measured the decomposition conditions of methane hydrate in silica sand, sandstone, and clays (kaoline and bentonite). They concluded that the decomposition conditions are mainly affected by the pore sizes, and the hydrates form not only between the particles but also in the interlayer of the bentonite. Yakushev [132] found that low water contents inhibit hydrate formation in spite of having good permeability in the unconsolidated clay powder. The hydrate accumulation in the same clay sample increases with the increase of the water content. Clennell et al.[133] found that the particle sizes of the marine sediments also affect the hydrate equilibrium decomposition pressure. $\mathrm{Lu}$ and Matsumoto [134] found that the equilibrium decomposition temperature of methane hydrate at a given pressure in a nannofossil-rich claystone column is shifted to the lower temperature field by $0.4{ }^{\circ} \mathrm{C}$ and $1.5{ }^{\circ} \mathrm{C}$, compared to those in sea water and pure water, respectively. By these studies, part of the effects of the real factors on the equilibrium conditions have been revealed, and these study results are helpful to understand the thermodynamic characterization of the real NGHs. However, there is still no clear parameter to determine the hydrate equilibrium conditions in natural materials due to its complicated characteristics.

Due to the importance of the gas hydrate equilibrium conditions, various models have been established to predict the hydrate equilibrium temperature and pressure. Van der Waals and Platteeuw[135] proposed a model for the chemical potential of water in the hydrate phase and computed incipient hydrate formation pressures for nine gases. On the basis of the van 
der Waals-Platteeuw model, Parrish and Prausnitz [136] presented an algorithm for the prediction of the hydrate equilibrium conditions in multicomponent mixtures. After that, this method was developed by Ng and Robinson [137], Holder et al.[138], John and Holder [139] John et al.[140], etc. Li et al.[141, 142] employed the statistical associating fluid theory (SAFT) equation of state for the correlation and prediction of vapor-liquid equilibrium (VLE) of different mixtures, and predicted the gas hydrate equilibrium formation conditions with the inhibiting effect of methanol, glycerol, ethylene glycol, and triethylene glycol. The SAFT equation takes into account hard-sphere repulsion, hard chain formation, dispersion, and association. The predictions were found to be in satisfactory to excellent agreement with the experimental data. Chen and Guo [143] proposed a model according to the two-step hydrate formation mechanism, in which the basic hydrate forms by chemical reaction for the first step and the gas is adsorbed into the linked cavities for the second step. Therefore, there are two kinds of equilibrium existing in the system: the chemical reaction equilibrium and the physical adsorption equilibrium. In general, the hydrate equilibrium conditions of bulk hydrate have been well predicted by different thermodynamic models. Shahnazar and Hasan [144] gived a review of the predictive studies on the hydrate equilibrium conditions without porous media. The theoretical models in describing the capillary effect are quite important in advancing the understanding of the microscopic mechanisms and predicting the thermodynamic and dynamic properties. Considering the capillary effect based on the Kelvin equation, the predictive model of hydrate equilibrium dissociation conditions in porous media was proposed by Clarke et al.[145] Later, Clennell et al.[133] and Henry et al.[146] applied Gibbs-Thomson equation to account for the capillary effect arising from the small pore size and established a thermodynamic model to predict the three-phase equilibria of $\mathrm{CH}_{4}$ hydrate in porous media. Llamedo et al.[147] pointed out that when the hydrate forms and dissociates in porous media, the solid-liquid curvature in the capillary pores is not same. They made a revision and gave the new hydrate-liquid interfacial tension values. Li et al.[148] employed two thermodynamic approaches, based on the equal fugacities and based on the equal activities, to predict the gas hydrate equilibrium dissociation conditions in the porous media. For the non-hydrate phase, the Trebble-Bishnoi equation and the Soave-Redlich-Kwong equation were used in the fugacity approach and the activity approach, respectively. For the hydrate phase, the van der Waals-Platteeuw model incorporated with the capillary model of Llamedo et al.[147] was used in both approaches. It was found that the predictive ability of the fugacity approach is better than that of the activity approach.

The Kelvin equation and Gibbs-Thomson equation are consistent intrinsically because they have the same relation of pore radius, interfacial tension and contact angle. Ever since, people generally used Gibbs-Thomson equation to describe the capillary effect of porous media. For improving predictions of the hydrate equilibria in the sediments, some modifications have been done on the Kelvin equation (or Gibbs-Thomson equation). For the pore radius in the Kelvin equation, the main revision is on the distribution of pore radius for the practical porous media, K1auda and Sandier [149] used the Gaussian probability density function to fit the pore size distribution. The activity of water in a pore of a given size was multiplied by the appropriate pore size probability density function, and integrated over all pore sizes.[149] Wilder et al.[150] also considered the pore size distribution in their modified model for the dissociation of hydrate in porous media. For the interfacial tension in the Kelvin 
equation, Chen et al.[151] introduced a linear relation between the interfacial tension and the temperature, combined the reaction adsorption two-step formation mechanism, and thus, established a revised model to consider the effect of capillarity. For the contact angle in the Kelvin equation, Peddireddy et al.[152] presented an empirical correlation of variable contact angles with gas solubility, which is determined in terms of experimental data. They obtained the result that the new variable contact angle model can reduce the prediction error for equilibrium pressure compared to the Clark-Bishnoi model, which used a constant angle of zero.

According to known publications in this field [147-152], it was found that the conditions of hydrate decomposition in porous media depend on the rock and fluid properties, such as the wetting angle and the pore radius. However, the current phase equilibrium experimental data and the theory models can be poorly applied to predict the equilibrium hydrate decomposition pressure in the natural NGH reservoir, and determine the production condition in the design of the production strategy due to the complicated physical and chemical properties of the sediments and the different coexistence of NGHs. Based on this reason, the further experimental and theoretical researches on the effects of porous media are quite significant, particularly on those of the natural sediments.

\subsection{Gas Hydrate Formation and Decomposition}

The nucleation, hydrate formation and decomposition rates of bulk gas hydrate have been studied widely. It has been reviewed by Englozos.[3] The formation and decomposition kinetics of gas hydrate were usually measured in a stirred semi-batch tank reactor at isothermal and isobaric conditions. The stirring rates should be enough to eliminate mass-transfer effects. Vysniauskas and Bishnoi [153] firstly investigated the methane hydrate formation kinetics in a stirred semi-batch tank reactor, and indicated that the formation kinetics are determined by the gas-water contact area, pressure, temperature and degree of supercooling. Englezos et al.[154, 155] developed a model for hydrate formation, based on two-film theory and crystallization. This study laid the ground work for several studies that followed it.[156-158] The decomposition rate was found to be proportional to the particle surface area and to the difference in the fugacity of methane at equilibrium decomposition pressure and the decomposition pressure. Kim et al.[159] determined the intrinsic rate constant as $1.24 \times 105 \mathrm{~mol} / \mathrm{m}^{2} \cdot \mathrm{Pa} \cdot \mathrm{s}$ based on their kinetic model. Clarke and Bishnoi [160] revised the work of Kim et al.[159] and modified the experimental measure apparatus by adding an online particle size analyzer. The obtained intrinsic rate constant is only approximately $10 \%$ of that reported by Kim et al.[159]

In contract to the researches of the kinetics of bulk hydrate systems, the formation and decomposition studies of the hydrate in the sediments would cross various challenges, which include not only the pressure and temperature, but also the rate constant, the specific surface area, the characteristics of host sediment, etc. Understanding the formation and decomposition kinetics of gas hydrates in porous media is quite significant because of their discovery in permafrost locations and marine sediments. Many researches have been carried out to investigate the hydrate formation and decomposition behaviors in the porous media to understand further formation/decomposition morphologies and kinetics.

The hydrate nucleation and growth in porous media are very different from those in bulk system and attract great attentions.[161-166] In porous media, the liquid state is very 
complicated. Only a part of the groundwater presenting in the sediments transforms to the hydrate and the rest of the water freezes at subzero temperatures. The porous media property can also affect the nucleation, gas diffusion and heat transfer in the hydrate formation process. $[161,162]$ The water migration was found to happens to the hydrate formation front and the mineralization of water promotes the hydrate formation in the porous media.[163] In addition, the gas diffusion also has important effects on the hydrate nucleation and growth in porous media. Kvamme[164] considered that methane hydrate initiation from the gas side of the gas/water interface may be dominant in hydrate formation through the multi-component diffusive interface theory. Katsuki et al.[165] observed visually that the crystal morphology in the porous medium filled with the methane-saturated liquid water depends upon the magnitude of the mass transfer of the methane molecules in the liquid water. Several studies focused on the effects of the sample characteristics on the hydrate formation behaviors, such as the particle size and pore size of the porous media, the water saturation, etc. Liu et al.[167] found that the methane hydrate formed in silica sands has the similar characteristics regarding cage occupancy and hydration number with bulk hydrate. There is no influence of the particle size on hydrate composition. Kang et al.[168] found that the rates of hydrate formation in silica gel pores are closely related to the driving force, and the rate of hydrate formation is not dependent upon the pore size of the silica gel. Linga et al.[169] investigated the potential dependency of the kinetics of hydrate formation on the size of the silica sand bed. They concluded that the dependency of the results on the size of the bed should be taken into account when modeling the rate of hydrate formation in a porous bed. Fitzgerald et al.[170] studied the formation behaviors of methane hydrate in the pore space at various water saturations. They observed that the hydrate growth rate is limited by the gas diffusion and has a quickly regime after the "punch through" event when the diffusion limit is eliminated. Similar to the study of Fitzgerald et al.[170], a two-step growth of hydrate formation in porous media was found by other researchers.[171, 172] The effects of different ratios of the silica sand and clay, and the different water saturations on hydrate formation were also studied by Kumar et al.[173] It was found that the presence of the clay reduces the hydrate formation kinetics significantly, and lower water saturation shows higher water to hydrate conversion rate in a pure sand bed as well as in a sand-clay mixture.

Besides above mechanism studies, to understand further the hydrate growth rate, heat transfer process and hydrate distribution in the porous media, the experimental investigation of the hydrate formation behaviors in a large reactor is essential. Zhang et al.[174] reported the investigations into the hydrate formation behaviors in the sediments in the cubic hydrate simulator (CHS, $5.8 \mathrm{~L}$, cubic) using the cooling method. They found that the hydrate formation firstly occurs at the local with the low temperature and grows to other place quickly. The gas consumption rate increases with the decrease of the super-cooling degree in the starting stage and the decreases of the temperature at the later stage. It was also found that methane hydrate distribution in the reactor is inhomogeneous.[174] Also, using the CHS, Wang et al.[35] designed a new method to form methane hydrate samples with high hydrate/water saturation and low gas saturation. The results showed that the formation rates are disproportionate to the fugacity differences but in proportion to the volume of the vessel and the change of the initial gas-water ratio has little effect on the rate of hydrate formation. Li et al.[175] firstly investigated the hydrate formation kinetics in porous media with a 
pilot-scale hydrate simulator and a new kinetic model of the hydrate formation in the porous media was established. In this model, the hydrate formation is mainly controlled by the mass transfer at the gas-water contact area, which is formed between the liquid and the "gas bubbles" in the pores. The reaction rate constant and the activation energy were determined to be approximately $8.06 \mathrm{~kg} /\left(\mathrm{m}^{2} \mathrm{~Pa} \mathrm{~s}\right)$ and $8.09 \times 10^{4} \mathrm{~J} / \mathrm{mol}$. The predicted results are in good agreement with their experimental data. In addition, Li et al.[176] also investigated the kinetic characteristics of hydrate formation in porous media with three different scales apparatus, the small-scale hydrate simulator (SHS, 0.4 L), the cubic hydrate simulator(CHS, $5.8 \mathrm{~L}$ ), and the pilot-scale hydrate simulator (PHS, $117.8 \mathrm{~L}$ ), and the above model. The results showed that the reaction rate constant decreases sharply with the increase of the scales of hydrate deposits, which indicates that the hydrate formation rate is inversely proportional to the scale of the hydrate deposit, and the initial fluid saturations and the properties of the porous media play an extraordinary role in the hydrate formation kinetics.

In the aspect of the kinetics of hydrate decomposition in porous media, many experiments have been carried out with different porous media, such as active carbon, silica gels, silica sands, etc. The experiments of the hydrate decomposition in porous media were usually carried out by the driving forces, such as thermal stimulation and depressurization. Selim and Sloan [177] used thermal stimulation to decompose hydrates formed in porous media in the laboratory. The dissociation rate was found to depend on the thermal properties and the porosity of the reservoir. Linga et al.[178] reported data on methane hydrate dissociation by thermal stimulation in bed of silica sand particles. It was found that the methane release per mole of water proceeds in two stages. The dissociation is found to depend on the size of the bed during the first stage of dissociation. By using the technique of Magnetic resonance imaging (MRI) to monitor the methane hydrate dissociation by thermal stimulation, Zhao et al.[179] found that the rate of hydrate decomposition increases at first and then decreases to zero due to the fugacity difference and the surface area of the hydrate particle increasing during the initial stages of hydrate decomposition, and subsequently decreasing. Moreover, the hydrate dissociation increases with the decrease of the size of the glass beads.

In the hydrate dissociation process by depressurization, the temperature reduction is an important phenomena, particularly near freezing, which will stop the dissociation process due the water freezing.[180] It is due to that the hydrate will decompose firstly by absorbing the sensible heat in the reservoir. After that, the heat for the hydrate dissociation should be transferred from the ambient. Therefore, different stages of the hydrate dissociation were usually observed in the experiments by depressurization. Haligva et al.[181] studied the methane hydrate decomposition by depressurization in three different sized beds of silica. The experimental results showed that the hydrate decomposition rate depends strongly on the size of the bed during the first time period from 0 to $0.5 \mathrm{~h}$, while depends weakly on the size during the second time period from 0.5 to $1.0 \mathrm{~h}$. They also observed the freezing in their experiments. Jiang et al.[182] studied the decomposition kinetics of methane hydrate in loess using the rapid depressurization method. They observed a faster hydrate dissociation rate for the higher dissociation temperature. Another important study by Mekala et al.[183] also showed the distinctive dissociation behaviors of methane hydrate and revealed that the dissociation rates are faster in pure water than that of seawater because of the inhibiting effect 
of the presence of the salts on the dissociation behavior.

Several models have been built to predict and more deeply understand the hydrate dissociation behaviors. Kono et al.[166] investigated the kinetic dissociation rate equation and the order of gas production reaction by depressurization from synthesized methane gas hydrate in porous sediments. It was found that the hydrate dissociation rate could be adjusted by the control of sediment properties. Oyama et al.[184] reported a dissociation model and experimental study of the core on hydrate decomposition. The decomposition model was expressed as a function of heat transfer and mass transfer. It was demonstrated that the heat transfer from the surroundings is predominant in their experiments. Liang et al.[185] established a mathematical model for describing the dissociation kinetic behaviors in porous activated carbon below ice point, and considered that the diffusion of methane molecules is one of the control steps in the hydrate decomposition process in activated carbon. Li and Zhang [29] studied the dissociation kinetic behaviors of methane hydrates by depressurization in the silica gels with the different pore sizes based on the experiments and theoretical model. They found that the rate of methane released from the hydrate dissociation increases as the initial formation pressure increases, the environmental temperature decreases, and the mean pore size increases. A fractional shrinking-core model to describe the dissociation kinetic behaviors of methane hydrate in the porous media above the quadruple-phase point temperatures was established, based on the phase equilibrium model in porous media [148] and the fractional theory. The experiments and the dissociation model demonstrated that the methane hydrate decomposition by depressurization in silica gel is controlled by the reaction process.

Till now, the equilibrium conditions of gas hydrates in complex system of porous media have not been understood completely. The complicated states and phase transformations of water in porous media would significantly influence the gas diffusion and hydrate formation process. In addition, the structure, the specific area, the pore size and particle size of the porous media can also affect the states and phase transformations of water, and then affect the hydrate formation and decomposition behaviors. These should require further investigation to comprehend the mechanisms of the hydrate formation and decomposition in the NGH production.

\subsection{Heat and mass transfers}

In the NGH production, the endothermic hydrate dissociation reaction requires huge heat provision to maintain the continuous gas production.[186, 187] Gas hydrate dissociation is a very complex process of coupling heat and mass transfers with the kinetics of hydrate dissociation.[188] Meanwhile, the convective heat transfer occurs with the mass transfer and the gas-water multiphase flow. Therefore, the heat and mass transfer is one of the key issues in the NGH production, and there have been some investigations.

Many studies have shown the importance of heat transfer to the hydrate decomposition as one of the dominating factors in gas production from hydrates.[189-191] The hydrate dissociation experiments showed that if heat transfer from the outer boundary is limited, the sensible heat for the hydrate dissociation is rapidly used up when there is no heat supplied.[192] In our previous experimental work, the methane hydrate dissociation experiments by depressurization were carried out in the different apparatuses. It was found that the heat conduction from the ambient is main driving force to dissociate the hydrate after 
the sensible heat of the hydrate reservoir is consumed.[28, 30] The effects of the heat transfer on the hydrate dissociation also widely investigated by the modeling studies. Pooladi-Darvish et al.[193] established a numerical model to study the effects of conductive and convection transfer on gas production from natural hydrates by depressurization. The numerical results showed that the heat conducted from both hydrate sediments and the cap- and base-rock has a more important effect on the hydrate decomposition than convective heat. In addition, Oyama et al.[184] expressed the dissociation model by depressurization as a function of heat transfer and mass transfer, and the heat transfer from the surroundings was regarded as the dominant factor. In other words, it means that the conduction heat transfer is the dominant factor for gas production from hydrates in the laboratory-scale, which is the same with the view of the Pooladi-Darvish et al.[193], and is different from the understanding of Ahmadi et al.[194] Ahmadi et al.[194] simulated the natural gas production from the dissociation of methane hydrate in a confined reservoir by a depressurizing well. They considered that both heat conduction and convection in the hydrate zone are important. Wang et al.[195] established an analytic model of the mass and heat transfers during hydrate dissociation in porous media by depressurization, thermal stimulation, and depressurization in conjunction with thermal stimulation without any empirical correlation. They found that if the heat conductivity of the sediment if lower than $2 \mathrm{w} \mathrm{m}^{-1} \mathrm{k}^{-1}$, the duration of hydrate dissociation can be quite long. In Zhao et al.'s the numerical simulation, it was found that a high thermal conductivity of the sediment can initially positively affect hydrate dissociation but may later partially inhibit the process. Convective heat transfer in the gas flow increases hydrate dissociation markedly compared to that in water flow.[196]

The mass transfer also has significant effect on the hydrate dissociation process. Some studies showed different controlling mechanism for the hydrate dissociation in laboratory-scale experiments and field-scale processes.[197] In the field-scale processes, the fluid flow is more important for the hydrate dissociation. Tang et al.[31] carried out the experimental study on the gas production from an experimental-scale hydrate sample by depressurization and used the Tough-Fx/Hydrate software to simulate the gas production behavior. It can be summarized that the control mechanism for gas production is related to the reservoir scale: in small scale, the dominant factor is the reaction kinetic and heat transfer; in field scale, the dominant factor is the fluid flow. Several studies gave further relationship of the mass transfer and the heat transfer. Tonnet et al.[198] both experimentally and numerically investigated the mass and heat transfers in the production of methane gas from methane hydrate bearing sediments. The simulated and experimental results demonstrated that the dissociation limiting step switches from thermal transfer to mass transfer depending on the initial permeability and conductivity of the porous media. Another study demonstrated that the reservoir permeability significantly affects the rate of convective heat transfer, and consequently, the rate of gas production for a homogenous hydrate reservoir. The movement of the decomposition front decreases sharply as zone permeability decreases.[199]

Through a review on heat transfer influencing on gas production from gas hydrates, we observe that most of the studies have raised the importance of heat transfer to enhance the gas production. However, it can be noted that the determining factor of the heat transfers influencing gas production is different, depending on the reservoir scale. In addition, it is difficult to distinguish clearly the effect of sensible heat, heat conduction or heat convection 
on gas production. As a result, the further investigations of gas production factors still require to be conducted. Meanwhile, the heat transfer characteristics are relation with the thermal properties of hydrate-bearing sediment (such as thermal conductivity, specific heat), which also play a significant role in assessing gas production from hydrates and heat transfer during hydrate dissociation.[200, 201] Therefore, It is essential to clarify how the thermal properties of hydrate-bearing sediment affect the hydrate dissociation, which may be useful to make the dominate factor of heat transfers on gas production from hydrates more clearly.

\subsection{Multiphase flow}

The multiphase flow in hydrate system is generally treated to the gas and water flow. It is because that the hydrates and sediment particles are assumed to be stagnant and do not participate in moving with the fluid flow. Thus, in previous studies, the gas/liquid flow properties of the sediments bearing with gas hydrate were primarily investigated, and the flow factors have been expected to play an important role in determining gas production performance, especially in the reservoir scale.[21, 40, 192, 202, 203] In the hypothesis, solid gas hydrate is part of the skeletal frame of sediments. From the fluid flow and gas production view, the hydrates hinder the multiphase flow, and hydrate dissociation alters the structure of the porous media and flow path.

In order to understand the multiphase flow characteristics in the hydrate-bearing sediments and gas production, the absolute permeability, gas-water relative permeability and the relationship of the capillary pressure to the saturations of the fluid phase require to be obtained. So far, the modular formation dynamic tester (MDT) tool, flow experiments and $\mathrm{NMR} / \mathrm{CT}$ measurements have been used to investigate the permeability of hydrate-bearing sediments. In the hydrate formation, the liquid and gas phases will turn into solid phase, it can be easily assumed that the permeability will be influenced by the hydrate saturation in hydrate-bearing sediments. It has been confirmed by the experiments.[204] Minagawa et al.[205] measured the water permeabilities of methane-hydrate-bearing sediments with different hydrate saturations for the different hydrate-bearing sands and the different methane-hydrate formation methods. An exponential relation was used to fit the measured data, the value of the exponent varied over a range from 2.5 to 9. Jin et al.[206] used X-ray computed tomography (CT) to measure the water permeabilities of the sediments bearing with hydrate. They found that the number ratio of the horizontal channel to vertical channel is a predominant fact that determines absolute permeability in similar porosity ranges.

Permeability variation of porous media in the presence of hydrates is critically affected by where and how hydrate forms within pore spaces.[207] Therefore, understanding how the modes of the hydrate forming in the pore space influence gas and water flow is critical in the prediction of the gas recovery. Kumar et al.[208] performed a series of experiments to measure the gas permeabilities in the $\mathrm{CO}_{2}$ hydrate sediments, and concluded that hydrate forms on the grain surfaces for initial water saturations of less than $35 \%$, while a pore-filling tendency is indicated for water saturations of above $35 \%$. A series of X-ray computed tomography experiments were carried out to investigate the water flow in presence of the hydrate by Kneafsey et al.[209]. Their experimental results indicated that water flow through the hydrate-bearing samples is significantly influenced by the presence of the hydrate. Water flow is enhanced by the increased capillary suction or deterred by the reduced permeability of higher-hydrate-saturation regions. Interestingly, by comparing the gas permeability 
experimental data with the permeability values calculated by a number of permeability conceptual models, they also found that the hydrate, forming in their test with the excess gas hydrate formation method, trends to occupy primarily pore bodies. Seol and Kneafsey [210] performed a further experimental study using CT to capture methane hydrate modes and examined the impacts of pore filling hydrate on multiphase fluid (gas and water) migration by comparing with numerical predictions. The results highlighted the importance of the permeability modification due to hydrate modes presenting in pore space when predicting multiphase flow through high saturation hydrate-bearing sediments. Ruan et al.[211] examined the effects of the hydrate modes presenting in porous media on gas production in their numerical simulations by adapting the conceptual permeability models considering the hydrate accumulation distributions in pore space. The numerical results indicated that the gas production could be the overpredicted by adapting the conventional reservoir permeability model (Corey model) and the gas production performances predicted by using the hydrate coating models are superior to that of hydrate filling models. That is mainly due to the fact that the changes in the permeability reduction are expected to be small when the hydrate coats the capillary/pore walls as a thin film, while the fluid permeability can be reduced more significantly if hydrate fills in the middle of the capillary/pore space, plugging pore throats and the flow channels.

As compared to the permeability measurement, the experimental measurement of gas-water relative permeability for hydrate-bearing sediments is a challenging problem due to a phase change (gas hydrate formation/dissociation) during gas-water flooding test. The relative permeabilities to the flow of water and gas also depend crucially on how hydrate forms in the pore space of rock and sediment. Good relative-permeability estimates are central to the accuracy of the reservoir simulators, which are used to predict how hydrate reservoirs respond to changes in temperature and pressure.[212] Ahn et al.[213] measured the relative permeability of gas and water in artificial methane hydrate bearing sediment by the unsteady state method, and found that the relative permeability shifts left with increasing hydrate saturation. Seol et al. [214] used X-ray CT scanning to aid in estimating the relative permeabilities in the hydrate-bearing sample.[215] They measured the relative gas permeability as a function of the phase saturation (i.e., gas, water, or hydrate) in hydrate-bearing sediments. The gas permeability data was compared with the Corey relative permeability model, and the relative permeability parameters were made corresponding to the values of permeability reduction exponent $n$ and irreducible water saturation $S_{w r}$ equal to 3, and 0.12 , respectively. In another study, Jaiswal et al.[216] obtained the relative permeability to gas and water by applying the Johnson-Bossler-Neumann method with a new developed experimental design, which allowed the measurement of relative permeability for different gas hydrate saturations. They found that the relative permeability is primarily affected by gas-hydrate saturations, and also vary with the gas hydrate mode for the same bulk saturation in the different porous media. Johnson et al.[217] reported an experimental investigation of gas-water relative permeability for natural hydrate samples from the Mt Elbert site on the Alaska North Slope. Their experimental results showed that the permeability of porous media can be significantly reduced with the hydrate saturation change from 1.5 to $36 \%$. Finally, they compared the relative permeability results obtained from Ahn et al.[213] and Jaiswal et al.[216], and pointed out that differences between the reduction in permeabilities is possibly 
influenced by how hydrates are distributed in pore space.

It should be pointed out that, because the hydrate-bearing sediments are usually unconsolidated for the permeability measurement experiments, if a conventional permeability measurement method is used, the sediment particles, especially as the typical hydrate-bearing sediments consisting of both coarse-grained sandy media and fine-grained deposits (clay, silt), will move or shift in water-gas flooding test system. Thus, the results of the permeabilities are not accurate due to the changes of the structures of porous media and so on. Therefore, further research is still required to quantify better the relative gas and water permeabilities in hydrate-bearing sediment and their evolution during dissociation.

Capillary pressure is a function of the medium (wettability, geometry) and the saturations of all phases (e.g. gas, hydrate, water) in the pore space. Numerous studies have confirmed that the gas flow [218] can be greatly affected by capillary effects. For gas production from hydrate, the relative permeability is a function of fluid phase saturation, and the fluid phase saturation is described by the capillary pressure-saturation relationship.[219] The presence of hydrate in the pore space will change the capillary pressure-saturation relationship for the medium. Understanding the capillary pressure-saturation relationship of hydrate-bearing media is important for modeling the flow of gas and water through that medium, and predicting natural gas production from hydrate-bearing reservoirs. In the investigation into the effect of capillary pressure on water flow through the heterogeneous hydrate-bearing sand using X-ray computed tomography (CT), Seol and Kneafsey [203] found that higher hydrate saturation increases water imbibition in the coarse sand due to the increased capillary strength, and higher capillary strength of the fine sand holds water tighter than gas as the hydrate releases water and gas. Ghezzehei and Kneafsey [219] developed a method for measuring the capillary pressure-saturation relationship in methane hydrate-bearing sand. They measured the pressure difference between the water and gas phases by step-wise drainage from full water saturation to residual water saturation. During drainage, a number of intermediate static equilibrium conditions were established and provided the water saturation vs. capillary pressure relations. Moreover, many numerical simulations of gas production from hydrate-bearing sediments have been performed to evaluate gas production under assumed conditions.[35-39] However, in these simulations, the accurate capillary model is also not known for hydrate systems. Therefore, more measurements and modeling are required to aid in understanding the behavior of the gas and water in hydrate-bearing sediment.

Gas production from hydrates in porous media could cause fluid volume expansion, gas and water flow, changes in porosity and permeability, and so on. However, in prior studies, few investigations into the fine-grained sediment migration and sand production during hydrates dissociation have been mentioned. These emergent processes may cause sediment instability, formation clogging, sand production, retardation of gas production, and low gas recovery efficiency.[220] In Canada's Mallik field, the test was stopped because of the sand production but resumed after well completion system was redesigned to consider the control of sand production, replacing the existing system. In the marine test production in the Nankai Trough of Japan, it has been known that there was significant sand production at the end of the test. Sand production makes a production trouble when the unconsolidated sand with production grains and water/gas flow out to inside well bore. Therefore, for successful performance of hydrate production, the research on sand migration and production in relation 
to the production conditions is necessary. Jung et al.[220] has used the large-size Seafloor Process Simulator(SPS) to investigate the role of fine-grained sediments on gas production. They confirmed the occurrence of the phenomena of fine sand migration, formation clogging and sand production during gas production process, and demonstrated that these phenomena have significantly relation with the critical fine fraction as the clay-to-sand mass ratio. Certainly, in their study, it is under the consideration without the hydrate-bearing sediment mechanical deformation, and the fine particles, which may migrate, are not part of the load carrying granular skeleton. According to the report by Hancock et al.[221], the options for sand-control technologies associated with production from hydrate-bearing sediments include gravel packs, screens, or liners. Lee et al.[222] have developed a visualized apparatus of sand control screen and implemented an experimental study to evaluate the performance of the sand control screen, which was used to inhibit the sand production accompanying hydrate depressurization-induced dissociation and gas production. The results indicated that sand production is not visible and the amount of sand collected after the hydrate dissociation experiment is less $0.012 \%$ of the total mass of the sediment samples. However, there are still several limitations regarding the experimental scale and the well completion types.

\subsection{Mechanic characterization}

The investigations on the mechanical characterizations of hydrate or hydrate-bearing sediment are quite significant to understand the deformation of hydrate-bearing layers and assess the stability of hydrate-bearing reservoirs. The studies have been carried out for several years. The focus has changed from pure hydrate to hydrate-bearing sediments.

The strengths of pure methane hydrate were measured in constant-strain-rate tests [223, 224], and the steady-state strength and yield strength were obtained as the range of 60 to 102 $\mathrm{MPa}$ and 71 to $100 \mathrm{MPa}$, respectively. Later, Durham et al.[225] studied the strength and rheology characteristics of pure artificial methane hydrate, and the results indicated that the strength of methane hydrates is over 20 times higher than that of ice under the same conditions, and this difference increases with the decrease of temperature. Hyodo et al.[226] measured the compressive strength of methane hydrate using a high pressure-low temperature triaxial equipment, they found that the strength of methane hydrate increases with increasing confining pressure and strain rate, and decreases with increasing temperature. In addition, the mechanical strength of $\mathrm{CO}_{2}$ hydrate [227] and THF hydrate [228] has also been investigated respectively. The similar results were observed as that of methane hydrate. Ning at al.[229] have reviewed current experimental and theoretical results on the mechanical properties of "pure" clathrate hydrates, and summed up the typical difficulties faced in this area. They indicated that the most important problem is obtaining pure hydrate samples in the experimental measurements of hydrate mechanical properties, and suggested to resolve the issues by combining novel macroscopic experiments and microscopic methods.

In the hydrate-bearing sediments, gas hydrates act as part of the solid skeleton or frame of sediments [230, 231], or cement the sediment particles [232, 233]. Gas hydrate formation within sediments stiffens the reservoir sediments, and hydrate decomposition would cause shear strength loss and the well instability [234, 235]. Besides, the water and gas from hydrate dissociation will increase the pore pressure, resulting in an effective stress reduction, sediment deformation and failure [236]. Therefore, mechanical deformation of gas hydrate sediment 
has a great significance not only on mechanical stability of gas hydrate reservoir in production but also on evaluation of gas productivity from hydrate reservoirs [237]. Thus, understanding the mechanical properties of hydrate-bearing sediments is essential and important.

Winters et al.[238] have used the Gas Hydrate and Sediment Testing Laboratories Instrument (GHASTLI) to conduct studies on mechanical properties of coarse-grained hydrate-bearing sediments recovered from the permafrost and marine areas. They found that significant amounts of gas hydrate occupying the sample pores substantially increases the shear strength of the sediments. Later, Winters et al.[239] reported triaxial compressive test results for fine-grained marine sediment samples recovered from the Krishna-Godavari Basin, located along India's eastern continental margin. They pointed out that the measurements of shear strength and other physical properties of hydrate-bearing fine-grained sediment at near in situ effective stress should be accomplished without freezing the sample and depressurizing the material. Waite et al.[240] have provided a summary of laboratory measurements of the mechanical properties of hydrate-bearing sediments, and suggested that the hydrates forming in the fine-grain media should be considered in the investigation into the mechanical properties, and the morphology of the hydrate in sediment must be known and controlled in these tests. In addition, many researchers studied the mechanical behaviors of laboratory-synthesized and natural ocean hydrate-bearing sediments by triaxial compression test [238, 241-246], the results indicated that the failure strength and stiffness of methane hydrate-bearing sediments increase with increasing hydrate saturation, effective confining stress and back pressure, while decrease with increasing temperature and porosity.

In addition, the mechanical properties of the hydrate-bearing sediment during hydrate dissociation and gas production have been taken more attentions recently. Wu and Grozic [247] studied the isotropic undrained dissociation behavior of carbon dioxide hydrate-bearing sands. The study demonstrated that the dissociation of even a small amount of gas hydrates can lead to soil failure. Hyodo et al.[248] studied the shear strength and deformation behaviors of the methane hydrate-bearing Toyoura sand samples during hydrate dissociation by heating or depressurization. The results indicated that the heating method will cause the failure of samples under certain conditions, and the depressurization method will not lead to collapse of samples during depressurization. They also studied the effects of temperature, pore pressure, effective confining pressure and hydrate saturation on the mechanical properties of gas-saturated methane hydrate and $\mathrm{CO}_{2}$ hydrate-bearing sediments, and made a comparison with the methane hydrate-bearing Toyoura sand samples [249, 250]. The results indicated that: (1) failure strength, and stiffness of gas-saturated specimens are higher than those of water-saturated specimens, and the gas-saturated specimens present more markedly shear dilation and strain-softening behavior; (2) it is feasible to use $\mathrm{CH}_{4}-\mathrm{CO}_{2}$ replacement technology for the production of methane from hydrate reservoirs in mechanical considerations.

Although the significant efforts have been devoted toward the studies of the mechanical characteristics of hydrate-bearing sediments, there are still some uncertainties in the mechanical deformations caused by hydrate dissociation, such as changes in stress conditions due to pore pressure changes during hydrate dissociating into gas and water, permeability changes due to vanishing hydrates and subsequent settlements, sediment softening and 
volume contraction due to loss of hydrate bonding. Numerical studies as an useful method to predict thermo-hydro-mechanical behavior during gas production process have been considered to evaluation of gas productivity from hydrate reservoirs. In the past few years, some constitutive models and numerical simulators have been developed to incorporate mechanical behaviors into numerical simulations. Klar and Soga [251] presented a flow-deformation analysis for gas extraction from hydrate using a finite difference code. They treated hydrate-bearing sediments as plastic materials whose strength is a function of hydrate saturation. Heat transfer was not considered in their simulations. Ogisako et al.[252] performed the numerical analyses of triaxial compression tests on hydrate-bearing soil samples obtained from seabed ground in deep sea by elasto-viscoplastic constitutive equation, and from the results of three dimensional finite element analyses it was found that the shear strain and volumetric strain are distributed nonuniformly in the test specimen. Kimoto et al. $[253,254]$ proposed a chemo-thermo-mechanical finite element model to investigate the geomechanical effects of hydrate dissociation, the phase changes from solids to fluids, flow of water and gas, heat transfer, and ground deformation have been taken into account. The numerical results showed that ground deformation is induced by generation and dissipation of water and gas, and by reduction of soil strength due to the loss of hydrates. Li et al.[255] studied the effect of temperature, confining pressure, strain rate and porosity on the mechanical properties of synthesized methane hydrate-bearing clayey sediments, and proposed a constitutive model describing the stress-strain behavior based on the nonlinear elastic Dunca-Chang model and established a strength criterion for methane hydrate-bearing sediments [256, 257]. Ng et al.[258] developed a geomechanical model in FLAC2D code to study the wellbore stability during gas production. The study showed that there is a major difference in the geomechanical performance around horizontal and vertical wells. In the case of production from horizontal wells, the anisotropic stress induced by the general reservoir depressurization can cause shear failure near the wellbore adjacent to the perforation. Rutqvist et al. [259] proposed a numerical method by coupling the simulator TOUGH+HYDRATE with the geomechanical code FLAC3D and investigated the coupled thermal, hydraulic and geomechanical behaviors of hydrate deposits. In their later study, the numerical results indicated that the yielding and shearing of the sediments can lead to the enhanced sand production if not prevented with appropriate sand control technology [260]. The phenomenon of sand production also occurred in the offshore gas production trial at Eastern Nankai Trough.[261] Therefore, it is necessary to investigate the mechanical behavior of the wellbore and the sediment in the surroundings to avoid the potential risk of sand production. Currently, because of the shortage of experimental data and constitutive models for the physical properties, few of hydrate simulators are available to be competent for predicting the behavior of mechanical deformation or failure of hydrate reservoir during gas production.

\section{Laboratory Investigations into Gas Production from NGHs 4.1 Techniques of Gas Production}

Technique of gas production from NGH is quite different from that from conventional

natural gas reservoirs. The conventional natural gases enrich in natural gas reservoirs, which can be seen as a sealed container with impermeability or/and ultra-low permeability. Consequently, the basic technique for gas production from the conventional gas reservoirs is 
generating certain fractures in the reservoirs to unlock natural gases and excavating a channel to flow natural gases to surface. Techniques for gas production from NGHs usually focus on in-situ dissociating natural gases from NGHs and creating a conduit to flow recovered natural gases to surface. Currently, most of the gas production methods are based on shifting the NGH reservoir condition to NGH dissociation side by hot injection, depressurization, hydrate formation inhibitor injection, etc.[2] As shown in Figure 3, thermal stimulation and depressurization techniques shift the local P-T conditions to the side, where NGHs is unstable and can automatically dissociate to natural gases and water; whereas inhibitor injection technique alters the phase equilibrium boundary and makes the local NGHs dissociate at the in-situ conditions. In addition, NGH dissociation is an endothermic process. Therefore, in order to keep the temperature constant during the gas production, a source of energy is supplemented timely.[262, 263] In this section, the research progress on gas production techniques from NGHs and its important findings will be looked into systematically.

\subsubsection{Depressurization}

The technique of depressurization seeks for gas production from NGH reservoirs by lowering the pressure below to the NGH equilibrium pressure at the local temperature [6-7]. It is noted that the local temperature will continuously drop while NGHs dissociate, and the dissociation of NGHs might stop once the local temperature drops to the equilibrium temperature at a certain pressure. Hence, the sufficient heat transfer or energy supplement must be insured timely.[8] Thereby, the NGHs start to dissociate from the regions near the wells and release natural gases and water. Then, along with the NGHs dissociation, the NGH saturation decreases and the effective permeability increases, further causing the enlarging of the regions with lower pressure. The sustainability of gas production by depressurization depends on the diffusion of pressure, the NGH saturation and effective permeability in the NGHs reservoirs.[9]

\subsubsection{Thermal stimulation}

Thermal stimulation means to increase the temperatures of the local NGH reservoirs by heating, heat water or steam injection, electrical heating, microwave radiation, etc.[10-12] The local temperature turns to above the phase equilibrium temperature at the local pressure by thermal stimulation, resulting in local NGHs dissociating and natural gases releasing along with water. In early 1980s, McGuire saw thermal stimulation as an effective gas production technique for producing gas from Class 2 NGH reservoirs with high permeability [13]. In 1982, thermal stimulation as a gas production from NGH technique was evaluated by Holder et al., and the feasibility and effectiveness of the technique were illustrated in their evaluation [14]. From then on, numerous experimental simulations by thermal stimulation have been carried out.[15-18] There are three ways for thermal stimulation, including hot water circulation [19], wellbore heating [20], and hot water huff and puff [21-23]. The gas-production system for the hot water circulation consists of two coaxial cylindrical channels (wells). The inner well is designed to transport the hot water to the open section of the well surrounded by the bottomhole. The outer well is used for gas/water production. In the wellbore heating method, the wellbore are heated by using the electric or other method. Electrical heating was first proposed by Islam in 1990s [24], and it can be considered as one in situ approach because the electrical heater is set in the methane hydrates. Compared to hot-water injection, the heat losses due to heat transmission through wells could be avoided. 
Therefore, the higher energy efficiency via electrical heating could be achieved.[25] Compared to the first two ways, the third one is complex but the most popular, and it can be described as injecting hot water or steam into the reservoirs through a wellbore (huff), then shorting-in the well for a time to transfer sufficiently the heat to the reservoir (soak), and then producing natural gases and water from well (puff).

\subsubsection{Chemical inhibitor injection}

Chemical inhibitor injection works by shifting the NGH phase equilibrium curve to higher pressure and lower temperature, leaving the NGHs unstable in the local condition of temperature and pressure. Chemical inhibitors generally include thermodynamic inhibitors and kinetic inhibitors. Thermodynamic inhibitor works by altering the NGH equilibrium conditions, while kinetic inhibitor works by slowing down the rate of gas hydrate formation.[16, 264-287] It should be mentioned that, compared to depressurization and thermal stimulation, the studies on chemical inhibitor injection as gas production technique are relatively less although there are many studies on chemical inhibitors focusing on the field of oil or/and gas transportation. Methanol and ethanol glycol (EG) are the two of the most common thermodynamic inhibitors for their high availability in market, low toxicity and relatively good performance in promoting hydrate dissociation. Due to the chemical inhibitors working in the form of fluids, the sufficient flow of chemical inhibitors to NGH reservoirs determines the gas production efficiency by the technique of chemical inhibitor injection. Consequently, similar to thermal stimulation, the crucial issue for chemical inhibitor injection also involves in diffusion and effective permeability to solution in the reservoirs. In addition, the concentration of inhibitor solution, inhibitor injection rate, hydrate-inhibitor interfacial area along with temperature and pressure are the important factors to NGH dissociation rate.

\subsection{4 $\mathrm{CO}_{2}-\mathrm{CH}_{4}$ replacement}

Since 1980s, inducing $\mathrm{CO}_{2}$ into NGHs to produce $\mathrm{CH}_{4}$ was proposed and investigated. A common belief is that $\mathrm{CO}_{2}$ not only works on recovering $\mathrm{CH}_{4}$ from NGHs but also can be sequestrated directly in the form of forming $\mathrm{CO}_{2}$ hydrates.[288] In addition, there is no hydrate structure transformation in the process of $\mathrm{CO}_{2}-\mathrm{CH}_{4}$ exchange in hydrates.[2, 3] The thermodynamic feasibility of $\mathrm{CO}_{2}-\mathrm{CH}_{4}$ replacement was fully proven through numerous studies. On the one hand, from the thermodynamic point of view, both pure $\mathrm{CO}_{2}$ and $\mathrm{CH}_{4}$ molecules typically form sI hydrates under corresponding conditions, and the enthalpy of $\mathrm{CO}_{2}$ hydrate formation (about $-57.98 \mathrm{~kJ} / \mathrm{mol}$ ) is lower than that of $\mathrm{CH}_{4}$ hydrate formation (about $-54.49 \mathrm{~kJ} / \mathrm{mol}$ ). It means $\mathrm{CO}_{2}$ hydrate is more stable than $\mathrm{CH}_{4}$ hydrate under a same condition of temperature and pressure.[289, 290] On the other hand, the Gibbs free energy of about $-12.00 \mathrm{~kJ} / \mathrm{mol}$ was obtained in the reaction of $\mathrm{CH}_{4}$ replacement by $\mathrm{CO}_{2}$ in hydrates from a molecular dynamic (MD) study.[290] The replacement mechanism has been widely studied by the experiments using in situ Raman spectroscopy, there are two standpoints. One is the replacement consists of two independent processes: $\mathrm{CH}_{4}$ hydrate dissociation and $\mathrm{CO}_{2}$ hydrate formation. For this standpoint, $\mathrm{CH}_{4}$ hydrate first dissociate and the released water reform $\mathrm{CO}_{2}$ hydrate together with $\mathrm{CO}_{2}$ molecule, and it can be described as a process of hydrate structure firstly disrupt then reconstruct;[291-295] the other is $\mathrm{CO}_{2}$ molecules directly replace $\mathrm{CH}_{4}$ molecules and hydrate cavities unchanged.[295] For the two standpoints, the core disputation is whether free water is produced or not during the replacement. Nevertheless, the feasibility of $\mathrm{CH}_{4}-\mathrm{CO}_{2}$ replacement in hydrate has been investigated and validated by lots of 
experimental and theoretical researches.[290-295]

Because pure $\mathrm{CO}_{2}$ does not exist in nature, which can be obtained after the separation and purification in industry, the gas mixtures containing mainly $\mathrm{CO}_{2} / \mathrm{N}_{2}$ originating from fired power plants can be induced to substitute pure $\mathrm{CO}_{2}$ for $\mathrm{CO}_{2}-\mathrm{CH}_{4}$ replacement in hydrates. In $\mathrm{CO}_{2}-\mathrm{CH}_{4}$ replacement in hydrate, $\mathrm{CO}_{2}$ molecules only replace $\mathrm{CH}_{4}$ molecules from $5^{12} 6^{2}$ middle cavities but not from $5^{12}$ small cavities as $\mathrm{CO}_{2}$ molecular diameter of $5.12 \AA$ is close to the diameter of $5^{12} 6^{2}$ middle cavity but larger than the diameter of $5^{12}$ small cavity. Therefore, the highest $\mathrm{CH}_{4}$ recovery from NGHs by $\mathrm{CO}_{2}-\mathrm{CH}_{4}$ replacement is $75 \%$ even though all $\mathrm{CH}_{4}$ molecules in middle cavities of sI hydrates are replaced by $\mathrm{CO}_{2}$ molecules.[2] Molecular diameter of $\mathrm{N}_{2}$ is smaller than those of $5^{12}$ small cavities. Therefore, it is possible that $\mathrm{CH}_{4}$ molecules in small cavities in sI hydrates can also be recovered by $\mathrm{N}_{2}$ molecules if $\mathrm{CO}_{2} / \mathrm{N}_{2}$ gas mixture substitutes pure $\mathrm{CO}_{2}$ for recovering $\mathrm{CH}_{4}$ from NGHs. Compared to utilizing pure $\mathrm{CO}_{2}$, the increase of $\mathrm{CH}_{4}$ recovery by utilizing $\mathrm{CO}_{2} / \mathrm{N}_{2}$ has been proven in some studies.[2] However, the real mechanism is still in disputation. In some studies, $\mathrm{N}_{2}$ molecules are not found in gas hydrates from Raman spectra. Consequently, other one view is that $\mathrm{N}_{2}$ molecules act as promoters to improve the $\mathrm{CO}_{2}-\mathrm{CH}_{4}$ replacement but not participate in directly replacing $\mathrm{CH}_{4}$ molecules.[2] Therefore, utilizing $\mathrm{CO}_{2} / \mathrm{N}_{2}$ to recover $\mathrm{CH}_{4}$ from NGHs is promising and of great interest.

\subsubsection{Combination technique}

Because the techniques discussed above have their individual limitations such as high energy consumption, low gas recovery, low gas production rate and environmental issues. The combination of the techniques is considered as a better technique to enhance the efficiency of gas production, lower the energy consumption, accelerate the gas production etc.[42] For example, Huff and puff in conjunction with depressurization is one of such the technique, which is actually composed of continuous loops of hot water or steams injection, soaking, gas production and depressurization.[42] Compared to thermal stimulation or depressurization, the combination technique is proven to be more efficient in natural gas production from NGHs.[42] Therefore, it gradually attracts more and more interest. Other one combination technique is chemical inhibitor injection combining with thermal stimulation, and it can be also described as hot solution injection in the presence of the chemical inhibitor.[22] The combination technique can effectively prevent the secondary formation of gas hydrate, which is induced by temperature decrease, while NGHs dissociate, and the chemical inhibitor can easily flow to more distant regions from the well along with hot water.[10] However, the combination technique attracts less concern as the chemical inhibitor causes environmental issues.

\subsubsection{Novel technologies of gas production from NGH}

Recently, Chen et al.[8] proposed a novel method of warm brine in situ seafloor to produce gas from marine gas hydrates. Figure 4 shows the conceptual depiction of the warm brine in situ seafloor gas production with a dual horizontal wells system. The rationale could be summarized as using the relatively higher gas hydrate formation heat to in situ dissociate $\mathrm{NGH}$, further producing $\mathrm{CH}_{4}$. It should say that the method belongs to one kind of thermal stimulation. However, it has its unique feature of no requirement of additional heat sources. As seen from Figure 4, a continuous reactor (a vertical steel tube) is divided into six parts: warm brine zone, hydrate formation zone, hydrate uplifting and brine descending zone, 
hydrate decomposition zone, brackish water zone and hydrate former zone. First, mixtures of hydrate formers (e.g., cyclopentane + methane) and methane-seawater mixtures are introduced into the hydrate formation zone, and the corresponding gas hydrates form instantaneously under the condition of submarine. The great exothermic effect from the hydrate formation raises the temperature of the whole hydrate slurry. Meanwhile, the unique desalination effect of gas hydrate formation enhances the salinity of the residual seawater (also called warm brine). Then, the brine water directly sinks down to the warm brine zone due to the relatively higher density resulted from the increase of the salinity. And then, the warm brine is induced into a horizontal production well from an injection well to produce $\mathrm{CH}_{4}$ by dissociating NGHs. The biggest advantages of this novel technology are, (1) relatively high energy efficiency due to the high heating coefficient of warm brine, (2) low heat loss. However, we must emphasize that there also are many challenges to the novel technology. First, a new hydrate former with higher hydrate formation enthalpy must be screened; second, the gas hydrate formation must be faster, third, no hydrates agglomerate in the system.

The other novel gas production technology or an innovative thermal stimulation conception is in situ combustion (ISC), and it was firstly proposed by Cranganu.[296, 297] By the technology, the gas hydrate is combusted to provide the desired heat right for dissociating NGH within the downhole NGH reservoir. Based on the Cranganu's research, Schick et al.[298, 299] designed and developed a reservoir simulator with $425 \mathrm{~L}$ to investigate experimentally ISC for producing $\mathrm{CH}_{4}$ from methane hydrates. Besides, Castaldi et al.[300] carried out numerical simulations to assess the technology for gas production.

\subsection{Apparatuses of Laboratory Investigations}

In order to simulate NGH production process with the different methods in laboratory, the experimental apparatus should have the functions as following: 1) providing a high pressure and controlling temperature condition to simulate the NGH characteristics in nature; 2) having essential monitoring instruments to measure the production behaviors, such as the temperature and pressure change, the gas and water production rate, and the heat and mass transfer in the reservoir, etc; 3) having the auxiliary equipment to simulate different production methods, for examples, the hot water injection equipment, the pressure controlling equipment, the gas and water separation equipment, the simulated wells in the hydrate reservoir, etc.

Lots of experiments apparatuses for the NGH production have been established in the past. The experimental simulations began with small and sealed reactors of effective volume less to $1 \mathrm{~L}$, which was mainly used to investigate the formation and dissociation behaviors of gas hydrates in porous media.[31, 166, 264, 301-305] In order to better mimic actual field conditions and study the efficiency and sustainability of the different gas production techniques, the experimental NGH simulators are developed in the direction of the large-scale and mulfi-function.

Zhou et al.[306] established a set of experimental apparatus with a $72 \mathrm{~L}$ hydrate formation reactor. The apparatus is a high-pressure vessel with a $59.2 \mathrm{~L}$ internal volume with 7 thermocouples placed in the reactor to temperature. Phelps et al.[307] developed a seafloor process simulator (SPS) with a reactor volume of $72.2 \mathrm{~L}$ for experimental investigations on 
methane hydrates and $\mathrm{CO}_{2}$ hydrates formation or/and dissociation behaviors at temperatures and pressures corresponding to ocean depth of $2 \mathrm{~km}$. The SPS is a corrosion-resistant pressure vessel, whose salient characteristics are: (i) an operating range suitable for study of methane and carbon dioxide hydrates; (ii) numerous access and observation ports, and (iii) a large $(72.2 \mathrm{~L})$ internal volume. Groups led by Chen designed a $7.1 \mathrm{~L}$ hydrate simulator, which includes a medium-sized cylindrical reactor.[308, 309] The gas production experiments using various methods such as hot-water injection, depressurization, gaseous and liquid carbon dioxide injection, can be performed in the simulator. In order to investigate the production behaviors from the three-dimensional hydrate reservoir, the three-dimensional cubic hydrate simulator (CHS) with the effective volume of 5.8L was developed by $\mathrm{Li}$ et al.[6-9] The reactor of CHS is equipped with multiple sets of the measuring points and wellheads, and the layout of the measuring points and the wellheads is divided into three layers, namely, top (A), middle (B), and bottom (C). There are a total of $25 \times 3$ temperature measuring points, $12 \times 3$ resistance measuring points, $9 \times 3$ vertical wells, and $3 \times 3$ horizontal wells in the reactor. The temperature and resistance measuring points in the different layers and production wellheads within the three-dimensional reactor are evenly distributed in the reactor. Based on the 5.8 L CHS, Li et al.[27, 28] developed Pilot-Scale Hydrate Simulator (PHS) for three-dimensional natural gas hydrate exploitation research with the effective volume of 117.8 L. In the PHS, there are 27 vertical wells and 9 horizontal wells, and total 147 ports with the temperature, pressure and resistance probes distributing in three horizontal layers with the different directions and depths.[27, 28] In the CHS and PHS, the three-dimensional variation trends of temperature, pressure and resistance could be ideally shown through data processing. The Pilot-Scale Hydrate Simulator (PHS) was a pioneering achievement, which holds the international leading level in the field of the natural gas hydrate scientific research. The pressure vessel of PHS can be operated up to $25 \mathrm{MPa}$ and has the visualization functional module. The following work can be carried out in the PHS: (1) the physical property tests by using the acoustics, electrics, mechanics, geochemistry and geophysics methods; (2) the experimental simulation of the formation process in the hydrate reservoir under the different geological structures; (3) the experimental investigations of the hydrate exploitation under complicated well conditions using the depressurization, the heat stimulation, the chemical inhibitor stimulation, the carbon dioxide replacement, the combination methods and the new methods of hydrate dissociation. A larger laboratory reservoir simulator (LARS) with volume of 425.0 L was developed by Schicks et al. in Helmholtz-Centre Potsdam GFZ German Research Centre for Geosciences.[298, 299] The system allows the hydrate formation in the sediment by use of four the different procedures, which will obtain the different hydrate distribution in the sediment sample. The distribution of $\mathrm{CH}_{4}$ in the sample can be detected by $\mathrm{CH}_{4}$ sensors placed in the water saturated sediment. Konno et al.[190] established a High-pressure Giant Unit for Methane-hydrate Analyses (HiGUMA), a hydrate reservoir simulating vessel $(1710 \mathrm{~L})$, to bridge the scale gas between conventional laboratory experiments (tens of centimeters in scale) and field tests (a few hundred meters in scale) for the investigation into the gas hydrate production. The HiGUMA consists of a main pressure vessel, which has three sections: the upper cap, sample container, and bottom part. Methane hydrate with sandy sediment is formed within the sample container. A vertical well system is located at the center of the sample chamber in the vessel. The well can be used for gas 
injection during the hydrate formation process and for the gas and water production during the production tests.

Clearly, the development of laboratory apparatus is a process from small to large, from one dimension to three-dimensions. And the development makes the simulated conditions more close to true situation, and the biggest and the most advanced laboratory apparatus could be used to show more experimental phenomena. However, even the largest equipment, the volume could not be unlimited. Therefore, the influence of the boundary on the gas production from NGHs is the biggest problem encountered in the development of the laboratory apparatus, which making the experiment results have some limitations.

\subsection{Experimental simulations}

By simulating NGHs formation and dissociation in porous media in laboratory, the researchers strive to reveal the mechanism of natural gas production from NGH reservoirs, grasp the relevant gas production techniques, know the change laws of parameters of NGH reservoirs, find out the governing factors to gas production, propose reasonable methods to enhance natural gases recovery, make the gas production sustainable, etc.. In order to make the simulations close to the real situations, the experimental apparatus, experimental conditions of temperature and pressure, characteristics of simulated NGH deposits are crucial aspects to carry out experimental simulations. In this section, the studies of the experimental simulations are systematically reviewed in the order of gas production techniques as stated as above.

\subsubsection{Experimental simulation via depressurization}

In the a early study of the gas production from methane hydrate by depressurization in laboratory proved that gas production and hydrate dissociation front positively change with time.[301] A significant thermal buffering was observed due to the endothermic of hydrate dissociation. In addition, the main controlling factor to the methane hydrate dissociation is considered to be the heat flow into the system although pressure difference resulted from depressurization is considered as the driving force of the dissociation.[310] Another study from showed the hydrate dissociation rate is controlled by intrinsic dissociation reaction at temperature above $273.15 \mathrm{~K}$, while the hydrate dissociation is governed by gas diffusion in hydrate and ice mixture at temperature below $273.15 \mathrm{~K}$. It was highlighted that water generated from hydrate dissociation will rapidly transform into ice at hydrate surface, and the hydrate dissociation process is completely considered as a process of moving ice-hydrate boundary below $273.15 \mathrm{~K}$.[311] Lee et al.[312] presented the comparison of gas productivities and propagations of hydrate dissociation in relation to time as hydrate was depressurized in different conditions, and the outstanding results were summarized as, on one hand, the hydrate dissociation is controlled by the pressure difference between equilibrium and outlet, and the higher pressure difference results in the slower dissociation rate; on the other hand, the degree of depressurization is a significant factor influencing the gas production rate, and the highest productivity and the least time required for complete dissociation are achieved when the pressure is the closest to the equilibrium pressure.[312] Another important study was carried out by Tang et al.[31] In the study, gas production from hydrate-bearing core was carried out by depressurization to $0.1,0.93$ and $1.93 \mathrm{MPa}$ at $273-$ $275 \mathrm{~K}$, respectively, and the experimental gas production behavior was simulated by hydrate 
reservoir simulator Tough-Fx/Hydrate. The studied results highlighted that the hydrate dissociation process are controlled by the different mechanisms for laboratory-scale and field-scale hydrate reservoirs. For laboratory scale, hydrate dissociation kinetics is quite important. Nevertheless, for field-scale, the gas production process is controlled by flow mechanism, and the kinetics played few roles of gas production. The study of the effect of hydrate saturation on the gas dissociation behavior showed that the proportion of hydrate decomposed decreases with the increase of the hydrate saturation in the rapid dissociation stage, and the hydrate dissociation rate increases as the dissociation pressure decreases.[21] In order to make the system of simulated methane hydrate close to the real situation, the reactor with enough large volume is strongly required. Recently, some hydrate simulation reactors with large volumes have been developed, as reviewed in section 4.2. Zhou et al. developed a set of experimental apparatus with a $72 \mathrm{~L}$ hydrate formation reactor.[306] By using the large reactor, they investigated methane gas production from simulated methane hydrate by depressurization, and the results illustrated using higher over pressure and step-up pressure can obtain better spatial distribution of hydrate formation in the reactor. In addition, a transition regime below $273.15 \mathrm{~K}$ was observed during the dissociation.

Li et al.[28, 29], Zhang et al.[313], Li et al.[15] and Li et al.[314] reported the investigations into the hydrate dissociation behaviors from methane hydrate in sediments by depressurization using the CHS (5.8) and PHS (117.8). The effects of the production pressure, hydrate saturation and the reservoir size on the production behaviors were investigated. The experimental results in different apparatuses showed that the gas production process consists three period (free gas production, mixed gas (free gas and gas dissociated from the hydrate) production and gas production from the hydrate dissociation. The hydrate dissociation is an analog of a moving boundary ablation process, and the hydrate dissociation interface separates the hydrate dissociated zone containing only gas and water from the undissociated zone containing the hydrate.[314] The gas dissociation rate and the cumulative dissociated gas increase with the decrease of the dissociation pressure. The water production increases with the decrease of the dissociation pressure. The cumulative gas production increases with the hydrate saturation. The average gas production rate firstly increases with the increase of the hydrate saturation, and then decreases at the hydrate saturation of $43.2 \%$.[29, 313] With the comparison of the experimental results in CHS and PHS, the duration for gas production with the PHS is approximately 20 times as many as that with the CHS in the third period. It was found from using the CHS and PHS that the first and second periods are mainly controlled by the pressure reduction rate. In the third period, the heat conduction from the ambient is the main driving force to dissociate the hydrate. However, the gas production rate in the period is low. Particularly, from the $60 \%$ to $100 \%$ of the dissociated gas production, the gas production rate is quite low, and the production time takes up approximately $70 \%$ of the whole the time of the dissociated gas production. Thus, they proposed that other methods should be applied to enhance the recovery efficiency for the production of the dissociated gas of the last $40 \%$.[28] Li et al.[15] investigated the kinetics behaviors of methane hydrate dissociation in hydrate-bearing sediments with low gas saturations under depressurization in PHS through experimental and numerical simulations. The results showed that the hydrate dissociation is mainly controlled by the mass and heat transfers. The gas production rate increases with the decrease of the production pressure, while the water extraction rate will rise 
much higher if the wellbore pressure is dropped extremely low. The free gas saturation is a key factor that affects the overall production behaviors of marine hydrate deposits. Methane hydrate dissociation by depressurization below the quadruple point in the sandy sediment is also studied in large scale reservoir by Wang et al.[315] The results indicated that methane hydrate dissociation below the quadruple point causes ice formation, which can strongly enhance the dissociation rate of the hydrate. The water generated from hydrate dissociation below the quadruple point may immediately form ice and the pore water in the reservoir turns into ice at the same time. Meanwhile, the hydrate dissociation below the quadruple point consumes the latent heat released by ice formation. Konno et al.[190] studied the gas recovery factors in HiGUMA at various depressurization schemes, including one-step depressurization, multistep depressurization, and depressurization below the quadruple point of methane hydrate. Through the investigation, Konno et al.[190] considered that an appropriate heat of the hydrate-bearing sediments is a crucial factor for driving hydrate dissociation, and intentional ice formation by adjusting production pressure could potentially enhance methane hydrate recovery at a comparable level of conventional natural gas production.[190]

As a summary, the depressurization technique for NGH production has been extensively investigated in laboratory. The effects of the depressurization degree, the hydrate saturation, depressurization scheme on the production behaviors have been studied in the different scale reactors. The heat supply for the hydrate dissociation is found to be the control factor for the depressurization technique, and the efficiency should be restricted if there is no extra heat supply in the later stage of the gas production via depressurization.

4.3.2 Experimental simulation via thermal stimulation

Summarizing the experimental simulation of gas production by depressurization, we observed that in most studies, the heat transfer is raised as an important factor for enhancing methane recovery from methane hydrate. It is reasonable because gas hydrate dissociation does be an endothermic process. Hence, in order to improve economically gas production, a combination technique combining depressurization with thermal stimulation is proposed and is generally agreed.[25,27] Before we review the studies by the combination technique, the experimental studies by thermal stimulation are comprehensively reviewed in this section.

Tang et al.[316] investigated into gas production behavior under thermal stimulation in unconsolidated sediment by using a set of one-dimensional experimental apparatus with 38 $\mathrm{mm}$ in internal diameter and $500 \mathrm{~mm}$ in length, and the highlights of their studies could be summarized as: the injection water temperature, injection rate and hydrate saturation have the crucial influence on energy ratio, i.e., the higher hydrate saturation as well as the lower initial water temperature and the lower injection rate results in the higher energy ratio. Pang et al. investigated methane hydrate dissociation at $268.15 \mathrm{~K}$ in a middle-sized quiescent reactor using thermal method.[317] In their study, a buffered dissociation due to ice melting was observed, and the experimental results indicated the heat transfer and thermodynamic driving force are the governing factors for gas hydrate dissociation in the closed reactor.

As discussed above, the experimental simulations were carried out in one or/and two dimensions. Experimental simulations in three dimensions could present more data for the possibly real gas production from NGH reservoirs. Yang et al.[318] carried out a series of three-dimensional simulations on gas production from methane hydrate-bearing sand by cyclic hot-water injection. The experimental results indicated the trends of overall 
temperatures increase with hot-water injection, and the distribution and fluctuation of temperature in the reactor are mainly dominated by the location of well and the porosity and permeability of hydrate reservoirs. In addition, the results also illustrated that the energy efficiency ratio is positively impacted by hydrate saturation and ambient temperature but negatively influenced by hot-water initial temperature and well pressure in the case of other conditions being similar. By using a single vertical well in the CHS and PHS, Li et al. carried out experimental simulations to investigate systematically methane production behaviors from methane hydrates in the three dimensional hydrate simulators using the huff and puff method.[13, 17, 23, 25, 27] Each huff and puff cycle includes three stages: heat injection, soaking, and gas production. The experiments verify that the hydrate decomposition process is a moving boundary ablation process. The region impacted by heat diffusion enlarges as the number of huff and puff cycles increases and eventually reaches the largest impact region. After that, the region impacted by heat diffusion is no longer increasing with continuous heat injection. By sensitivity analysis, they proved that the gas production depends on the initial hydrate saturation, ambient temperature and hot-water injection rate. Meanwhile, they highlighted, without the soaking stage, the range of thermal diffusion is restricted around the well, resulting in low energy efficiency. The gas production performance from hydrate-bearing porous media using the huff and puff method through both experimental and numerical simulations is investigated by Li et al.[13] The numerical simulation results agree well with the experiment. The secondary hydrate is formed under the pressurization effect caused by the hot water injection in the injection stage.

With a five-spot well system (one is heat water injection well and the other four are gas production wells), Wang et al.[33] investigated the methane production behaviors from NGH in porous sediments by heat stimulation in the CHS. The hydrate decomposition boundary moved from the central point to the surroundings gradually and finally covered almost the entire hydrate field in the CHS during the thermal stimulation process. The heat conduction plays a more significant role than the convection for the heat diffusion in the thermal stimulation process. More importantly, the higher hot-water injection rate $\left(\mathrm{R}_{\mathrm{inj}}\right)$ caused the higher average gas production rate and the lower energy efficiency, though $\mathrm{R}_{\text {inj }}$ had little influence on the final gas recovery. Wang et al.[32] established the scaling criteria for gas hydrate production by the heat stimulation in five-spot well system. The experimental results verify that the scaling criteria for gas hydrate production are reliable. The scaling criteria are used for predicting the production behavior of the real-scale hydrate reservoir. In the model of the real-scale hydrate reservoir with the size of $36 \mathrm{~m} \times 36 \mathrm{~m} \times 36 \mathrm{~m}$, methane of $1.168 \times 106$ $\mathrm{m}^{3}$ (STP) is produced from the hydrate reservoir during 13.9 days of gas production. It is determined that the gas recovery is 0.73 , and the final energy efficiency is 9.5 .

Feng et al.[319] evaluated the methane hydrate dissociation behaviors using both vertical well and horizontal well experimentally. The results indicated that, for the depressurization and thermal stimulation methods, the gas production rate, the heat transfer rate, and the accumulative dissociation ratio with the horizontal well pattern are higher than those with the vertical well pattern. Meanwhile, the evaluations of the energy ratio and the thermal efficiency indicated that the horizontal well pattern has the advantage of higher production efficiency by the thermal stimulation. Thus, it is determined that the production performance is better using the horizontal well pattern. 
On the whole, almost all studies on gas production via thermal stimulation focus on revealing the governing factors for $\mathrm{CH}_{4}$ recovery from methane hydrate, enhancing energy efficiency through utilizing the different sediment media and different modes of the hot-water injection. Hot-water injection rate, initial temperature and ambient pressure play quite significant roles in gas production. Nevertheless, the core problems are heat transfer and diffusion of water/gas. In order to enhance the energy efficiency, it is necessary to reduce the heat losses; in order to increase the gas production and make gas production sustainable, it is necessary to eliminate the temperature self-preservation and improve the ambient to make gas/water flow easily in the NGH reservoirs. Compared to small reactor, the larger reactor can present the ambient closer to real situation, and cloud the charts of various parameters on three-dimensional level.

\subsubsection{Experimental simulation via chemical inhibitor injection}

In the past decades, numerous valuable studies have been reported on experimentally simulating gas production from NGH using the chemical inhibitor injection method.[16, 161, 261-285] Through these studies, the thermodynamics and the kinetics of gas production from NGH were systematically investigated. Chemical inhibitors include thermodynamic and kinetic inhibitors, and from chemistry of view, chemical inhibitors can also be divided into the volatile and non-volatile inhibitors. Presently, most chemical inhibitors are volatile. Katz et al.[320] found that the inhibiting effect reduced with the increase of volatility of the inhibitor. The conclusion was easily understandable and reasonable. In addition, due to the volatility, the inhibiting effect was proved to be impacted by the operating pressure. Makogon considered that, with the increase of the operating pressure, much more chemical inhibitor volatilized to build new balance of its partial pressure.[4] Methanol and EG were the most popular inhibitors. Sira et al.[321] used them to investigate into the methane hydrate dissociation behaviors and found that the dissociation rate was regulated by the inhibitor concentration, inhibitor injection rate, interfacial area between hydrate and inhibitor, and pressure. 10 - $30 \mathrm{wt} \%$ EG were injected into a $3.5 \mathrm{~L}$ reactor to investigate the effect of EG on $\mathrm{CH}_{4}$ hydrate dissociation. The study results indicated that the hydrate dissociation rate is positively affected by the concentration of EG and the injection rate. Similarly, Li et al.[16] investigated $\mathrm{CH}_{4}$ production from methane hydrate in porous sediments by injecting EG into a one-dimensional apparatus, and they found $\mathrm{CH}_{4}$ production efficiency is regulated by the concentration of EG and the injection rate, and the highest efficiency is achieved at EG of 60 $\mathrm{wt} \%$. By using a three-dimensional apparatus, Yuan et al.[322] investigated gas production behaviors from $\mathrm{CH}_{4}$ hydrate bearing sediments by injecting EG. Their results illustrated that a maximum gas production ratio (ratio of gas recovered from hydrate to initial amount of gas in the hydrate) corresponds to an optimal value of mass ratio of EG to initial water. However, the results also showed that the gas production efficiency decreases with the increase of the quantity of EG though the concentration of EG do have positively effect on gas production at the certain degree.

The non-volatile inhibitors generally cover brines containing $\mathrm{Cl}^{-}, \mathrm{Br}^{-}$such as $\mathrm{NaCl}$, $\mathrm{CaCl}_{2}, \mathrm{CaBr}_{2}$.[323-327] The exiting of such salt ions change the positions of water molecules in the hydrate cavities, making the clathrate structures easily fractured, and the mechanism was proved by a molecular dynamic study.[328] Therefore, such non-volatile inhibitors are considered as the kinetic inhibitors. A low brine concentration (approximately $3.45 \mathrm{wt} \%$ ) was 
found to be able to cause hydrate dissociation and increase significantly the gas production from Lee's study.[329] However, from the study, Lee also observed that the methane hydrate dissociation rate is reduced when the concentration of the brine exceeds approximately 20.0 wt $\%$ because excessive $\mathrm{NaCl}$ molecules disturb fluid flow between pore sand, and significantly reduce the permeability.

Till now, few technique of chemical inhibitor injection has not ever been used in field test because the inhibitors are considered to be environment-unfriendly and relatively expensive. In addition, the relatively low permeability of hydrate-bearing sediments hinders the chemical inhibitor to spread easily, causing the low gas production efficiency. Therefore, chemical inhibitor injection as a single gas production technique might be gradually abandoned. Nevertheless, as chemical inhibitor injection can lower the heat of dissociation, it is promising to accompany the chemical inhibitor with depressurization or thermal stimulation. In fact, hot-brine water injection as a combination method had used for gas production, which has been mentioned in section 4.1.5.

4.3.4 Experimental simulation via $\mathrm{CO}_{2}-\mathrm{CH}_{4}$ replacement

Investigations into $\mathrm{CO}_{2}-\mathrm{CH}_{4}$ replacement for $\mathrm{CH}_{4}$ recovery from $\mathrm{NGH}$ has become a hot spot because it can provide a win-win result of simultaneous $\mathrm{CH}_{4}$ production and $\mathrm{CO}_{2}$ sequestration.[330] In the experiments, $\mathrm{CO}_{2}$ is injected into the $\mathrm{CH}_{4}$ hydrate reservoirs in the forms of liquid $\mathrm{CO}_{2}$, pure $\mathrm{CO}_{2}$ gas, $\mathrm{CO}_{2}$ emulsion and gas mixtures containing $\mathrm{CO}_{2}$ etc.[331 340]

The replacement efficiency and rate of recovering $\mathrm{CH}_{4}$ from $\mathrm{NGH}$ with are $\mathrm{CO}_{2}$ is of significance for the application of the $\mathrm{CO}_{2}-\mathrm{CH}_{4}$ replacement technique. Uchida et al.[341] measured the replacement rate of $\mathrm{CH}_{4}$ hydrate with gasous $\mathrm{CO}_{2}$ by use of situ Raman analysis and found that replacement reaction is very slow and the induction period lasts for several days. Lee et al. [334] inferred that the slow rate of $\mathrm{CH}_{4}-\mathrm{CO}_{2}$ replacement may be attributed to the new $\mathrm{CO}_{2}$ hydrate formed on the surface of the $\mathrm{CH}_{4}$ hydrate, which wraps the $\mathrm{CH}_{4}$ hydrate and prevents the replacement reaction. Ota et al.[337] experimentally investigated the kinetics of the $\mathrm{CO}_{2}-\mathrm{CH}_{4}$ replacement reaction using gaseous $\mathrm{CO}_{2}$. They proposed a kinetic model of $\mathrm{CO}_{2}-\mathrm{CH}_{4}$ replacement including the $\mathrm{CH}_{4}$ hydrate decomposition and $\mathrm{CO}_{2}$ hydrate formation by assuming the driving force for $\mathrm{CH}_{4}-\mathrm{CO}_{2}$ replacement in the hydrate to be proportional to the fugacity difference between gas phase and hydrate phase. The experimental data reported by $\mathrm{Li}$ et al. [342] showed that the variation tendency of the decomposed $\mathrm{CH}_{4}$ hydrate and formed $\mathrm{CO}_{2}$ hydrate during the replacement process is the same as that of Ota et al.'s [337] experiment. Li et al.[342] observed that the high replacement rate is sustained for about $10 \mathrm{~h}$ at the early stage of the replacement. Due to the free water at the beginning of the replacement reaction in their experiments, the amount of $\mathrm{CO}_{2}$ hydrate formed is much more than that of decomposed $\mathrm{CH}_{4}$ hydrate. Yuan et al.[343] investigated the favorable conditions for methane recovery from hydrate reservoir with gaseous $\mathrm{CO}_{2}$ using a three-dimensional middle-size reactor--The replacement rate and the mole fraction of $\mathrm{CH}_{4}$ in gas phase were found to increase with the increase of initial $\mathrm{CO}_{2}$ mole fraction, the decrease of system pressure, and the increase of diffusion coefficient of $\mathrm{CH}_{4}$ in the hydrate layer.

Liquid carbon dioxide has a higher density than gaseous carbon dioxide and might offer some advantages compared with the gaseous carbon dioxide in the replacement of $\mathrm{CH}_{4}$ in hydrate. In addition, the temperatures and pressures in the permafrost and the deep-sea 
sediments mostly lie in the regions where the carbon dioxide is in liquid form [289]. The replacement reaction with liquid $\mathrm{CO}_{2}$ implied that the driving force for the replacement is probably the fugacity difference between the fluid and the hydrate phases, assuming a direct replacement mechanism.[333] Ota et al.[338] measured the dynamics of $\mathrm{CH}_{4}$ replacement in the $\mathrm{CH}_{4}$ hydrate with saturated liquid $\mathrm{CO}_{2}$ at $273.2 \mathrm{~K}$. A kinetic model for calculation of the $\mathrm{CH}_{4}$ remaining in the hydrate considering the decomposition rate difference between the M-cage and S-cage in the $\mathrm{CH}_{4}$ hydrate was developed. The driving force of the $\mathrm{CH}_{4}$ replacement in the $\mathrm{CH}_{4}$ hydrate with liquid $\mathrm{CO}_{2}$ was considered as the fugacity difference between the liquid and the hydrate phase. Zhang et al.[344] changed the experimental conditions in the replacement reaction by use of liquid $\mathrm{CO}_{2}$ at the different temperatures and initial pressures, and the experiment was conducted in porous sediment. His research showed that the recovery ratio of $\mathrm{CH}_{4}$ can reach approximately $45 \%$ after $288 \mathrm{~h}$, while in Ota's experiment,[338] the recovery ratio is about $37 \%$ after $307 \mathrm{~h}$ and the recovery ratio is $18.6 \%$ after $96 \mathrm{~h}$ in Zhou et al.'s experiment.[339] They concluded that the initial pressure has few effects on the replacement rate and the decrease of the temperature causes the lower replacement rate.

It can be noted that the replacement rate is still very slow. In order to enhance the replacement rate, McGrail et al.[345] proposed a scenario, in which $\mathrm{CH}_{4}$ in gas hydrate is replaced by a carbon dioxide-in-water emulsion and performed some primary experiments. Because of intellectual property concerns, the method of preparing $\mathrm{CO}_{2}$ emulsion failed to be found from their paper. Zhou et al.[335] performed the replacement experiments of $\mathrm{CH}_{4}$ from hydrate in quartz sand with carbon dioxide-in-water emulsions and liquid $\mathrm{CO}_{2}$. Their study indicated that the use of $\mathrm{CO}_{2}$ emulsions is advantageous, compared to the use of liquid $\mathrm{CO}_{2}$ in replacing $\mathrm{CH}_{4}$ from its hydrate. $\mathrm{CH}_{4}-\mathrm{CO}_{2}$ replacement was affected by many parameters especially in the presence of porous sediment.[335] In the experiments of Zhou et al.[339], $\mathrm{CO}_{2}$ gas and $\mathrm{CO}_{2}$ emulsion were used in the replacement. The replacement rates using $\mathrm{CO}_{2}$ emulsion are much greater than those using $\mathrm{CO}_{2}$ gas. Zhang et al.[346] pointed that the kinetics of $\mathrm{CH}_{4}$ replacement by $\mathrm{CO}_{2}$ emulsion, the varieties and contents of emulsifier, the ratio of water and liquid $\mathrm{CO}_{2}$, the influence on replacement rate of the dispersed phase in the emulsion have to be further researched. In the actual exploitation, the existence of porous media, the statistical circumstances of $\mathrm{CH}_{4}$ hydrate presence in the stratum and the pumping of $\mathrm{CO}_{2}$ emulsion require to be considered. Compared with gaseous $\mathrm{CO}_{2}$ and liquid $\mathrm{CO}_{2}, \mathrm{CO}_{2}$ emulsion is proven to be more efficient in replacing $\mathrm{CH}_{4}$ from the hydrate by experimental methods. However, the preparation technique of $\mathrm{CO}_{2}$ emulsion is still immature, and the experimental research on the replacement with $\mathrm{CO}_{2}$ emulsion is scarce, so the influencing factors of reaction are not quite clear. Thus, the technique of $\mathrm{CO}_{2}$ emulsion preparation and the optimum conditions for the replacement with $\mathrm{CO}_{2}$ emulsion should be studied further in the future work.

Another replacement method is using supercritical $\mathrm{CO}_{2}$. Deusner et al.[293] investigated methane production from $\mathrm{NGH}$ deposits through injection of supercritical $\mathrm{CO}_{2} \cdot \mathrm{CO}_{2}$ was heated to about $368.15 \mathrm{~K}$ before injecting $\mathrm{CO}_{2}$ into the simulated NGH deposits. They considered that the hot supercritical $\mathrm{CO}_{2}$ can efficiently activate the $\mathrm{CH}_{4}$ hydrate reservoir, overcome the mass transfer limitations, which always occurred in other experimental simulations of $\mathrm{CH}_{4}$ production by $\mathrm{CO}_{2}-\mathrm{CH}_{4}$ replacement as a control factor, and create the 
conditions for the released $\mathrm{CH}_{4}$ migrating easily from inner hydrate deposits towards the outlet. A good $\mathrm{CH}_{4}$ yield and considerable gas production in unit time under condition of 13 $\mathrm{MPa}$ and $281 \mathrm{~K}$ did achieve. However, the investigation did not mention the division of $\mathrm{CO}_{2}$ $\mathrm{CH}_{4}$ replacement and thermal stimulation in $\mathrm{CH}_{4}$ production from $\mathrm{NGH}$ deposits, i.e., we could not obtain the information that the individual specific contribution of the thermal stimulation and $\mathrm{CO}_{2}-\mathrm{CH}_{4}$ replacement into the $\mathrm{CH}_{4}$ production in the investigation with the combination method.

As mentioned in 4.1.4, it is feasible to use gas mixture of $\mathrm{CO}_{2} / \mathrm{N}_{2}$ to recover $\mathrm{CH}_{4}$ from $\mathrm{CH}_{4}$ hydrates. Park et al.[294] investigated the $\mathrm{CH}_{4}-\mathrm{CO}_{2}$ replacement behavior and compared the possible hydrate structure change. In their investigation, the activity of $\mathrm{CH}_{4}$ recovered by $\mathrm{CO}_{2}$ and $\mathrm{N}_{2}$ from large and small cages of sI hydrates was discussed in detail by in situ Raman and NMR spectra. By using gas mixture of $\mathrm{CO}_{2}(80 \mathrm{~mol} \%)$ and $\mathrm{N}_{2}(20 \mathrm{~mol} \%)$ to recover $\mathrm{CH}_{4}$ from $\mathrm{CH}_{4}$ hydrates, they found $\mathrm{CH}_{4}$ recovery was enhanced from $64 \%$ (achieved by pure $\mathrm{CO}_{2}$ ) to approximately $85 \%$. The quantitative analysis revealed that about $23 \%$ of $\mathrm{CH}_{4}$ in hydrates is replaced with $\mathrm{N}_{2}$, whereas $62 \%$ of $\mathrm{CH}_{4}$ is replaced with $\mathrm{CO}_{2}$. Koh et al.[295] also carried out the experiments to investigate the recovery of $\mathrm{CH}_{4}$ from gas hydrates intercalated within natural sediments using $\mathrm{CO}_{2}$ and a $\mathrm{CO}_{2} / \mathrm{N}_{2}$ gas mixture. From the above two investigations, we can found that $\mathrm{CH}_{4}$ recovery is independent on $\mathrm{CO}_{2}$ composition in gas mixtures of $\mathrm{CO}_{2}+\mathrm{N}_{2}$. Lee et al.[335] investigated $\mathrm{CH}_{4}$ recovery and $\mathrm{CO}_{2}$ sequestration by using flue gas in natural gas hydrates. $\mathrm{N}_{2}$ molecules were proven to preferentially replace $\mathrm{CH}_{4}$ molecules from the small $5^{12}$ cages of the sI hydrate. The interesting discussion was that the final extent of replacement quite slightly increases with the increase of $\mathrm{CO}_{2}$ from $10 \%$ to $20 \%$ in the $\mathrm{CO}_{2} / \mathrm{N}_{2}$ gas mixtures because $\mathrm{N}_{2}$ molecules only compete $\mathrm{CH}_{4}$ molecules with small $5^{12}$ cages and the offered the small $5^{12}$ cages were only half of the large $5^{12} 6^{2}$ cages in sI hydrates. The similar conclusions were also drawn by others.[334, 347] However, in fact, the $\mathrm{CH}_{4}$ recovery might be significantly lower than the value of $85 \%$ even lower than $64 \%$ due to a variety of factors, such as hydrate saturation, hydrate particle size and gas transport in the sediment.

The all above experiments focused on the $\mathrm{CO}_{2}-\mathrm{CH}_{4}$ replacement from $\mathrm{CH}_{4}$ hydrate, which is sI hydrates. In fact, not only sI and sII $\mathrm{CH}_{4}$ hydrates, but also $\mathrm{sH}_{\mathrm{CH}_{4}}$ hydrates exist in nature.[348] Shin et al. investigated $\mathrm{CH}_{4}$ recovering from sH (isopentane $+\mathrm{CH}_{4}$ ) hydrate by $\mathrm{CO}_{2}-\mathrm{CH}_{4}$ replacement with pure $\mathrm{CO}_{2}$ and a $\left(\mathrm{CO}_{2}+\mathrm{N}_{2}\right)$ gas mixture.[349] They found the $\mathrm{sH}$ hydrate rapidly transforms to sI hydrate during the replacement, and total $\mathrm{CH}_{4}$ recovery is more than $90 \%$. Compared to pure $\mathrm{CO}_{2}$, the $\mathrm{CO}_{2}+\mathrm{N}_{2}$ gas mixture more positively promotes the structural transition of $\mathrm{sH}$ to sI during the whole replacement because the added $\mathrm{N}_{2}$ firstly attacks the $\mathrm{CH}_{4}$ in the small cages of $\mathrm{sH}$ hydrate, causing simultaneous host water cages rearrangement and eventually structural transition to sI.

\subsubsection{Experimental simulation via combination technique}

The combination techniques mainly include depressurization in conjunction with thermal stimulation and thermal stimulation in conjunction with chemical inhibitor injection. The main reason for developing the combination techniques is that a single technique has its individual limitation for methane production as mentioned in section 4.2.

The most popular combination technique is the depressurization in conjunction with thermal stimulation. In the study from Li et al.[24], the gas production behaviors of methane 
hydrate in porous media were investigated in the CHS with a single vertical well using the different methods, depressurization (DP), regular huff and puff (HP), huff and puff in conjunction with depressurization (HP-D), and huff and puff with no-soaking (HP-NS), at $281.15 \mathrm{~K}$ and hydrate saturation of $33.5 \%$. The gas production efficiencies with the four methods were evaluated by the gas recoveries, average production rates, thermal efficiencies, and energy efficiencies. It was found that HP-D is the optimal method for gas hydrate recovery in a single vertical well. In a five spot well system, A novel method for hydrate production named "Five-spot thermal huff and puff (HP-5S)"[33, 34] is designed and employed to investigate the behaviors of hydrate dissociation. This method uses the thermal huff and puff method in a five-spot well system. In addition, the experiments with the methods of the five-spot thermal huff and puff in conjunction with depressurization (HP-5S-D), the heat stimulation with a five-spot well (HS-5S), the heat stimulation in conjunction with depressurization with a five-spot well (HS-5S-D), the thermal huff and puff (HP), and the huff and puff in conjunction with depressurization (HP-D), are also carried out. The analysis of hydrate decomposition showed that the thermal huff and puff method in a five-spot well system is superior to those in a single vertical well on the aspects of the energy efficiency, thermal efficiency, gas recovery, and average gas production rate. The HP-5S-D method, which can obtain the highest gas recovery, thermal efficiency, and energy efficiency, is the optimal method for hydrate production. Feng et al.[350] carried out the hydrate dissociation experiments by the depressurization in conjunction with warm water injection with dual horizontal wells in a cubic hydrate simulator. The results indicated that the heat transfer rate along the injection well is the fastest, and the heat for the hydrate dissociation mainly originates from the boundaries. Hydrate dissociation evolves by means of ablation with double-moving boundary. One dissociation interface moves from the injection well to the neighboring regions, and the other dissociation interface spreads from the boundary to the central reservoir. In order to investigate into the optimized injection temperature for hydrate dissociation, Feng et al.[351] evaluated the entropy production minimization (EPM), the energy ratio and the thermal efficiency of the depressurization in conjunction with warm water stimulation using dual horizontal wells. The optimal injection temperatures for the hydrate dissociation from the points of the maximizing the energy production and minimizing the energy consumption, respectively, are $38.8{ }^{\circ} \mathrm{C}$ and $37.9^{\circ} \mathrm{C}$. Thus, the warm water injection of approximately $38-39{ }^{\circ} \mathrm{C}$ is suitable for hydrate dissociation with the heat stimulation method by the dual horizontal wells, and the hot water injection beyond $39{ }^{\circ} \mathrm{C}$ is uneconomical for hydrate dissociation. Song et al.[352] investigated the gas production processes from methane hydrate in porous media using depressurization, two-cycle warm-water injection, and a combination of the two methods. The percentage of gas production, rate of gas production, and energy efficiency were obtained and compared for the three methods. The experimental results also proved that the combined method has obvious advantages for hydrate exploitation. Loh et al.[353] carried out gas production tests using the dual wellbore system with different combinations of pressure and temperature at the depressurization and heating wellbores, respectively. They found that a lower depressurization at the same wellbore heating increases the energy-efficient and a higher wellbore temperature at the same depressurization results in more gas produced but no improvement in efficiency.

Other one combination technique is the conjunction of thermal stimulation and chemical 
inhibitor injection, i.e., adding a chemical inhibitor into the hot water. Li et al.[22] investigated methane production behavior from hydrate-bearing sediments by injecting brine with the salinity of $0 \sim 24 \%$ and the temperature of $-1 \sim 130{ }^{\circ} \mathrm{C}$. The results showed that the hydrate gradually dissociates and the system temperature decrease with the injection of the $\mathrm{NaCl}$ solution. With the injection of hot brine, the instantaneous hydrate dissociation rate increases with the increase of the salinity. When the $\mathrm{NaCl}$ concentration is more than $16 \%$, the salinity has little effect on the hydrate instantaneous dissociation rate. Hence, in the process of hydrate dissociation with the injection of hot brine, it is not essential to use the brine with very high salinity. Compared to hot water injection, thermal efficiency and energy ratio could be enhanced by hot brine injection. The appropriate temperature in conjunction with the high salinity of brine solution creates relatively high recovery efficiency. The injection with too high temperature results in the energy loss. Li et al.[354] carried out an experimental study on hydrate dissociation behavior by hot brine injection with a $2 \mathrm{D}$ sand-packed system. The result of continuous hot brine injection is superior to that of intermittent injection. Yuan et al.[355] investigated the gas production behavior at different injected solutions (hot water, saline solution, and ethylene glycol) with continuous injection mode using a three-dimensional quiescent reactor. This work examined the influence of hot water temperature, injection rate, and injected solution type on the gas production and the energy efficiency. The results indicated that, under the same conditions, hydrate dissociation with $\mathrm{NaCl}$ solution has the highest gas production, compared with $\mathrm{Na}_{2} \mathrm{SO}_{4}$ and ethylene glycol. However, because most chemical inhibitors are environmentally unfriendly, there are fewer reports on the combination technique.

\subsubsection{Novel technologies of gas production from NGH}

Chen et al.[8] developed a novel technique to prepare hot brine in situ seafloor for marine NGH exploitation based on hydrate technology. The major obstacle of this technique include the rapid hydration condition, low hydrate formation rate, and low heat emission. To overcome the obstacle, it is needed to find a suitable chemical additive to reduce the formation pressure, shorten the induction time, accelerate the hydrate formation rate, and enlarge the heat emission. Several experiments have been carried out to investigate these issues. Lv et al.[356] compared the equilibrium formation pressure and dissociation enthalpies for hydrates of various water-insoluble organic promoters with methane. They found trimethylene sulfide has the biggest effect of hydrate promotion as a water-insoluble chemical promoter. Chen et al.[357] and Li et al.[358] studied the phase equilibria and enthalpies of CP + methane hydrates and Trimethylene Sulfide + Methane hydrates in brine water, respectively. The phase equilibrium pressure of $\mathrm{CP}+$ methane hydrates is found to increase with the increases of the temperature and the $\mathrm{NaCl}$ concentration. The dissociation enthalpies decrease with the increase in temperature and the increase in $\mathrm{NaCl}$ concentration. $\mathrm{Lv}$ et al.[359] studied the kinetics of the formation of cyclopentane + methane hydrates to find the optimum condition for rapid hydrate formation under submarine condition. They found that the formation rate of $\mathrm{CP}+$ methane hydrates increases with the increase of the volume ratio of $\mathrm{CP} /$ liquid phase and the biggest gas uptake is obtained when the $\mathrm{CP} /$ liquid phase volume ratio is 0.05 . Furthermore, Lv et al.[360] investigated the effects of the flow rates of cyclopentane and methane gas, operating pressure, and experimental temperature on the formation of cyclopentane + methane hydrate using a novel bubble column reactor. It was noted that 
average methane consumption rate can be effectively enhanced with an increase of the flow rate of gas at relatively low pressure and high temperature. The flow rate of $\mathrm{CP}$ has a minimal effect on the cumulative gas consumption and gas conversion ratio. However, an increase of the flow rate of $\mathrm{CP}$ can reduce the induction time. Overall, more investigations into finding a suitable chemical additive and determining the proper formation conditions were needed to verify the feasibility of this technique.

Other one important experimental simulation on methane production from $\mathrm{CH}_{4}$ hydrate was carried out by the method of in situ combustion.[296-299] A Counter-current heat-exchange reactor was designed and developed to dissociate gas hydrates in sediments.[298, 299] In the simulation, the heat was produced via the catalytic oxidation of $\mathrm{CH}_{4}$, and aluminum foam was employed in the design in order to optimize the heat transfer into the sediments. The gas production tests showed that about $15 \%$ of the produced $\mathrm{CH}_{4}$ are used to generate the necessary heat for dissociating almost all $\mathrm{CH}_{4}$ hydrates in the sediments, and the efficiency of the thermal stimulation via in situ combustion is considered as to be promising. Besides, Chen et al.[361] carried out the combustion experiments of the pure propane hydrates and the mixtures of hydrates and quartz sands. They found that the flame propagates very rapidly for the pure propane hydrate combustion and the burn lasts for a much shorter of time for the hydrate-sand mixture combustion. High porosity and high hydrate saturation is considered to be beneficial to the combustion. Misyura [362] carried out experimental simulation to investigate effect of heat transfer on the kinetics of methane hydrate dissociation via in situ combustion method. In the simulation, the increase in the density of heat flux from 255 to $13700 \mathrm{Wm}^{-2}$ results in 9-fold increase in $\mathrm{CH}_{4}$ hydrate dissociation rate, and the heat flux directly regulates the hydrate dissociation rate and changes the gas/water diffusion in the hydrate sediment. With the increase of heat flux, the temperature self-preservation gradually disappears. The kinetics of hydrate dissociation is also regulated by the pressure in pores of sediments, and the dissociation rate changes dramatically with the decrease of the pressure in the pores. Fitzgerald et al.[363] performed in situ combustion study with a special apparatus only in laboratory, and they achieved relevant low energy efficiency for methane recovery from methane hydrate. Consequently, the in situ combustion as one approach for gas production from NGH has been proven. However, the safety problem resulted from the uncontrollability of combustion still requires to be resolved before the in situ combustion is utilized for the field test of gas production.

Among all the techniques mentioned above, the combination technique undoubtedly is the best choice to improve the gas production efficiency and reduce the production cost. Therefore, further optimization of the combination technique is the next development. However, in our opinion, the further development of $\mathrm{CH}_{4}-\mathrm{CO}_{2}$ replacement technique may make more sense for its win-win feature.

\subsection{Numerical simulations}

\subsubsection{Numerical simulators}

In order to assess hydrate production potential and predict the possible behaviors, numerical simulations are systematically developed based on plenty of experiments. Numerical simulation, in nature, is to simulate the possibilities of gas production process by numerous computations, which are entirely based on the developed simulators or codes. 
Thermodynamic modeling of the hydrate decomposition process has been reported. Holder et al.[364] first reported a three dimensional (3D) finite-difference numerical simulation of heat and mass transfer in a reservoir containing layers of gas hydrates and free natural gas, and the depressurization process of this hydrate reservoir. Burshears et al.[365] extended the model of Holder et al.[366] and considered the influence of water transport in the layer. Yousif et al.[180] developed an one dimensional (1D) apparatus and a three-phase 1D model to simulate the process of gas production from Berea sandstone samples containing methane hydrate by depressurization mechanism. Makogon [367] described the process of hydrate decomposition with an analog of a moving boundary ablation process. Conductive-convective heat transfer, as well as the effect of the throttling process, was included in the energy equation. Neglecting the effect of the release of water, a self-similar solution for the pressure distributions in the hydrate reservoir was obtained and analytical expressions for the temperature and pressure profiles for the linearized system of equations for both 1D and cylindrical models were reported. Tsypkin [368] extended the model by including the effect of water movement in a 1D model. Similarity solutions for temperature and pressure distributions were also obtained using a perturbation method. Ahmadi et al.[193] and Ji et al.[196] reported numerical results for the 1D model described by Makogon [367] and made a series of sensitivity analyses of natural gas production as variations of reservoir parameters. Sun et al.[194] developed a thermal, three-phase, 1D numerical model to simulate two regimes of gas production from sediments containing methane hydrates by depressurization: the dissociation-controlled regime and the flow-controlled regime. A dimensionless parameter namely dissociation-flow time-scale ratio was defined and employed to identify the two regimes.

In recent years, several numerical simulation codes have been developed. TOUGH+HYDRATE is originally developed from Lawrence Berkeley National Laboratory (LBNL). It models the non-isothermal gas release, phase behavior and flow of fluids and heat in complex geologic media. The code can simulate production from natural $\mathrm{CH}_{4}$ hydrate deposits in the subsurface (i.e., in the permafrost and in deep ocean sediments), as well as laboratory experiments of hydrate dissociation/formation in porous/fractured media. This code includes both an equilibrium and a kinetic model of hydrate formation and dissociation. TOUGH+HYDRATE is one of the most popular simulators in the field of numerical simulation of gas production from NGHs for its wide applicability and relatively easy program language. TOUGH+HYDRATE came out in 2008, and almost at the same time, Zhang et al.[369] developed $\mathrm{pT}+\mathrm{H}$ which was the parallel version of TOUGH+HYDRATE. Compared to TOUGH+HYDRATE, $\mathrm{pT}+\mathrm{H}$ can simulate a quite large-scale field gas production because of the application of the parallel computing technique. CMG-STARS (developed by Computer Modelling Group Ltd.) is a thermal, k-value (KV) compositional, chemical reaction and geo-mechanics reservoir simulator. It is ideally suited for advanced modelling of recovery processes involving the injection of steam, solvent, air and chemicals. Therefore, it is available for simulating gas production by thermal stimulation, or chemical inhibitor injection, or the combination technique of thermal stimulation and chemical inhibitor injection. We should confess that CMG-STARS has its great advantages in gas production by thermal stimulation. However, few simulations by depressurization were reported with CMG-STARS. Moreover, the price of the software of CMG-STARS is 
expensive. STOMP-HYD comes from the Pacific Northwest National Laboratory. STOMP-HYD can well reveal the motion and change of multi-phase fluids. The equilibrium model and kinetic model based on mass conservation equation and energy conservation equation are the two models in STOMP-HYD with assumptions of hydrates, ice, precipitated salts and guests being immobile.[370-376] However, such assumptions are always unreal because the precipitated salts and guests are mobile in most situations, making the limitation of STOMP-HYD evident. MH21-HYDRES is developed by a team in which the members come from the Japan Oil Engineering Company, the National Institute for Advanced Industrial Science and Technology, and the University of Tokyo, respectively. It is designed for simulating $\mathrm{CH}_{4}$ production from NGHs by thermal stimulation, or depressurization, or combination technique of thermal stimulation and depressurization. It can be used to simulate a complex system which involves three dimensions, five phases and at least six components. However, the meshes used in the MH21-HYDRES are considered to be coarse because the grids are relatively extensive. Therefore, numerical errors are often inevitable during a numerical simulation although a high computation speed can be obtained.

However, it is quite difficult to evaluate the simulators because they all have their individual advantages and disadvantages. Wilder et al.[377] made an international effort to compare the gas hydrate reservoir simulators. In the comparison, five problems were dealt by above five simulators. The basic conclusion was each simulator has certain advantages and disadvantages but none is either completely accurate or proven reliable from first principles. Besides, much more intentions were achieved through the comparison, including enabling improvements in reservoir modeling by exchanging information regarding gas hydrate dissociation and physical properties, building confidence in all the simulators via exchanging ideas and cross-validation of the simulating results on common data sets of escalating complexity.

\subsubsection{Numerical simulations on $\mathrm{CH}_{4}$ production from $\mathrm{NGH}$}

As we all know, all numerical simulations on $\mathrm{CH}_{4}$ production from $\mathrm{NGH}$ firstly are carried out, based on the data achieved from the laboratory experiments and field gas production tests. Then, researchers can evaluate the possibility, feasibility, capacity of methane production from NGHs from a certain region in seafloor or permafrost according to the results of numerical simulations. Pawar et al.[378, 379] presented numerical modeling studies on field scale simulations of production from a hypothetical hydrate reservoir. In the studies, the gas productions by hot water injection and depressurization were explored, and the sensitivity of results to variation in values of operational and reservoir parameters were systematically determined by use of modified LANL's in-house porous flow simulator and FEHM (Finite Element Heat and Mass) simulator. The simulation results showed, on one hand, hot water injection method provides significantly better production performance than depressurization method, on the other hand, the hot water initial temperature, injection rate and production well pressure have an impact on gas production for hot water method, and the production well pumping pressure plays an important role in gas production for depressurization method. Besides, the effects of variability in hydrate specific fluid flow properties were determined. The effective permeability of a hydrate-containing medium has an inverse influence on the gas production, while the relative permeability has slight effect on the gas production. A positive information for the reservoir scale was that the influence of the 
hydrate reformation on the gas production is quite small. For the similar hypothetical hydrate reservoir, Liu et al.[380] carried out numerical simulations on methane production from the hypothetical NGH reservoir by depressurization with a one-dimensional model. By the simulations, they investigated the effects of the well pressure and the absolute permeability of the porous media on the NGH dissociation moving boundary. The commercial software FLUENT and the governing equations covering the convective-conductive heat transfer and mass transfer in both gas and hydrate zones along with the energy balance at the moving front were employed. The highlighted conclusions were, (1) the water saturation decreases gradually from the dissociation moving front to the production well, (2) with the higher hydrate reservoir permeability and the lower well pressure, the front movement is the faster and gas production is the higher. In addition, Gamwo et al.[381] developed an open simulation code based on HydrateResSim to evaluate the gas production. By the developed simulation code, they clearly demonstrated the effect of thermal boundary conditions on the dissociation moving front. They considered the adiabatic boundary conditions result in a single dissociation front, whereas the constant-temperature boundary conditions lead to multi-boundaries. By use of the developed simulation code, they also found the surface area factor has positive effect on the hydrate dissociation rate. Thereby, they strongly recommend to measure the surface area factor accurately in the experimental simulations. Ruan et al.[382] investigated methane production behavior from simulated NGHs by different depressurization approaches with a 2D axisymmetric model. The effect of the depressurization range and depressurization rate on gas production and production lifetime were demonstrated in detail. The depressurization range has significant influence on the final gas production, while the depressurization rage only plays role in the production lifetime. Compared to the Class 1 hydrate reservoir, the Class 2 has a longer and more stable gas production process in the simulations. For simulation cases of depressurization range, the ambient temperature positively affects the gas production process, while the function of the thermal conductivity is quite weak. For the cases of depressurization rate, either the ambient temperature or the thermal conductivity has dominant influence on the gas production process. Bai et al.[383] also developed the simulation code and compared the experimental and numerical simulations on methane production from hydrate reservoir by depressurization. They firstly compared the results obtained from the experimental simulations and the numerical simulations for 1- and 2-D hydrate dissociation systems. After confirming the results from the two simulations to be consistent, they used the model to evaluate the methane production behavior from Class 3 hydrate reservoir by depressurization. The results showed that energy efficiency of a single depressurization for gas production from Class 3 hydrate reservoir is low. Therefore, they considered that the more reasonable method for gas production from Class 3 hydrate reservoir was the depressurization for the initial production stage, and then the other methods such as thermal stimulation or inhibitor injection were applied for the next stage. In addition, they suggested to install a de-water equipment in field gas production because the water production was large.

From the above description, we know the purposes of numerical simulation for a certain hypothetical hydrate reservoir are finding some problems, which possibly occur in experimental simulation or in field gas production test, revealing some laws such as the influences of different parameters on gas production, methane recovery, production time, 
energy efficiency, etc. However, such hypothetical hydrate reservoir is very different from the real hydrate reservoir in the world, after all. The conclusions achieved from the simulation on the hypothetical hydrate reservoir could only be suggestive, and the conclusions of more practical value must come from the simulations on the real hydrate reservoir. The real hydrate reservoirs in Shenhu area in the South China Sea (SCS),[10, 11, 18-20, 87, 382-386] in the Ulleung basin of the Korea East Sea,[39, 68, 387] at the Walker ridge 313 site, North Gulf of Mexico,[388] at the Mallik site, Mackenzie Delta, Canada,[36, 37, 389, 390] in Qilian Mountain permafrost region[12, 14, 21, 26] are the hottest to be simulated.

As early as 1998-1999, two gas research wells (the Mallik L-28 and Mallik 2L-38) were drilled at Mallik site where an onshore permafrost-associated gas hydrate in the Mackenzie Delta, Northwest Territories, Canada, was represented. Gas hydrate deposits from five Zones (Zone \#1, \#2, \#3, \#4 and \#5) were simulated using the EOSHYDR2 model based on three main assumptions, (1) the pressure distribution was hydrostatic, (2) a heat flux corresponding to the geothermal gradient was used in the region covered by top and bottom boundaries of the simulated domain, (3) the gas hydrate was pure methane hydrate.[37] The details for describing the five zones and the gas production schemes were shown in Table 1. The hydrate deposits from the five zones were qualitatively summarized according to the results of the numerical simulations. For Zone \#1, gas production by depressurization is possible, and single horizontal well system is better than single vertical well system because water production is delayed and relatively more produced methane comes from gas hydrate dissociation. It also verified that the gas production scheme with two-well system and combination method (depressurization and thermal stimulation) is substantially superior to a single well system, especially for the situation of injection of hot non-condensable gases. For Zone \#2, depressurization can lead to significant gas production, but it also inevitably results in large amount of water production. For Zones \#3-5, thermal stimulation can help to produce measurable amount of H-methane. Furthermore, the sensitivity analysis indicated that, for Zones \#3-5, gas production is positively affected by gas hydrate saturation, hydrate initial temperature, circulating water temperature and thermal conductivity of the system. However it is less sensitive to the rock and gas hydrate specific heat and the permeability of the formation.

In 2001 to 2002, the field operations for the 2002 Mallik program were carried out, and a gas production well at Mallik 5L-38 and two observation wells at Mallik 3L-38, Mallik 4L-38 were drilled.[391] Moridis et al.[389] carried out numerical simulations on the Mallik 5L-38 gas hydrate production research well for analyzing and interpreting the gas hydrate dissociation by thermal stimulation with a single horizontal well or/and a single vertical well. Mallik 5L-38 hydrate deposit belongs to Class 3 hydrate reservoir, and the model used for this numerical simulation was TOUGH-Fx/HYDRATE. The properties and characteristics of the simulated hydrate deposit could be described as: impermeable flow boundaries, gas hydrate interval from $-906 \mathrm{~m}$ to $-925 \mathrm{~m}$, cylindrical simulation domain radius about $10 \mathrm{~m}$, water saturation (Sw) of 0.2. Through the simulations, on one hand, the model TOUGH-Fx/HYDRATE were verified to be valid for the simulation results being highly consistent with real thermal test; on the other hand, it also implied that only quite small total gas production could result from the hydrate deposits by single thermal stimulation or depressurization in conventional well configurations. Therefore, it appeals to a combination 
gas production scheme such as combination of thermal stimulation and depressurization, on another hand, due to the low energy efficiency and low gas production, which were achieved from the simulation, it requires innovative approaches for gas production from Class 3 hydrate reservoir. Other one valuable numerical simulation on gas hydrate deposit from Mallik 5L-38 was carried out by Kurihara et al.[390] Different from Moridis et al.'s work [389], Kurihara et al.[390] chose MH21-HYDRES as the simulator and the depressurization as gas production scheme. Of course, due to the difference of simulator, the model properties and parameters were different from those used by Moridis et al.[389] The simulation results, thereby, were different. From this simulation, the detail gas production along with water production was achieved. First, the too low gas and water production rates could be neglect during the first few hours of the testing; second, 1000 to $2000 \mathrm{~m}^{3} / \mathrm{d}$ of sustainable gas production and 10 to $70 \mathrm{~m}^{3} / \mathrm{d}$ of continuous water production could be achieved when the bottom hole pressure decreased from $11 \mathrm{MPa}$ to $7.2-7.5 \mathrm{MPa}$, and the instantaneous gas production could reach to $8000 \mathrm{~m}^{3} / \mathrm{d}$ when the pressure decreased to $6.9 \mathrm{MPa}$; third, the wellbore pressure could increase because water reversed-flowed upwards towards the test interval; forth, sand production accompanying with gas production and water production may create relatively high permeability conduits, resulting in significant enhancement of the formation permeability near the wellbore, further speeding up the gas production.

Shenhu area is considered as one of the most promising fields containing a lot of NGHs on North continent slope of the South China Sea. Many hydrate reservoir samples have been drilled and sampled in the area. Li et al.[19] assessed the production potential of the laminar hydrate deposit at drilling site SH7 in the Shenhu area by numerical simulation. They suggested over pressurization and depressurization should be avoided during each huff and puff cycle by a reasonable injection and production rates. The above hydrate deposit sample from SH7 site is covered by permeable overburden and underburden. Another sample from SH7 site covered by impermeable overburden and impermeable or/and permeable underburden was also simulated.[18] The results indicated, compared to hydrate deposits with permeable overburden and underburden, the depressurization is considered to be promising scheme as it brings larger gas production, gas production rate and energy efficiency. Furthermore, the hydrate deposits with impermeable overburden and under burden are of more potential for commercial application of gas production. However, from the well configuration, for the samples drilled at drilling sites $\mathrm{SH}$, SH3, and $\mathrm{SH} 7$ in Shenhu area in South China Sea, a single well for gas production is not reasonable or could not meet commercial application. It looks forward to new well configurations. Su et al.[385] also confirmed the results in their simulation on a Class 3 hydrate deposit sample drilled from drilling site SH3 with a single horizontal well. In the simulation, TOUGH+HYDRATE simulator was used, and the gas production scheme was depressurization with a vertical well. The simulated hydrate deposit was of Class 2 configuration and $10 \mathrm{~m}$ thick, locating in middle of the overburden and underburden of $190 \mathrm{~m}$ permeable water zones. Before the simulation, the properties and conditions pertaining to the reference case must be confirmed, such as porosity, hydrate saturation, intrinsic permeability, density, gas composition, salinity, hydraulic diffusion, conductivity, compressibility, capillary pressure model, radius of the simulation domain, etc. By the comparisons of gas production, water production, and changes of the spatial distributions, and sensitivity analysis, they considered the 
depressurization-induced NGH dissociation through a vertical well at constant well pressure was not a promising approach for the deposit of low hydraulic diffusion, and hydrate dissociation and gas production could be sustainably improved by a high reservoir permeability and an impermeable boundary. Another sample drilled at drilling site $\mathrm{SH} 2$ was also simulated.[385] The sample was Class 2 hydrate reservoir which located in the zone around 1423 - $1426 \mathrm{~m}$ underocean surface with $20 \mathrm{~m}$ permeable overburden water zone and $20 \mathrm{~m}$ permeable underburden water zone. The gas production scheme was huff-and-puff thermal stimulation with a vertical well. The investigation objects and contents were similar to the simulation on SH3 sample, and the results achieved from the simulation were also unsensational. The simulation results showed that gas production rate too slow to meet the commercial production. What more important is that a large proportion of gases due to the hydrate dissociation during the production process converts into secondary gas hydrates but not release out from the well. Therefore, for Class 2 and Class 3 hydrate reservoir, a single vertical well is not a reasonable way to efficiently produce methane from NGHs by either depressurization or thermal stimulation. Feng et al.[11] carried out numerical simulation on methane production from hydrate deposits from the South China Sea with different horizontal well configurations. In the simulation, two dual horizontal well systems were designed. For the first system, two vertical wells located at upper and lower sites in the same Y direction in a $2 \mathrm{D}$ coordinates, for the second system, wells located left and right in the same $\mathrm{X}$ direction in a 2D coordinates. For the two wells, one was special for injection, and the other is for production in a single simulation unit, and the distance between the two wells was $45 \mathrm{~m}$. The simulated hydrate deposit was Class 3 hydrate reservoir, and the simulator of TOUGH+HYDRATE was employed, and production scheme was hot brine water injection. The simulation results indicated that, the gas production rate, ratio of gas to water, energy efficiency increase distinctly relative to the single well system because the dual well system has higher efficiency of heat transfer between the hot brine water and the hydrate reservoir. The sensitivity analysis also indicated that although the higher injection rate could improve the gas production rate, the lower injection rate leads to higher energy efficiency. The dual well system was also verified by the combination method of hot brine water injection and depressurization.[10] On one hand, the economic feasibility of the combination production scheme was achieved because a relatively high energy efficiency was obtained relative to other schemes; on the other hand, the simulation results also illustrated that the gas and water productions were strongly dependent on the intrinsic permeability of the hydrate reservoir. With the decrease of the intrinsic permeability from $75 \mathrm{mD}$ to $5 \mathrm{mD}$, the gas and water production rates decrease, and the energy efficiency also decreases dramatically. Another new well configuration is a Five-spot well system.[33, 34] So called five-spot well system could be described as there are total 5 wells in a production unit, one in the middle of a square as injection well, other 4 wells in four corners of the square as gas production wells. From the experimental simulations, the five-spot well system brings higher gas production rate and energy efficiency because the five-spot well system offers a reasonable situation for maintenance of pressure and promoting the mass transfer and heat transfer/convection. Numerical simulations of gas hydrate dissociation with the five-spot well configuration are firstly carried out by $\mathrm{Li}$ et al.[392] They divided the combination forms of the hydrate dissociation methods in different well systems into 6 main patterns. Dissociation processes of 
methane hydrate in porous media using the inverted five-spot water flooding method (Pattern 4) were investigated by the experimental observation and numerical simulation. In situ methane hydrate is synthesized in the Cubic Hydrate Simulator (CHS), a 5.8-L cubic reactor. One of the common characteristics of the inverted five-spot water flooding method was that both the gas and water production rates decrease with the reduction of the hydrate dissociation rate. The evaluation of the energy efficiency ratio might indicated the inverted five-spot water flooding as a promising gas producing method from the hydrate reservoir.

In 2008 - 2009, four test wells (DK-1, DK-2, DK-3 and DK-4) locating in the north of the Qinghai-Tibet Plateau permafrost (QTPP) were drilled, and gas hydrates were observed in the collected cores samples. The hydrate layers in the QTPP situates in depths of $133-396 \mathrm{~m}$ underground with average temperature of -1 to $-3 \square .[103]$ The hydrate samples drilled from the DK-1, DK-2, DK-3 and DK-4 were thereby simulated. Li et al.[21, 26] carried out numerical simulation to investigate the gas production potential for hydrate deposit from DK-3 by huff-and-puff and depressurization methods with a single horizontal well. Li et al. $[12,14]$ investigated the gas production potential for DK-2, with two horizontal wells. Simulator TOUGH+HYDRATE was employed. Similar to those achieved from simulations on hydrate deposits from Shenhu area of the SCS, (1) dual horizontal well system is better than single well system for it brings higher gas production, gas production rate and energy efficiency, (2) combination gas production scheme of depressurization and thermal stimulation is feasible for producing methane from gas hydrate deposits in QTPP, (3) the sensitivity analysis indicated that the gas production is strongly dependent on the intrinsic permeability and the porosity of the hydrate deposits, (4) suitable heat injection rate and driving force of depressurization are two important factors to obtain higher gas-to-water ratio and energy ratio, (5) due to the absolute gas production being low, the presented gas production scheme and well configurations still need improve to meet the commercial requirement.

\subsection{Comments and suggestions}

Though methane production from NHGs has been investigated for more than 20 years, it is mainly still in the stage of the experimental research. Presently, the key issues on the methane production from NGHs are relatively low energy efficiency, unsustainability, low ratio of gas production to water production, gas production rate and total gas production. Around these key issues, the researchers developed many techniques and well configurations. Either experimental simulations or numerical simulations prove that the combination production technique (e.g., combination of depressurization and thermal stimulation) and multi-well configuration could enhance the energy efficiency, improve the gas production. However, the new techniques could still not make the methane production from NGHs commercialized. Why? It is because the core problems of thermodynamics, kinetics, heat transfer or/and mass transfer as well as multi-phase flow etc. in the inner NGHs during the gas production process are still fully unknown or the people's already understanding on the core problems are somewhat different from the real situations. For numerical simulation, the selected governing equations might not fully express the behaviors of the inner gas hydrate reservoir, especially the continuous change of multi-phase flow and the changes of porosity, permeability, hydrate saturation and water saturation in the inner hydrate reservoir could not 
dynamically expressed. Of course, it is worthy of affirming the achievements mentioned above. In fact, the achievements strongly push the experiments towards field test, and help us know more deeply the different parameters such as porosity, permeability, saturation, conductivity, etc., under the conditions of different gas production techniques or/and different well configurations during a certain gas production simulation.

However, we must confess that any the present gas production schemes could not be turned to a commercial application. In order to more accurately know the behaviors of gas production from one real gas hydrate reservoir, we strongly suggest to carry out the experimental simulations in a real hydrate deposit drilled from a certain region. For the numerical simulation, the governing equations involving the dynamical changes of the parameters must be employed and modified. Additionally, the gas hydrate phase and porous media could not be assumed to be immobile. Actually, both the gas hydrate and the porous media are mobile during the gas production. The mobile gas hydrate and porous media are proved in the field production tests.

\section{Field Production Test from Hydrate Deposits}

\subsection{Field test from onshore and offshore gas hydrate deposits}

Based on the series of experimental simulations and numerical simulations, the researchers carried out the field trials on gas production from NGHs in the different NGH regions. Figure 5 is a schematic of distribution of gas hydrate resources and locations of field trials. The areas including the Messoyakha hydrate gas field in Western Siberia, the Alaska North Slope, the Mackenzie Delta, the QTPP and Nankai Trough are the hottest areas for field production trials. In this paper, we will discuss the relevant field tests occurred in these areas.

\subsubsection{Messoyakha field test}

As seen from Figure 5, the Messoyakha gas hydrate resources locate in the Arctic on the eastern border of West Siberia, Russia. The Messoyakha hydrate deposits were first discovered in 1967, and the field contains a free gas zone overlaid by hydrate layer and underlain by an unknown strength aquifer. In 1969 to 1970, the first field gas production test was carried out in the area.[393] The hydrate deposit was drilled in a short time and developed without taking into account the presence of hydrates. The main gas production scheme is pressurization, and the field area is about $19.5 \times 12 \mathrm{~km}$. Since 1969 to 2011, many wells were continuously drilled as producing wells and observation wells, as seen from Figure 6. And since 1970, the gas was intermittently produced.[112] The initial gas prior to the beginning of the field development in the areal extent for production could be up to $36 \times 10^{9}$ $\mathrm{m}^{3}$ (1271 BSCF) of which $24 \times 10^{9} \mathrm{~m}^{3}$ (847 BSCF) could be in the free gas state, and up to 9 $-12 \times 10^{9} \mathrm{~m}^{3}$ (440 BSCF) in hydrate state. At the end of 2011, the totally accumulative gas produced from the field is $12.9 \times 10^{9} \mathrm{~m}^{3}$ (455 BSCF) of which $5.4 \times 10^{9} \mathrm{~m}^{3}(190 \mathrm{BSCF})$ was obtained due to hydrate decomposition. Cumulative water produced was $48 \times 10^{3} \mathrm{~m}^{3}(1700 \times$ $\left.10^{3} \mathrm{SCF}\right)$ of which $45 \times 10^{6} \mathrm{~m}^{3}\left(1060 \times 10^{6} \mathrm{SCF}\right)$ was obtained due to hydrate decomposition. One interesting and important feature of the Messoyakha field is the hydrate reservoir pressure keeps almost constant for more than 25 years. A water saturated zone forms between free gas and hydrate zone due to the low water production rates. During the gas production, the decrease of the pressure in the hydrate reservoir is balanced by the gas released from the hydrate dissociation. Thus, the Messoyakha was considered as the only sample of 
commercially successful gas hydrate reservoir. However, Collett and Ginsburg questioned the statement because they considered the gas produced from the reservoir might be released from free gas zone rather than hydrate dissociation.[6] From 2011 to now, no updated information was reported from the Messoyakha field. Although the Messoyakha with an approved initial gas in place (IGIP) of about 24 billion $\mathrm{m}^{3}$ (847 BSCF) was a dwarf compared to the giants of this region such as Urengoy, Yamburg, Medvezhye. However, the Messoyakha field test played a catalytic role in the development of natural gas hydrate research in the world.[112]

\subsubsection{Mallik field test}

The Mallik gas hydrate field locates at the northeastern edge of Canada's Mackenzie Delta, and the gas hydrates exist in an area underlain by over $600 \mathrm{~m}$ of permafrost within a sequence of Tertiary sediments. In 1971 to 1972, the first discovery well was drilled, then in 1998, the first research well program was carried out by a consortium of the Geological Survey of Canada, the Japan National Oil Corporation, the Geo Forschungs Zentrum Potsdam, the U.S. Geological Survey, the U.S. Department of Energy and the Gas Authority of India Ltd/Oil and Natural Gas Corporation Ltd. By analysis of the wells and drilled cores, it was found the discrete gas hydrate layers distribute in the regions from around 890 to $1106 \mathrm{~m}$ depth, exceeding $110 \mathrm{~m}$ in total thickness. Through analyzing the cores from the discovery well, the characteristics of the hydrate reservoir were determined. In some cases, the hydrate saturation exceeds $80 \%$, which making the Mallik gas hydrate field to be one of the most concentrated gas hydrate reservoirs in the world. From December 2001 to March 2002, the consortium completed a production research well program, drilling a main production research well of $1200 \mathrm{~m}$ in depth and nearby two science observation wells.[394] The primary purpose of the production research well program involved investigating the geophysical, geochemical, advanced fundamental geological projects and field production tests by depressurization and thermal stimulation, while the observation wells were used to in situ monitor the field tests as referring wells. The program comprised sampling gas-hydrate-bearing cores and logging downhole geophysics. The data collected from the research program such as the sedimentology, physical properties, geochemistry, geophysics, reservoir features and production behaviors were comprehensively documented for experimental and numerical simulations.

In April 2007 and March 2008, another consortium of the Japan National Oil Corporation, Gas and Metals National Corporation (JOGMEC), Natural Resources Canada and Aurora conducted field production trial by depressurization in the place.[395] The primary objectives of the 2007 winter tests were to complete the production and water injection wells by re-entry of both $2 \mathrm{~L}-38$ and $3 \mathrm{~L}-38$ wells, to conduct a short term production test by depressurization to obtain insights prior to a longer term test planned for the 2008 winter tests and to install and test the monitoring systems. Figures 7 and 8 show the gas and water production process in 2007 winter test and 2008 winter tests, respectively.[395] In the 2007 winter test, a certain amount of gas and water were produced by reducing the bottomhole pressure from $11.0 \mathrm{MPa}$ down to $7.2-7.5 \mathrm{MPa}$ from a $12 \mathrm{~m}$ perforation interval in Zone A methane hydrate reservoir at Mallik site in Canada. The program lasted for total 60 hours. The $1000-2000 \mathrm{~m}^{3} / \mathrm{d}$ of sustainable gas production and $10-70 \mathrm{~m}^{3} / \mathrm{d}$ water production were achieved, and estimated total $830 \mathrm{~m}^{3}$ of gas produced and $20 \mathrm{~m}^{3}$ of water produced during the production test period. 
Then, the well was suspended by installing cement and bridge plugs toward the 2008 winter test. It is noted that the produced gas was not directly delivered to the surface via the tubing but accumulated at the top of casing for the irregular (on-off) pumping operations, which were probably caused by the excessive sand production. The biggest problem, for 2007 winter test, was that accompanying with the gas and water production, sand production rate and total amount of gas production increase with the increase of permeability. The sand must plug off the pump and significantly reduced the pump efficiency. The only goal of the 2008 winter test is to take longer term gas production test. In fact, the bottomhole pressure decrease was divided into three stages for total 144 hours ( 6 days). For stage 1, the pressure was reduced from the initial $11.0 \mathrm{MPa}$ to $7.4 \mathrm{MPa}$, taking about 12 hours, and then the pressure was kept constant for 39 hours. For stage 2, after spending 6 hours, the pressure was reduced from 7.4 $\mathrm{MPa}$ to $5.2 \mathrm{MPa}$, and the process took 59 hours. For stage 3, after another 4 hours spending, the pressure was continuously reduced from 5.2 MPa to 4.5 MPa, and then the pressure was kept constant for 24 hours. During the 2008 winter test, the stable gas production of 2000 $3000 \mathrm{~m}^{3} / \mathrm{d}$ and water production of $10-20 \mathrm{~m}^{3} / \mathrm{d}$ were achieved, which also were suggested the inherent potential of gas and water production from the hydrate reservoir. In the total 6 days' test, total gas and water production were estimated at about $13000 \mathrm{~m}^{3}$ and $70 \mathrm{~m}^{3}$ respectively. Compared to the 2007 winter test, in 2008 winter test, the produced sands were prevented from flowing into the wellbore by screen. The produced gas and water were delivered directly to the surface. However, it was found that the real water production was far lower than that estimated, which meant that a large amount of water reversely flowed from the injection zone to wellhead when the pump was idle during the test. Besides, during the pump periods in the field test, the pump efficiency was considerable lower than that previously estimated, especially in the stage 2 . The main problem for 2008 winter test was that the well may have suffered from the skin effects, which was caused when the conduits with high permeability created in 2007 winter test collapsed and/or deformed, resulting in the subsequent decrease of the gas production rate.

\subsubsection{Mount Elbert field test}

The Alaska North Slope (ANS) is other one region containing a large amount of methane hydrates. According to the assessment made by USGS, around $2.4 \mathrm{tcm}$ gas could be technically recovered from the ANS gas hydrates.[40] From February 3 to 19, 2007, the Mount Elbert Gas Hydrate Stratigraphic Test Well was drilled within the Alaska North Slope (ANS) Milne Point Unit (MPU).[115] The well was conducted as part of a Cooperative Research Agreement (CRA) project co-sponsored by BP Exploration (Alaska), Inc. (BPXA) and the U.S. Department of Energy (DOE) since 2001. In addition, the U.S. Geological Survey (USGS) collaborated to help determine whether ANS gas hydrate can become a technically and commercially viable gas resource. Before conducting the well, the researchers carried out the study on the regional characterization and the reservoir modeling simulation. The study results indicated that up to 0.34 trillion cubic meters (tcm) gas might be technically recoverable from total $0.92 \mathrm{tcm}$ gas-in-place within Eileen gas hydrate reservoir, which was near the industry infrastructure ANS MPU, Prudho Bay Unit (PBU), and Kuparuk River Unit (KRU) area.[5] In order to further confirm the results and to select a test site for further data acquisition, the USGS reprocessed and interpreted MPU 3D seismic data, which were provided by BPXA to depict total 14 prospects containing significant highly-saturated gas 
hydrate-bearing sand reservoirs. Thereby, the "Mount Elbert" site was selected, and a stratigraphic test well was drilled to acquire a full suite of wireline log, core, and formation pressure test data. By the analysis of the data, it was found that the gas hydrates with high saturation occurs together with mobile formation water in the site. The ability to mobilizing water depends on the pressures drawdown in the system, which made the depressurization be the possible gas production method for the future field gas production test. Although no any field production tests conducted in the Mount Elbert site, the well program also provided significant information that a collaborative, scientific evaluation program could be safely and efficiently conducted within the ANS, and featured several advances such as the first use of wireline-retrievable coring systems on the ANS and the ability to conduct extended duration, open-hole MDT tests in a gas hydrate-bearing reservoir.[396]

\subsubsection{Ignik Sikumi field tests}

Ignik Sikumi site is also within in the Eileen gas hydrate reservoir region in the ANS. Based on the results of the experimental simulations and numerical simulations on replacement of $\mathrm{CH}_{4}$ by $\mathrm{CO}_{2}$ in gas hydrates in sediments in laboratory, the $\mathrm{CO}_{2}-\mathrm{CH}_{4}$ replacement in hydrate is thereby expected to be used in field gas production trial, and a work was began to determine a suitable reservoir to conduct such field trial in 2008.[397, 398] As mentioned in 5.1.3, on one hand, the reservoir properties in Eileen hydrate in the ANS are suitable for field production; on the other hand, the infrastructure in the place is complete. Consequently, the ANS was chosen as a suitable field location for gas production field trial by $\mathrm{CO}_{2}-\mathrm{CH}_{4}$ replacement. In 2011, ConocoPhillips, collaborating with US DOE, USGS, West Virginia University and JOGMEC, established a pilot test in the ANS by $\mathrm{CO}_{2}$ injection into methane hydrates, and a well of $792.5 \mathrm{~m}$ was drilled, logged and completed at the Ignik Sikumi site. Then, the tests were carried out and continued to 2012. For a field trial by $\mathrm{CO}_{2}$ injection, it required that the weight of the injected $\mathrm{CO}_{2}$ could overcome the fracture pressure of the reservoir. In this test, based on the experiments performed at University of Bergen, $\mathrm{CO}_{2} / \mathrm{N}_{2}(23 \% / 77 \%)$ gas mixture were injected into the well to replace $\mathrm{CH}_{4}$ from the methane hydrates due to, with the adding of $\mathrm{N}_{2}$ into $\mathrm{CO}_{2}$, (1) the injected $\mathrm{CO}_{2} / \mathrm{N}_{2}$ column and bottomhole pressure reducing, (2) hydrate formation reducing. The injection lasted for total 14 days, and total 6.1 metric standard cubic meter $\left(\mathrm{MSm}^{3}\right.$ ) of fluid (liquefied $\mathrm{CO}_{2} / \mathrm{N}_{2}$ ) was injected into the reservoir, and in the end of the injection, $4.7 \mathrm{MSm}^{3}$ of $\mathrm{N}_{2}$ and $1.4 \mathrm{MSm}^{3}$ of $\mathrm{CO}_{2}$ were injected. By applying a constant injection pressure of approximately $9.79 \mathrm{MPa}$, the flow rate was systematically regulated. With the injection of liquefied $\mathrm{CO}_{2} / \mathrm{N}_{2}$ mixture, the estimated permeability firstly dropped from $5.5 \mathrm{mD}$ to $0.6 \mathrm{mD}$ in the early stage and then gradually recovered to $1.2 \mathrm{mD}$, resulting in the increase of injection rate. After the injection, the reservoir was shut-in for five days. The shut-in process was called as pre-production period. And in the period, the bottomhole pressure dropped to $8.25 \mathrm{MPa}$ from the initial 9.79 MPa. Then the pressure recovered in a short time, which indicated that the hydrate dissociation and reformation in the near well bore region were possible. After then, it came to the production period. The production period from the Ignik Sikumi field was divided into two categories of unassisted flowback and assisted flowback. And depending on how close to hydrate stable condition the bottomhole pressure was, the assisted flowback was divided into another three phases. The detail production period could be seen in reference [397]. During the production period, the gas compositions in the flow steam were determined by using an 
in-line gas chromatograph. After the production process started, the fraction of $\mathrm{CH}_{4}$ increased rapidly and $\mathrm{CH}_{4}$ was the dominant produced gas. As the jet-pump started, the $\mathrm{CH}_{4}$ continuously increased to more than $80 \mathrm{~mol} \%$, even to $95 \mathrm{~mol} \%$. After a period of replacement, the fraction of $\mathrm{CO}_{2}$ in the flow steam had a burst increase, and in this while, the fraction of $\mathrm{CH}_{4}$ could dropped to lower than $2 \mathrm{~mol} \%$, which meant the replacement complete. In this production period, total $24 \mathrm{MSm}^{3} \mathrm{CH}_{4}$ was produced, $70 \%$ injected $\mathrm{N}_{2}$ and $40 \%$ injected $\mathrm{CO}_{2}$ were recovered, remaining $60 \%$ injected $\mathrm{CO}_{2}$ stayed in the hydrate reservoir. In the same time, a large amount of water production and sand production occurred. In the different production stages, the water production rate varied, and there were total $180 \mathrm{~m}^{3}$ water production in the end. The sand production mainly occurred in the first stage of the production, few sands produced in the final stage of the production, and total $11.1 \mathrm{~m}^{3}$ sands were produced in the test.

The Ignik Sikumi field test was the first trial of gas production by $\mathrm{CO}_{2}-\mathrm{CH}_{4}$ replacement, and $\mathrm{CH}_{4}$ was successfully recovered. Therefore, it was of great significance for future gas production field tests. From the Ignik Sikumi field test, it was found that the $\mathrm{CO}_{2}$ $\mathrm{CH}_{4}$ replacement rate is compromised due to the decrease of the driving forces resulted from $\mathrm{CO}_{2}$ decrease during the production. The reason was, in this test, a huff and puff strategy of $\mathrm{CO}_{2}$ injection was employed, and in the strategy, the injected $\mathrm{CO}_{2}$ and gas mixture were produced back in the same well. Then the injected $\mathrm{CO}_{2}$ was diluted by the produced methane.

\subsubsection{QTPP production trial}

During 2008 to 2013, the China Geological Survey (CGS) conducted no less than 10 NGH scientific drillings in the South Syncline of the Juhugeng mine in the QTPP, and the physical samples from the wells of DK-1, 2, 3, 7, 8, 9 were collected for investigating the characteristics of the NGH reservoir in the QTPP. Besides, in the process of drilling, a series of abnormal information was also observed from the wells of DK-4, 5, 6, 10, such as existing of high pressure gas, the kick of wellhead, water seepage, relatively low temperature in the crack surface.[399] In order to assess the potential NGH production from the QTPP, the CGS organized a production field test in 2011, and the well of DK-8 was selected for the production field test. The detail location of the DK- 8 well is in Muri, Tianjun country of Qinghai province, which is quite near to the Juhugeng mine of the Muri coalfield in the Muri basin in the Qilian Mountain Permafrost. The production scheme could be described as: the depressurization combining with thermal stimulation was employed as the production method, and the well configuration was a single vertical well system. Figure 9 shows the designation of the production field trial well. As shown in Figure 9, the submersible pump set in the bottom of the well (lowering the water) was used for depressurizing the system pressure, inducing the gas production. The results showed that the average gas production rate was around $30 \mathrm{~m}^{3} /$ day for total 3.5 days of depressurization-induced production. After the gas production rate decreased to $27.7 \mathrm{~m}^{3} /$ day, the hot-air injection was introduced, and the rate increased from $27.7 \mathrm{~m}^{3} /$ day to $27.9 \mathrm{~m}^{3} /$ day during the hot air injection of 11 hours. Then, it again dropped to $27.8 \mathrm{~m}^{3} /$ day. Subsquently, hot steam replacing the hot air was introduced for the total $5.3 \mathrm{~h}$ steam injection-induced production, and the gas production rate went up from $27.8 \mathrm{~m}^{3} /$ day to $28.7 \mathrm{~m}^{3} /$ day. Then, after the gas production rate fell to $28.4 \mathrm{~m}^{3} /$ day within 0.7 $\mathrm{h}$, the heat injection completed. Thus, after $84 \mathrm{~h}$ depressurization induction, real $102 \mathrm{~m}^{3}$ of gas was achieved. Then, injecting hot air (approximately $50 \square$ ) for $11 \mathrm{~h}, 9.73 \mathrm{~m}^{3}$ of gas was 
obtained, while injecting steam $(150 \square)$ for total $6 \mathrm{~h}(5.3 \mathrm{~h}$ for heating and $0.7 \mathrm{~h}$ for production), $3.3 \mathrm{~m}^{3}$ of gas was collected. The production field trial in the QTPP could be only a trial for assessing qualitatively the possibility of $\mathrm{CH}_{4}$ production from the QTPP. From the field test, it indicated, on one hand, the steam injection is better than hot air injection. However, the steam injection requires a larger equipment and more energy consumption; on the other hand, the thermal stimulation are not suitable for gas production from NGH reservoir with the low hydrate saturation in the QTPP due to the limitation of the poor heat conductivity; on the other hand, the depressurization-induced production is the optimal choice for the next longer and large scale field production.[400]

\subsubsection{Nankai Trough field test}

The above are offshore field tests because they all occurred in the permafrost region. In 2013, JOGMEC combining with the National Institute of Advanced Industrial Science and Technolgoy (AIST) carried out the first gas production field test from occurring naturally marine gas-hydrate deposits in Nankai Trough under the funding from the Ministry of Economy, Trade and Industry (MEIT) of Japan.[401] The field test was conducted in the Daini Atsumi Knoll area of the Eastern Nankai Trough off the Pacific coast of Japan. The well configuration was still a single well system, as shown in Figure 10. In the figure, we can see that one production well with two monitoring boreholes was drilled in the test site for the test. The flow test started in March 12, 2013 and ended in March 18, 2013 because of the severe sand production. Along with the flow test, the program of intensive data acquisitions was implemented to investigate the methane hydrate dissociation behavior in the sediments against depressurization. During the production period, gas flow rate was about $20,000 \mathrm{~m}^{3}$ per day under atmosphere condition, and gas liquid ratio more than 100 was achieved, which meant that the water production rate was approximately $200 \mathrm{~m}^{3} /$ day. In the $6^{\text {th }}$ day, water production rate increased sharply after a strong sand flow to the surface. Then, the downhole pressure increased soon, resulting in the termination of the gas production. In the well system, gas and sand in the flow lines were displaced by pumping the water from production tubing. The continuously produced sands (total sand volume more than $30 \mathrm{~m}^{3}$ ) filled with the bottom production hole, finally leading to the downhole production device being disabled. The total produced $\mathrm{CH}_{4}$ reached approximately $119,500 \mathrm{~m}^{3}$ in the 6 days production. It was noted that the gas production rate was larger than that expected by numerical simulations.

\subsection{Problems and comments}

As mentioned above, so far there were 6 field tests carried out in the world from 1997 to 2013. Among the 6 field tests, 5 were offshore field tests and only one was onshore field test. Depressurization, thermal stimulation and $\mathrm{CO}_{2}-\mathrm{CH}_{4}$ replacement in hydrate were employed as the field production methods. For the field productions by depressurization and thermal stimulation, the continuous production time of most of them was no more than 6 days due to a large amount of water production and sand production. Besides, the relatively low permeability of the inner hydrate deposits during the production was also the constraint factor to prolong the production time. For the $\mathrm{CO}_{2}-\mathrm{CH}_{4}$ replacement production, it lasted for around 6 weeks including the preproduction and production. The reason for such long time compared to those by other two production methods, was the quite low $\mathrm{CO}_{2}$ injection rate and replacement rate. Therefore, for the field test by $\mathrm{CO}_{2}-\mathrm{CH}_{4}$ replacement, the low production 
rate along with sand production in the first product period is the biggest challenges. According to the information from the field tests, the single well system was the only well configuration. However, based on the experimental and numerical simulations, the single well system brings the relatively low production efficiency and production rate, compared to the dual well system or multi-well system. Consequently, in order to achieve a commercial field production in the future, the dual well configuration or the multi-well configuration system is expected. In addition, during the production process, the produced water and sand must pumped out in time to maintain the permeability of the hydrate deposits. Anyway, such field tests provide numerous data to us to develop deeply the production scheme and recognize the real characteristics of the gas hydrate reservoirs. However, to realize the commercial field production from NGH reservoir over the world still requires a long time and more efforts.

In fact, many countries are investing much on gas hydrate research and development, including gas hydrate exploration and field drilling and test.[402] USGS made a road map for showing the completed and future national methane hydrate R\&D program from 1990 to 2040. In the coming 25 years, many field trials for longer term production will be carried out. And from around 2020, the commercial scale production from onshore and offshore may happen in the ANS in USA and in Japan, respectively. The commercial field production requires the gas production rate at 20,000 to $30,000 \mathrm{~m}^{3}$ per day for a long duration of time. However, we also need to note that, before realizing the commercial field production in around 2020, some issues for $\mathrm{CH}_{4}$ production from NGH must be overcame firstly besides the production technology and the deep knowing methane hydrate dissociation behavior, including the environmental challenge and economic analysis.

Based on the previous work, a large number of sand production and heat and mass transfer are two of the most urgent problems to be resolved. Therefore, before starting the next field production test, researchers should firstly get rid of the negative effects of a large number of sand production and heat and mass transfer, and the core to be solved is how to separate gas production and water/sand production in a same system. Only by addressing these issues, can the sustainable field production test be more deeply developed.

\section{Environmental Challenges for Gas Production from Hydrates}

The environmental challenges for gas production from hydrates mainly are the global warming induced by the large amount of $\mathrm{CH}_{4}$ released from methane hydrates and the continental margin sediment instability caused by the dissociation of NGHs. Although methane hydrate is considered as an alternative energy for the coming years, it has also been considered as a potential source for climate change.[403] Generally think that the immense global warming occurred around 15,000 years ago was caused by the release of $\mathrm{CH}_{4}$ from the MH.[404] However, Reeburgh thought that the rate of the methane hydrate decomposition could not support the general think.[405] In fact, the research on Hydrate Ridge has demonstrated that the natural hydrates in seafloors are dynamic. Similarly, the methane hydrates in ocean sediments are also dynamic, and the decomposition of these methane hydrates may be an important source of $\mathrm{CH}_{4}$ emissions from a certain region, and these $\mathrm{CH}_{4}$ emissions could be the reason of global warming.[405] However, it is quite difficult to assess directly the impacts of $\mathrm{CH}_{4}$ emissions from the $\mathrm{MHs}$ because there still is no suitable way to achieve the methane hydrate dissociation rate. Presently, the estimation of the methane 
hydrate dissociation rate is determined via the different heat-transfer models, and through these models, one unique data set on the methane hydrate dissociation in the seafloor at Barkley Canyon was given as the hydrate surface dissolution rates of 22.5 and $33.9 \mathrm{~nm} / \mathrm{s} .[406$, 407]

Once methane hydrates in seafloor decompose to methane gas and water, the transformation can significantly decrease the shear strength in the sediments in the seafloor, further cause the collapse of the sediments, and finally lead to the seafloor subsidence and submarine landslides.[408, 409] In fact, hydrate dissociation causing the major slumps of the continental margins have been reported so many times. However, some scientists proposed their questions on the reports. They thought that all these reports are based on BSRs and there must be errors in a way because the presence of gas hydrate in the sediments around the eruption or erosion was remotely detected by BSR.

\section{Economic Analysis on Gas Production from Hydrates}

Milkov and Sassen proposed a scheme sample for classifying the resource/reserve of NGH, as shown in Figure 11.[410] The scheme sample gives the increase trends of geologic assurance and economic feasibility. In this scheme, we can find the gas hydrate resources are divided into two parts, subeconomic gas hydrate resource and gas hydrate reserve (marginal and economic). The subeconomic hydrate resource is a part of hydrate resources, which are identified not to meet the economic standard of marginal and economic reserves, while the Gas hydrate reserves (marginal and economic) are defined as the gas hydrate resources that may be economically produced. Among the Gas hydrate reserves, the marginal gas hydrate reserves are those gas hydrate deposits or reservoirs on border of being producible if economic or technological factors change, and the economic gas hydrate reserves are those gas hydrate reservoirs of being produced profitably under defined investment assumptions. Actually, the economic feasibility of gas hydrate exploitation is affected by numerous factors such as geology, technology and costs. Milkov and Sassen made a table for the main geological, technological and economic features of gas hydrate reservoirs in different regions, as seen from Table 2.[410] In the following discussion, we will take the gas hydrate reservoirs in Northwestern Gulf of Mexico and Nankai Trough as examples.

For structural gas hydrates in the Northwestern Gulf Mexico, the gas hydrate concentration is relatively high, and the volume of gas contained in the gas hydrates is also high to $8-11 \times 10^{12} \mathrm{~m}^{3}$. It is generally recognized that gas hydrates with higher fracture porosity and permeability in the shallow sediments could result in higher recovery. Although the average resource density in the Gulf of Mexico is not high, it is suggested to be much greater in a specific hydrate reservoir or interval.[411] Due to the gas hydrates locate at relatively shallow water depth and near the seafloor, the development costs for this region are suggested to be low. The thermal stimulation in combination with chemical inhibition with a single horizontal well system could be employed as production scheme.[2, 411, 412] Thus, the production costs may also be low because it needs not much hot water or steam to decompose the highly concentrated gas hydrate near the equilibrium conditions. And finally, due to the gas hydrate reservoir is near the seafloor, it only needs a relatively simple well-developed petroleum infrastructure to transport the gas, significantly reducing the transportation costs. Consequently, it is considered that the structural gas hydrates in the 
Northwestern Gulf Mexico have relatively high economic potential. Then again, if the gas production from the hydrate reservoir is profitable, it needs more detailed economic analysis. On the contrary, for the stratigraphic hydrate reservoirs in the Northwestern Gulf of Mexico, the economic potential is classified to be low. The stratigraphic hydrate reservoirs locate in minibasins in the Gulf of Mexico, its gas hydrate concentration (hydrate saturation), gas resource density and gas resource are non-significant, and the gas hydrates situate at very deep regions, which is of low permeability. Therefore, the development costs, production costs and transportation costs are quite high relative to those for the structural gas hydrate reservoirs.

For gas hydrates in Nankai Trough, as seen from Table 2, it has the highest gas hydrate resource and gas resource density in relatively permeable sand layers. Thus, it is easily to be recovered. However, due to the hydrates situate under significant water depth, the development costs might be high. According to the results from the previous experimental and numerical simulations, depressurization is considered to be the suitable method to producing gas from the hydrates. Thus, the production costs might be low because power only need for pump. In Nankai Trough, there is lack of petroleum infrastructure, resulting in the high gas transportation costs. However, Japan is lacks of energy resources, both natural gas and petroleum are transported by sea, and the costs of transporting natural gas or petroleum are very high, for example, relative to the U.S. Thus, from the point of view, although the gas transportation costs from Nankai Trough may be high, it could still be considered that the gas hydrates in Nankai Trough have economic potential.

In order to estimate the economics of exploiting gas hydrates, Dopke and Requate established a model to assess the economics of gas hydrates as a new fossil-fuel resource.[413] The model incorporates the natural decomposition of the gas hydrates and geological risk resulting from gas production from the hydrates sediments in the seafloor. Through the model, it was found the feasibility of the gas production from the NGH in seafloor depends on the relation between the choke price and the marginal damage. If the choke price is sufficiently low or the risk of a natural disaster is sufficiently high, the resource exploitation should be stopped in finite time. By contrast, if the choke price is sufficiently high, the gas production could last until to complete in a certain time.

The result came from the model is relatively vague. Walsh et al.[414] proposed a preliminary report on the commercial viability of gas production from natural gas hydrates. In this report, the economics of Arctic Region hydrates and economics of marine hydrates were analyzed comprehensively. For Arctic Region hydrates, the Class 1 and 2 gas hydrates deposits from Alaska North Slope were taken as samples. The economic analysis was carried out from the aspects of the development cost, production cost, gas transportation cost and risk capital. Hancock and Okazawa [415] used CMG-STARS to model the processes of free-gas and gas-from hydrate production for the two hydrate samples. The characteristic of the Class 1 hydrate deposits is a $50 \mathrm{~m}$ gas hydrate zone underlain by a $10 \mathrm{~m}$ free-gas zone. The hydrate saturation and water saturation are $75 \%$ and $25 \%$, respectively. The total gas resources are approximately 1.07 TCF of gas-in-hydrate deposits and 232 BCF of gas-in-free gas zone. Class 2 hydrate deposits has the similar characteristics with Class 1 except for no an underlying free-gas zone. The field development consisted of 5 production wells, and 2 water disposal wells were drilled. In the meantime, depressurization was employed as production 
method. The results obtained from the CMG-STGS indicated that the gas price should be about \$CDN 7.50/Mscf for Class 1 and \$CDN 12.0/Mscf for Class 2. Then, Hancock presented another study on economics of a deepwater Class 3 gas hydrate development in the CERI 2008 Natural Gas Conference in Calgary, Alberta, Canada.[416] In this study, the gas production economics was based on the results obtained by Moridis and Reagan in 2007.[417] In this economic analysis, it assumed that no previous energy infrastructure existed prior to drilling in the area. Thus, the total costs were composed of a set of new production facility, subsea development, a $120 \mathrm{~km}$ pipeline, compression, dehydration and separation. The economics of a conventional project was also analyzed as comparison. The results indicated that the gas production cost from offshore gas hydrate deposits was $\$$ US $3.50-4.00 / \mathrm{Mscf}$ higher than that from a conventional gas project. Moreover, IEA gave a production cost comparison from conventional gas resource, tight gas, shale gas, coal bed methane (CBM) and NGH, and the costs (USD/Mbtu) are $0.53-6.02,2.75-8.03,4.01-9.08$ and $4.65-9.08$, respectively.

\section{Conclusions}

A comprehensive review on studies of NGHs is proposed in this paper from the aspects of NGH resources, fundamental investigation of gas hydrates, laboratory investigations, field production tests, environmental challenges, and economic analysis. The review nearly involves all the investigation directions for $\mathrm{NGH}$, and provides lots of valuable information. In addition, the objective and pertinent opinions, suggestions and comments are properly made. The NGHs as an alternative energy for the future have been found in some regions. However, the different NGH reservoirs present the different characteristics, which determine the feasibility of gas production. The production scheme, including gas production technology and well configuration, is the main project being investigated for putting the experimental studies forward to field production trials, and then finally to the commercial production. However, it seems that almost all the investigations encounter many bottlenecks. Therefore, till now from 1997, few field production tests last for more than 6 days due to a series of reasons such as the vast sands production and low energy efficiency. The key problems for gas production from NGH reservoirs are still under resolved. Meanwhile, the environmental impacts and economics of the gas production from NGH reservoirs are still unclear and await further research. The results of economic analysis would determine the future of the gas production from NGH reservoirs.

\section{Acknowledgement}

This work was supported by the National Science Foundation for Distinguished Young Scholars of China (51225603), and the National Natural Science Foundation of China (51376184, 51476174). We gratefully acknowledge each of these supporting agencies.

\section{References}

[1]Birol F. World Energy Outlook: The role of nuclear \& renewables: EDP Sciences; 2013.

[2] Sloan ED. Clathrate Hydrates of Natural Gases: Taylor \& Francis; 2007.

[3] Englezos P. Clathrate Hydrates. Ind Eng Chem Res. 1993;32:1251-74.

[4] Makogon YF. Hydrates of Natural Gas. Tulsa, OK, USA: PennWell; 1981. 
[5] Collett TS. Assessment of Gas Hydrate Resources on the North Slope, Alaska, 2008. American Geophysical Union. 2008;-1.

[6] Collett TS, Ginsburg GD. Gas hydrates in the Messoyakha gas field of the west Siberian basin - A re-examination of the geologic evidence. Int Offshore Polar E. 1997:96-103.

[7] Collett TS, Kuuskraa VA. Hydrates contain vast store of world gas resources. Oil Gas J. 1998;96:90-5.

[8] Chen ZY, Feng JC, Li XS, Zhang Y, Li B, Lv QN. Preparation of Warm Brine in Situ Seafloor Based on the Hydrate Process for Marine Gas Hydrate Thermal Stimulation. Ind Eng Chem Res. 2014;53:14142-57.

[9] Chen ZY, Li QP, Yan ZY, Yan KF, Zeng ZY, Li XS. Phase Equilibrium and Dissociation Enthalpies for Cyclopentane plus Methane Hydrates in $\mathrm{NaCl}$ Aqueous Solutions. J Chem Eng Data. 2010;55:4444-9.

[10] Feng JC, Li G, Li XS, Li B, Chen ZY. Evolution of Hydrate Dissociation by Warm Brine Stimulation Combined Depressurization in the South China Sea. Energies 2013;6:5402-25.

[11] Feng JC, Li XS, Li G, Li B, Chen ZY, Wang Y. Numerical Investigation of Hydrate Dissociation Performance in the South China Sea with Different Horizontal Well Configurations. Energies 2014;7:4813-34.

[12] Li B, Li G, Li XS, Chen ZY, Zhang Y. The use of heat-assisted antigravity drainage method in the two horizontal wells in gas production from the Qilian Mountain permafrost hydrate deposits. J Petrol Sci Eng 2014;120:141-53.

[13] Li B, Li G, Li XS, Li QP, Yang B, Zhang Y, et al. Gas Production from Methane Hydrate in a Pilot-Scale Hydrate Simulator Using the Huff and Puff Method by Experimental and Numerical Studies. Energy \& Fuels 2012;26:7183-94.

[14] Li B, Li XS, Li G, Chen ZY. Evaluation of gas production from Qilian Mountain permafrost hydrate deposits in two-spot horizontal well system. Cold Reg Sci Technol 2015;109:87-98.

[15] Li B, Li XS, Li G, Feng JC, Wang Y. Depressurization induced gas production from hydrate deposits with low gas saturation in a pilot-scale hydrate simulator. Appl Energ 2014;129:274-86.

[16] Li G, Li XS, Tang LG, Zhang Y. Experimental investigation of production behavior of methane hydrate under ethylene glycol injection in unconsolidated sediment. Energy \& Fuels 2007;21:3388-93.

[17] Li G, Li XS, Wang Y, Zhang Y. Production behavior of methane hydrate in porous media using huff and puff method in a novel three-dimensional simulator. Energy. 2011;36:3170-8.

[18] Li G, Li XS, Zhang KN, Li B, Zhang Y. Effects of Impermeable Boundaries on Gas Production from Hydrate Accumulations in the Shenhu Area of the South China Sea. Energies 2013;6:4078-96.

[19] Li G, Moridis GJ, Zhang K, Li XS. The use of huff and puff method in a single horizontal well in gas production from marine gas hydrate deposits in the Shenhu Area of South China Sea. J Petrol Sci Eng 2011;77:49-68.

[20] Li G, Moridis GJ, Zhang KN, Li XS. Evaluation of Gas Production Potential from Marine Gas Hydrate Deposits in Shenhu Area of South China Sea. Energy \& Fuels 
2010;24:6018-33.

[21] Li XS, Li B, Li G, Yang B. Numerical simulation of gas production potential from permafrost hydrate deposits by huff and puff method in a single horizontal well in Qilian Mountain, Qinghai province. Energy 2012;40:59-75.

[22] Li XS, Wan LH, Li G, Li QP, Chen ZY, Yan KF. Experimental Investigation into the Production Behavior of Methane Hydrate in Porous Sediment with Hot Brine Stimulation. Ind Eng Chem Res 2008;47:9696-702.

[23] Li XS, Wang Y, Duan LP, Li G, Zhang Y, Huang NS, et al. Experimental investigation into methane hydrate production during three-dimensional thermal huff and puff. Appl Energ 2012;94:48-57.

[24] Li XS, Wang Y, Li G, Zhang Y. Experimental Investigations into Gas Production Behaviors from Methane Hydrate with Different Methods in a Cubic Hydrate Simulator. Energy \& Fuels 2012;26:1124-34.

[25] Li XS, Wang Y, Li G, Zhang Y, Chen ZY. Experimental Investigation into Methane Hydrate Decomposition during Three-Dimensional Thermal Huff and Puff. Energy \& Fuels 2011;25:1650-8.

[26] Li XS, Yang B, Li G, Li B. Numerical Simulation of Gas Production from Natural Gas Hydrate Using a Single Horizontal Well by Depressurization in Qilian Mountain Permafrost. Ind Eng Chem Res 2012;51:4424-32.

[27] Li XS, Yang B, Li G, Li B, Zhang Y, Chen ZY. Experimental study on gas production from methane hydrate in porous media by huff and puff method in Pilot-Scale Hydrate Simulator. Fuel 2012;94:486-94.

[28] Li XS, Yang B, Zhang Y, Li G, Duan LP, Wang Y, et al. Experimental investigation into gas production from methane hydrate in sediment by depressurization in a novel pilot-scale hydrate simulator. Appl Energ 2012;93:722-32.

[29] Li XS, Zhang Y. Study on Dissociation Behaviors of Methane Hydrate in Porous Media Based on Experiments and Fractional Dimension Shrinking-Core Model. Ind Eng Chem Res 2011;50:8263-71.

[30] Li XS, Zhang Y, Li G, Chen ZY, Wu HJ. Experimental Investigation into the Production Behavior of Methane Hydrate in Porous Sediment by Depressurization with a Novel Three-Dimensional Cubic Hydrate Simulator. Energy \& Fuels 2011;25:4497-505.

[31] Tang LG, Li XS, Feng ZP, Li G, Fan SS. Control mechanisms for gas hydrate production by depressurization in different scale hydrate reservoirs. Energy \& Fuels 2007;21:227-33.

[32] Wang Y, Li XS, Li G, Zhang Y, Feng JC. Experimental investigation into scaling models of methane hydrate reservoir. Appl Energ 2014;115:47-56.

[33] Wang Y, Li XS, Li G, Zhang Y, Li B, Chen ZY. Experimental investigation into methane hydrate production during three-dimensional thermal stimulation with five-spot well system. Appl Energ 2013;110:90-7.

[34] Wang Y, Li XS, Li G, Zhang Y, Li B, Feng JC. A three-dimensional study on methane hydrate decomposition with different methods using five-spot well. Appl Energ 2013;112:83-92.

[35] Wang Y, Li XS, Xu WY, Li QP, Zhang Y, Li G, et al. Experimental investigation into factors influencing methane hydrate formation and a novel method for hydrate formation in 
porous media. Energy \& Fuels 2013;27:3751-7.

[36] Moridis GJ. Numerical studies of gas production from Class 2 and Class 3 hydrate accumulations at the Mallik site, Mackenzie Delta, Canada. Spe Reserv Eval Eng 2004; 7:175-83.

[37] Moridis GJ, Collett TS, Dallimore SR, Satoh T, Hancock S, Weatherill B. Numerical studies of gas production from several CH4 hydrate zones at the Mallik site, Mackenzie Delta, Canada. J Petrol Sci Eng 2004;43:219-38.

[38] Moridis G, Kowalsky MB, Pruess K. TOUGH+Hydrate v1.0 User's Manual: A Code for the Simulation of System Behavior in Hydrate-Bearing Geologic Media Lawrence Berkeley National Laboratory. 2008.

[39] Moridis GJ, Reagan MI, Kim SJ, Seol Y, Zhang K. Evaluation of the Gas Production Potential of Marine Hydrate Deposits in the Ulleung Basin of the Korean East Sea Spe J 2009;14:759-81.

[40] Moridis GJ, Silpngarmlert S, Reagan MT, Collett T, Zhang K. Gas production from a cold, stratigraphically-bounded gas hydrate deposit at the Mount Elbert Gas Hydrate Stratigraphic Test Well, Alaska North Slope: Implications of uncertainties. Mar Petrol Geol 2011;28:517-34.

[41] Zhao Jf, Xu K, Song YC, Liu WG, Lam W, Liu Y, Xue KH, Zhu YM, Yu XC, Li QP. A review on research on replacement of $\mathrm{CH} 4$ in natural gas hydrates by use of $\mathrm{CO} 2$.

[42] Xu CG, Li XS. Research progress on methane production from natural gas hydrates. Rsc Adv 2015;5:54672-99.

[43] Koh CA, Sloan ED. Natural gas hydrates: Recent advances and challenges in energy and environmental applications. Aiche J. 2007;53:1636-43.

[44] Song YC, Yang L, Zhao JF, Liu WG, Yang MJ, Li YH, et al. The status of natural gas hydrate research in China: A review. Renew Sust Energ Rev 2014;31:778-91.

[45] Xu K, Zhao JF, Liu D, Song YC, Liu WG, Xue KH, et al. A Review on Experimental Research on Natural Gas Production From the Hydrate with $\mathrm{CO}_{2}$. Proceedings Of the Asme 31st International Conference on Ocean, Offshore And Artic Engineering 2013;7:137-42.

[46] Sun YH, Lu XS, Guo W. A review on simulation models for exploration and exploitation of natural gas hydrate. Arab J Geosci 2014;7:2199-214.

[47] Lee JY, Ryu BJ, Yun TS, Lee J, Cho GC. Review on the Gas Hydrate Development and Production as a New Energy Resource. Ksce J Civ Eng 2011;15:689-96.

[48] Mokhatab S, Wilkens RJ, Leontaritis KJ. A review of strategies for solving gas-hydrate problems in subsea pipelines. Energ Source Part A 2007;29:39-45.

[49] Guo TM, Wu BH, Zhu YH, Fan SS, Chen GJ. A review on the gas hydrate research in China. J Petrol Sci Eng 2004;41:11-20.

[50] Kvenvolden KA. A review of the geochemistry of methane in natural gas hydrate. Org Geochem 1995;23:997-1008.

[51] Pearson CF, Halleck PM, Mcguire PL, Hermes R, Mathews M. Natural-Gas Hydrate Deposits - a Review Of Insitu Properties. J Phys Chem-Us 1983;87:4180-5.

[52] Veluswamy HP, Kumar R, Linga P. Hydrogen storage in clathrate hydrates: Current stage of the art and future directions. Appl Energ 2014;112:112-32.

[53] Chong ZR, Yang SHB, Babu P, Linga P, Li XS. Review of natural gas hydrates as an energy resource: Prospects and challenges. Appl Energ 2016;162:1633-52. 
[54] Makogon YF. Natural gas hydrates-A promising source of energy. Journal of Natural Gas Science and Engineering 2010;2:49-59.

[55] Makogon YF, Holditch SA, Makogon TY. Natural gas-hydrates - A potential energy source for the 21st Century. J Petrol Sci Eng 2007;56:14-31.

[56] Makogon YF, Holste JC, Holditch SA. Natural gas hydrates and global change. Proceedings Of the Eighth International Offshore And Polar Engineering Conference 1998;1:73-4.

[57] Davidson DW. Gas Hydrates as Clathrate Ices. Abstr Pap Am Chem S 1980;180:5-Geoc.

[58] Kirschke S, Bousquet P, Ciais P, Saunois M, Canadell JG, Dlugokencky EJ, et al. Three decades of global methane sources and sinks. Nat Geosci 2013;6:813-23.

[59] Stolper DA, Lawson M, Davis CL, Ferreira AA, Neto EVS, Ellis GS, et al. Formation temperatures of thermogenic and biogenic methane. Science 2014;344:1500-3.

[60] Gray ND, Sherry A, Larter SR, Erdmann M, Leyris J, Liengen T, et al. Biogenic methane production in formation waters from a large gas field in the North Sea. Extremophiles 2009;13:511-9.

[61] Martini AM, Walter LM, Budai JM, Ku TCW, Kaiser CJ, Schoell M. Genetic and temporal relations between formation waters and biogenic methane: Upper Devonian Antrim Shale, Michigan Basin, USA. Geochim Cosmochim Ac. 1998;62:1699-720.

[62] Whiticar MJ, Faber E, Schoell M. Biogenic Methane Formation In Marine And Fresh-Water Environments - Co2 Reduction Vs Acetate Fermentation Isotope Evidence. Geochim Cosmochim Ac 1986;50:693-709.

[63] Gutsalo LK. On the Mechanism Of Formation Of Biogenic Methane In Natural Gases. Dokl Akad Nauk Sssr+. 1982;267:729-32.

[64] Paull C, Reeburgh WS, Dallimore SR, Enciso G, Koh CA, Kvenvolden KA, et al. Realizing the energy potential of methane hydrate for the United State. National Research Council of the National Academies, Washington DC.; 2010.

[65] Westbrook GK, Chand S, Rossi G, Long C, Bunz S, Camerlenghi A, et al. Estimation of gas hydrate concentration from multi-component seismic data at sites on the continental margins of NW Svalbard and the Storegga region of Norway. Mar Petrol Geol 2008;25:744-58.

[66] Haacke RR, Westbrook GK, Riley MS. Controls on the formation and stability of gas hydrate-related bottom-simulating reflectors (BSRs): A case study from the west Svalbard continental slope. J Geophys Res-Sol Ea 2008;113.

[67] Haacke RR, Westbrook GK, Hyndman RD. Gas hydrate, fluid flow and free gas: Formation of the bottom-simulating reflector. Earth And Planetary Science Letters 2007;261:407-20.

[68] Kim AR, Cho GC, Song KI, Kim SJ. Settlement Prediction In the Ulleung Basin Due To Gas Hydrate Production. Offshore Technology Conference. Houston, Texas, USA2014. p. 9. [69] Ryu BJ, Collett TS, Riedel M, Kim GY, Chun JH, Bahk JJ, et al. Scientific results of the Second Gas Hydrate Drilling Expedition in the Ulleung Basin (UBGH2). Mar Petrol Geol 2013;47:1-20.

[70] Chand S, Minshull TA. Seismic constraints on the effects of gas hydrate on sediment physical properties and fluid flow: a review. Geofluids 2003;3:275-89. 
[71] Boswell R, Collett TS, Frye M, Shedd W, McConnell DR, Shelander D. Subsurface gas hydrates in the northern Gulf of Mexico. Mar Petrol Geol 2012;34:4-30.

[72] Collett TS, Boswell R. Resource and hazard implications of gas hydrates in the Northern Gulf of Mexico: Results of the 2009 Joint Industry Project Leg II Drilling Expedition Preface. Mar Petrol Geol 2012;34:1-3.

[73] Shelander D, Dai JC, Bunge G, Singh S, Eissa M, Fisher K. Estimating saturation of gas hydrates using conventional 3D seismic data, Gulf of Mexico Joint Industry Project Leg II. Mar Petrol Geol 2012;34:96-110.

[74]Shelander D, Dai JC, Bunge G. Predicting saturation of gas hydrates using pre-stack seismic data, Gulf of Mexico. Mar Geophys Res 2010;31:39-57.

[75] Klapp SA, Bohrmann G, Kuhs WF, Murshed MM, Pape T, Klein H, et al. Microstructures of structure I and II gas hydrates from the Gulf of Mexico. Mar Petrol Geol 2010;27:116-25.

[76] Paull CK, Ussler W, Lorenson T, Winters W, Dougherty J. Geochemical constraints on the distribution of gas hydrates in the Gulf of Mexico. Geo-Mar Lett 2005;25:273-80.

[77] Sassen R, MacDonald IR. Thermogenic gas hydrates, Gulf of Mexico continental slope. Abstr Pap Am Chem S 1997;213:26-Fuel.

[78] Brooks JM, Kennicutt MC, Fay RR, Mcdonald TJ, Sassen R. Thermogenic Gas Hydrates In the Gulf Of Mexico. Science 1984;225:409-11.

[79] Kida M, Suzuki K, Kawamura T, Oyama H, Nagao J, Ebinuma T, et al. Characteristics of Natural Gas Hydrates Occurring in Pore-Spaces of Marine Sediments Collected from the Eastern Nankai Trough, off Japan. Energy \& Fuels 2009;23:5580-6.

[80] Muramatsu Y, Doi T, Tomaru H, Fehn U, Takeuchi R, Matsumoto R. Halogen concentrations in pore waters and sediments of the Nankai Trough, Japan: Implications for the origin of gas hydrates. Appl Geochem 2007;22:534-56.

[81] Colwell F, Matsumoto R, Reed D. A review of the gas hydrates, geology, and biology of the Nankai Trough. Chem Geol 2004;205:391-404.

[82] Matsumoto R, Tomaru H, Lu HL. Detection and evaluation of gas hydrates in the eastern Nankai Trough by geochemical and geophysical methods. Resour Geol 2004;54:53-67.

[83] Uchida T, Tsuji T. Petrophysical properties of natural gas hydrates-bearing sands and their sedimentology in the Nankai Trough. Resour Geol 2004;54:79-87.

[84] Guo HR, Lu WJ, Zhuang XG. 2D basin-scale modeling of accumulation of gas hydrates in northern slope of South China Sea. J China Univ Geosci 2007;18:345-7.

[85] Hao ZG, Fei HC, Hao QQ, Turner S. Reserves of Natural Gas Hydrates Equivalent to 100-150 Billion 3 Natural Gas Has Been Discovered in the Pearl Mouth Basin of the South China Sea. Acta Geol Sin-Engl 2014;88:361-.

[86] Jiang SY, Yang T, Ge L, Yang JH, Ling HF, Wu NY, et al. Geochemistry of pore waters from the Xisha Trough, northern South China Sea and their implications for gas hydrates. J Oceanogr 2008;64:459-70.

[87] Liu CL, Ye YG, Meng QG, He XL, Lu HL, Zhang J, et al. The Characteristics of Gas Hydrates Recovered from Shenhu Area in the South China Sea. Marine Geology 2012;307:22-7.

[88] Lu ZQ, Wu BH, Zhu YH, Qiang ZJ, Wang ZM, Zhang FY. Geochemical indications of 
possible gas hydrates in the northeastern South China Sea. Acta Geol Sin-Engl 2006;80:564-73.

[89] Song HB, Geng JH, Wang HK, Zhang WS, Fang YX, Hao TY, et al. A preliminary study of gas hydrates in Dongsha region north of South China Sea. Chinese J Geophys-Ch 2001;44:687-95.

[90] Sun YB, Wu SG, Dong DD, Ludmann T, Gong YH. Gas hydrates associated with gas chimneys in fine-grained sediments of the northern South China Sea. Marine Geology 2012;311:32-40.

[91] Wang TK, Yang BJ, Deng JM, Lee CS, Liu CS. Seismic imaging of gas hydrates in the northernmost South China sea. Mar Geophys Res 2010;31:59-76.

[92] Yang R, Su M, Qiao SH, Cong XR, Su Z, Liang JQ, et al. Migration of methane associated with gas hydrates of the Shenhu Area, northern slope of South China Sea. Mar Geophys Res 2015;36:253-61.

[93] Yang R, Yan P, Wu NY, Sha ZB, Liang JQ. Application of AVO analysis to gas hydrates identification in the northern slope of the South China Sea. Acta Geophys 2014;62:802-17.

[94] Yu XH, Wang JZ, Liang JQ, Li SL, Zeng XM, Li W. Depositional characteristics and accumulation model of gas hydrates in northern South China Sea. Mar Petrol Geol 2014;56:74-86.

[95] Zhang M, Konishi H, Sun XM, Xu HF, Lu Y, Xu L. Graphitic carbon in the pyrite rods in the sediment of South China Sea as a mineral indicator for gas hydrates. Geochim Cosmochim Ac 2010;74:A1210-A.

[96] Zhu YH, Huang X, Fu SY, Su PB. Gas Sources of Natural Gas Hydrates in the Shenhu Drilling Area, South China Sea: Geochemical Evidence and Geological Analysis Acta Geol Sin-Engl. 2013;87:767-76.

[97] Yelisetti S, Spence GD, Riedel M. Role of gas hydrates in slope failure on frontal ridge of northern Cascadia margin. Geophys J Int 2014;199:441-58.

[98] Dash R, Spence G. P-wave and S-wave velocity structure of northern Cascadia margin gas hydrates. Geophys J Int 2011;187:1363-77.

[99] Tomaru H, Matsumoto R, Coffin RB, Pohlman JW, Spence GD. Geochemical relation between gas hydrates and water venting in the seismic blanking zone on the northern Cascadia continental margin offshore Vancouver Island, Canada J Geochem Explor. 2007;95:40-7.

[100] Pohlman JW, Canuel EA, Chapman NR, Spence GD, Whiticar MJ, Coffin RB. The origin of thermogenic gas hydrates on the northern Cascadia Margin as inferred from isotopic (C-13/C-12 and D/H) and molecular composition of hydrate and vent gas. Org Geochem 2005;36:703-16.

[101] Diaconescu CC, Knapp JH. Buried gas hydrates in the deepwater of the South Caspian Sea, Azerbaijan: Implications for geo-hazards. Energ Explor Exploit 2000;18:385-400.

[102] Ginsburg GD, Soloviev VA. Mud volcano gas hydrates in the Caspian Sea. B Geol Soc Denmark 1994;41:95-100.

[103] Zhu YH, Zhang YQ, Wen HJ, Lu ZQ, Jia ZY, Li YH, et al. Gas Hydrates in the Qilian Mountain Permafrost, Qinghai, Northwest China. Acta Geol Sin-Engl 2010;84:1-10.

[104] Kurihara M, Narita H. Gas Production From Methane Hydrate Reservoirs. 
Proceedings of the 7th International Conference on Gas Hydrates (ICGH 2011). Edingburgh, Scotland, United Kingdom 2011.

[105] N.Y. Wu, H.Q. Zhang, S.X. Yang, J.Q. Liang, H.B. Wang, Nat. Gas Ind. 27(2007) 1-6. [106] Dallimore S R, Collett T S. Summary and implication of the Mallik 2002 gas hydrate production research well program[C]\|Dallimore S R, Collett T S, eds. Scientific Results from the Mallik 2002 Gas Hydrate Production Research Well Program, Mackenzie Delta, Northwest Territories, Canada. Geological Survey of Canada, Bulletin 585, 2005:1-36.

[107] Boswell R, Collett T. The gas hydrates resource pyramid, Fire in the Ice. US Department of Energy, Office of Fossil Energy, National Energy Technology Laboratory; 2006. p. 5-7.

[108] Demirbas A. Methane hydrates as potential energy resource: Part 2-Methane production processes from gas hydrates. Energ Convers Manage 2010;51:1562-71.

[109] Boswell, R., R. L. Kleinberg, T. Collett, and M. Frye (2007), exploration priorities for marine gas hydrates, edited, Fire in the ice, methane hydrate $R \& D$ program newsletter.

[110] Rutqvist J, Moridis GJ. Numerical Studies on the Geomechanical Stability of Hydrate-Bearing Sediments. Spe J 2009;14:267-82.

[111] Moridis GJ, Collett TS, Boswell R, Kurihara M, Reagan MT, Koh C, et al. Toward Production From Gas Hydrates: Current Status, Assessment of Resources, and Simulation-Based Evaluation of Technology and Potential. Spe Reserv Eval Eng 2009;12:745-71.

[112] Grover T, Moridis G, Holditch SA. Analysis of reservoir performance of Messoyakha Gas hydrate Field. Proceedings Of the Eighteenth (2008) International Offshore And Polar Engineering Conference 2008;1:49-56.

[113] Huang JW, Bellefleur G, Milkereit B. Seismic modeling of multidimensional heterogeneity scales of Mallik gas hydrate reservoirs, Northwest Territories of Canada $\mathrm{J}$ Geophys Res-Sol Ea 2009;114.

[114] Bybee K. Overview of the mallik gas-hydrate production research well. J Petrol Technol. 2004;56:53-4.

[115] Matsumoto R. Special issue on "Gas hydrate in Nankai Trough, Japan" - Preface. Resour Geol 2004;54:1-2.

[116] Takahashi H, Tsuji Y. Offshore Japan - Conclusion - Japan drills, logs gas hydrate wells in the Nankai Trough. Oil Gas J 2005;103:37-42.

[117] Henninges J, Huenges E, Burkhardt H. In situ thermal conductivity of gas-hydrate-bearing sediments of the Mallik 5L-38 well. J Geophys Res-Sol Ea 2005;110.

[118] Collett TS. Results at Mallik highlight progress in gas hydrate energy resource research and development. Petrophysics 2005;46:237-43.

[119] Stern LA, Lorenson TD, Pinkston JC. Gas hydrate characterization and grain-scale imaging of recovered cores from the Mount Elbert Gas Hydrate Stratigraphic Test Well, Alaska North Slope. Mar Petrol Geol 2011;28:394-403.

[120] Hunter RB, Collett TS, Boswell R, Anderson BJ, Digert SA, Pospisil G, et al. Mount Elbert Gas Hydrate Stratigraphic Test Well, Alaska North Slope: Overview of scientific and technical program. Mar Petrol Geol 2011;28:295-310.

[121] Handa YP, Stupin D. Thermodynamic Properties And Dissociation Characteristics Of Methane And Propane Hydrates In 70-Angstrom-Radius Silica-Gel Pores. J Phys Chem-Us 
1992;96:8599-603.

[122] Anderson R, Llamedo M, Tohidi B, Burgass RW. Experimental measurement of methane and carbon dioxide clathrate hydrate equilibria in mesoporous silica. J Phys Chem B 2003;107:3507-14.

[123] Zhang W, Wilder JW, Smith DH. Interpretation of ethane hydrate equilibrium data for porous media involving hydrate-ice equilibria. Aiche J 2002;48:2324-31.

[124] Seshadri K, Wilder JW, Smith DH. Measurements of equilibrium pressures and temperatures for propane hydrate in silica gels with different pore-size distributions. J Phys Chem B 2001;105:2627-31.

[125] Uchida T, Ebinuma T, Ishizaki T. Dissociation condition measurements of methane hydrate in confined small pores of porous glass. J Phys Chem B 1999;103:3659-62.

[126] Uchida T, Ebinuma T, Takeya S, Nagao J, Narita H. Effects of pore sizes on dissociation temperatures and pressures of methane, carbon dioxide, and propane hydrates in porous media. J Phys Chem B 2002;106:820-6.

[127] Seo Y, Lee H, Uchida T. Methane and carbon dioxide hydrate phase behavior in small porous silica gels: Three-phase equilibrium determination and thermodynamic modeling. Langmuir 2002;18:9164-70.

[128] Kang SP, Ryu HJ, Seo Y. Phase Behavior of CO2 and CH4 Hydrate in Porous Media. Proc Wrld Acad Sci E 2007;22:421-6.

[129] Lee S, Seo Y. Experimental Measurement and Thermodynamic Modeling of the Mixed CH4 + C3H8 Clathrate Hydrate Equilibria in Silica Gel Pores: Effects of Pore Size and Salinity. Langmuir 2010;26:9742-8.

[130] Turner DJ, Cherry RS, Sloan ED. Sensitivity of methane hydrate phase equilibria to sediment pore size. Fluid Phase Equilibr 2005;228:505-10.

[131] Uchida T, Takeya S, Chuvilin EM, Ohmura R, Nagao J, Yakushev VS, et al. Decomposition of methane hydrates in sand, sandstone, clays, and glass beads. J Geophys Res-Sol Ea 2004;109.

[132] Yakushev VS, Istomin VA. Peculiarities Of Existence Of Gas-Hydrates In Rocks at Subzero Temperatures. Geokhimiya+. 1990:899-903.

[133] Clennell MB, Hovland M, Booth JS, Henry P Winters WJ. J Geophys Res B 1999;104: 22985-003.

[134] Lu HL, Matsumoto R. Preliminary experimental results of the stable P-T conditions of methane hydrate in a nannofossil-rich claystone column. Geochem J 2002;36:21-30.

[135] Vanderwaals JH, Platteeuw JC. Clathrate Solutions. Adv Chem Phys 1959;2:1-57.

[136] Parrish WR, Prausnit.Jm. Dissociation Pressures Of Gas Hydrates Formed by Gas-Mixtures. Ind Eng Chem Proc Dd 1972;11:26-\&.

[137] Ng HI, Robinson DB. The measurement and prediction of hydrate formation in liquid hydrocarbon - water systems. Ind Eng Chem Fundam 1976;15:293-8.

[138] Holder GD, Corbin G, Papadopoulos KD. Thermodynamic And Molecular-Properties Of Gas Hydrates From Mixtures Containing Methane, Argon, And Krypton. Ind Eng Chem Fund 1980;19:282-6.

[139] John VT, Holder GD. Contribution of Second and Subsequent Water Shells to the Potential Energy of Guest-Host Interactions in Clathrate Hydrates. J Chem Phys 1982;86:455-9. 
[140] John VT, Papadopoulos KD, Holder GD. A Generalized-Model for Predicting Equilibrium Conditions for Gas Hydrates. Aiche J 1985;31:252-9.

[141] Li XS, Wu HJ, Englezos P. Prediction of gas hydrate formation conditions in the presence of methanol, glycerol, ethylene glycol, and triethylene glycol with the statistical associating fluid theory equation of state. Ind Eng Chem Res 2006;45:2131-7.

[142] Li XS, Wu HJ, Li YG, Feng ZP, Tang LG, Fan SS. Hydrate dissociation conditions for gas mixtures containing carbon dioxide, hydrogen, hydrogen sulfide, nitrogen, and hydrocarbons using SAFT. J Chem Thermodyn 2007;39:417-25.

[143] Chen GJ, Guo TM. A new approach to gas hydrate modelling. Chem Eng J 1998;71:145-51.

[144] Shahnazar S, Hasan N. Gas hydrate formation condition: Review on experimental and modeling approaches. Fluid Phase Equilibr 2014;379:72-85.

[145] Clarke MA, Pooladi-Darvish M, Bishnoi PR. A method to predict equilibrium conditions of gas hydrate formation in porous media. Ind Eng Chem Res 1999;38:2485-90.

[146] Henry P, Thomas M, Ben Clennell M. Formation of natural gas hydrates in marine sediments 2. Thermodynamic calculations of stability conditions in porous sediments. J Geophys Res-Sol Ea 1999;104:23005-22.

[147] Llamedo M, Anderson R, Tohidi B. Thermodynamic prediction of clathrate hydrate dissociation conditions in mesoporous media. Am Mineral 2004;89:1264-70.

[148] Li XS, Zhang Y, Li G, Chen ZY, Yan KF, Li QP. Gas hydrate equilibrium dissociation conditions in porous media using two thermodynamic approaches. J Chem Thermodyn 2008;40:1464-74.

[149] Klauda JB, Sandler SI. Modeling gas hydrate phase equilibria in laboratory and natural porous media. Ind Eng Chem Res 2001;40:4197-208.

[150] Wilder JW, Seshadri K, Smith DH. Modeling hydrate formation in media with broad pore size distributions. Langmuir 2001;17:6729-35.

[151] Chen LT, Sun CY, Chen GJ, Nie YQ. Thermodynamics Model of Predicting Gas Hydrate in Porous Media Based on Reaction-Adsorption Two-Step Formation Mechanism. Ind Eng Chem Res 2010;49:3936-43.

[152] Peddireddy S, Lee SY, Lee JW. Variable contact angle model for gas hydrate equilibrium in porous media. Aiche J 2006;52:1228-34.

[153] Vysniauskas A, Bishnoi PR. A Kinetic-Study Of Methane Hydrate Formation. Chem Eng Sci 1983;38:1061-72.

[154] Englezos P, Kalogerakis N, Dholabhai P, Bishnoi P. Kinetics of formation of methane and ethane gas hydrates. Chemical Engineering Science 1987;42:2647-58.

[155] Englezos P, Kalogerakis N, Dholabhai PD, Bishnoi PR. Kinetics of gas hydrate formation from mixtures of methane and ethane. Chemical engineering science 1987;42(11):2659-66.

[156] Dholabhai PD, Kalogerakis NE, Bishnoi PR. Kinetics of Methane Hydrate Formation in Aqueous Electrolyte Solutions. Can J Chem Eng 1993;71:68-74.

[157] Malegaonkar MB, Dholabhai PD, Bishnoi PR. Kinetics of carbon dioxide and methane hydrate formation. Can J Chem Eng 1997;75(6):1090-9.

[158] Chun MK, Lee H. Kinetics of formation of carbon dioxide clathrate hydrates. Korean Jounal of Chemical Engineering 1996;13(6):620-6. 
[159] Kim H, Bishnoi P, Heidemann R, Rizvi S. Kinetics of methane hydrate decomposition. Chemical engineering science 1987;42:1645-53.

[160] Clarke M, Bishnoi PR. Determination of the activation energy and intrinsic rate constant of methane gas hydrate decomposition. The Canadian Journal of Chemical Engineering 2001;79:143-7.

[161]Chuvilin E, Kozlova E, Makhonina N, Yakushev V, Dubinyak D. Peculiarities of methane hydrate formation/dissociation $\mathrm{P} / \mathrm{T}$ conditions in sediments of different composition. Proc 4th int Conf on gas Hydrates Int Sci Comm of ICGH-4, Yokohama, Japan2002. p. 734-9. [162] Chuvilin EM, Makhonina NA, Titenskaya OA, Boldina OM. Petrophysical Investigations on Frozen Sediments Artificially Saturated by Hydrate. 2002.

[163]Melnikov V, Nesterov A. Modelling of gas hydrates formation in porous media. In the 2nd International Conference on Gas Hydrates, Toulouse, France, June 2-6, 1996; pp 541-548.

[164] Kvamme B. Kinetics of hydrate formation from nucleation theory. International Journal of Offshore and Polar Engineering. Int J Offshore Polar Eng 2002;12:256.

[165] Katsuki D, Ohmura R, Ebinuma T, Narita H. Methane hydrate crystal growth in a porous medium filled with methane-saturated liquid water. Philosophical Magazine 2007;87:1057-69.

[166] Kono HO, Narasimhan S, Song F, Smith DH. Synthesis of methane gas hydrate in porous sediments and its dissociation by depressurizing. Powder Technology 2002;122:239-46.

[167] Liu C, Lu H, Ye Y, Ripmeester JA, Zhang X. Raman spectroscopic observations on the structural characteristics and dissociation behavior of methane hydrate synthesized in silica sands with various sizes. Energy \& Fuels 2008;22:3986-8.

[168] Kang S-P, Seo Y, Jang W. Kinetics of methane and carbon dioxide hydrate formation in silica gel pores. Energy \& Fuels 2009;23:3711-5.

[169] Linga P, Haligva C, Nam SC, Ripmeester JA, Englezos P. Gas hydrate formation in a variable volume bed of silica sand particles. Energy \& Fuels 2009;23:5496-507.

[170] Fitzgerald GC, Castaldi MJ, Schicks JM. Methane Hydrate Formation and Thermal Based Dissociation Behavior in Silica Glass Bead Porous Media. Industrial \& Engineering Chemistry Research 2014;53:6840-54.

[171] Jin Y, Konno Y, Nagao J. Growth of methane clathrate hydrates in porous media. Energy \& Fuels 2012;26:2242-7.

[172] Klapproth A, Techmer K, Klapp S, Murshed M, Kuhs W. Microstructure of gas hydrates in porous media. Physics and Chemistry of Ice 2007;321-8.

[173] Kumar A, Sakpal T, Roy S, Kumar R. Methane hydrate formation in a test sediment of sand and clay at various levels of water saturation. Canadian Journal of Chemistry 2015;93:1-8.

[174] Zhang Y, Li XS, Chen ZY, Li G, Wang Y. Experimental Investigation into Gas Hydrate Formation in Sediments with Cooling Method in Three-Dimensional Simulator. Industrial \& Engineering Chemistry Research 2014;53:14208-16.

[175] Li B, Li XS, Li G. Kinetic studies of methane hydrate formation in porous media based on experiments in a pilot-scale hydrate simulator and a new model. Chemical Engineering Science. 2014;105:220-30. 
[176] Li B, Li XS, Li G, Wang Y, Feng JC. Kinetic behaviors of methane hydrate formation in porous media in different hydrate deposits. Industrial \& Engineering Chemistry Research 2014;53:5464-74.

[177] Selim MS, Sloan ED. Soc Petr Eng Reservoir Eng 1990;245.

[178] Linga P, Haligva C, Nam SC, Ripmeester JA, Englezos P. Recovery of methane from hydrate formed in a variable volume bed of silica sand particles. Energy \& Fuels 2009;23:5508-16.

[179] Zhao J, Lv Q, Li Y, Yang M, Liu W, Yao L, et al. In-situ visual observation for the formation and dissociation of methane hydrates in porous media by magnetic resonance imaging. Magnetic resonance imaging 2015;33:485-90.

[180] Yousif M, Abass H, Selim M, Sloan E. Experimental and theoretical investigation of methane-gas-hydrate dissociation in porous media. SPE reservoir Engineering 1991;6:69-76.

[181] Haligva C, Linga P, Ripmeester JA, Englezos P. Recovery of methane from a variable-volume bed of silica sand/hydrate by depressurization. Energy \& Fuels 2010;24:2947-55.

[182] Jiang G, Wu Q, Zhan J. Experimental studies of the formation and dissociation of methane hydrate in loess. Journal of Natural Gas Chemistry 2010;19:217-23.

[183] Mekala P, Babu P, Sangwai JS, Linga P. Fomration and dissociation kinetics of methane hydrates in seawater and silica sand. Energy Fuels 2014;28:2708-16.

[184] Oyama H, Konno Y, Masuda Y, Narita H. Dependence of depressurization-induced dissociation of methane hydrate bearing laboratory cores on heat transfer. Energy \& Fuels 2009;23:4995-5002.

[185] Liang M, Chen G, Sun C, Yan L, Liu J, Ma Q. Experimental and modeling study on decomposition kinetics of methane hydrates in different media. The Journal of Physical Chemistry B. 2005;109:19034-41.

[186] Konno Y, Jin Y, Shinjou K, Nagao J. Experimental evaluation of the gas recovery factor of methane hydrate in sandy sediment. RSC Advances 2014;4:51666-75.

[187] Goel N, Wiggins M, Shah S. Analytical modeling of gas recovery from in situ hydrates dissociation. Journal of Petroleum Science and Engineering 2001;29:115-27.

[188] Nagao J, Konno Y. Development of Large Scale Production System for Methane Hydrates. Tenth ISOPE Ocean Mining and Gas Hydrates Symposium: International Society of Offshore and Polar Engineers; 2013.

[189] Hong H, Pooladi-Darvish M, Bishnoi P. Analytical modelling of gas production from hydrates in porous media. Journal of Canadian Petroleum Technology 2003;42:45-56.

[190] Selim M, Sloan E. Heat and mass transfer during the dissociation of hydrates in porous media. AIChE Journal 1989;35:1049-52.

[191] Tsypkin GG. Mathematical models of gas hydrates dissociation in porous media. Annals of the New York academy of sciences 2000;912:428-36.

[192] Falser S, Uchida S, Palmer A, Soga K, Tan T. Increased gas production from hydrates by combining depressurization with heating of the wellbore. Energy \& Fuels 2012;26:6259-67.

[193] Pooladi-Darvish M. Gas production from hydrate reservoirs and its modeling. Journal of Petroleum Technology 2004;56:65-71.

[194] Ahmadi G, Ji C, Smith DH. Numerical solution for natural gas production from 
methane hydrate dissociation. Journal of petroleum science and engineering 2004;41:269-85.

[195] Wang Y, Feng JC, Li XS, Zhang Y, Li G. Analytic modeling and large-scale experimental study of mass and heat transfer during hydrate dissociation in sediment with different dissociation methods. Energy 2015; 90: 1931-48.

[196] Zhao J, Liu D, Yang M, Song Y. Analysis of heat transfer effects on gas production from methane hydrate by depressurization. International Journal of Heat and Mass Transfer 2014;77:529-41.

[197] Sun X, Nanchary N, Mohanty K. 1-D modeling of hydrate depressurization in porous media. Transport in Porous Media 2005;58:315-38.

[198] Tonnet N, Herri JM. Methane hydrates bearing synthetic sediments—Experimental and numerical approaches of the dissociation. Chemical Engineering Science 2009;64:4089-100.

[199] Ji C, Ahmadi G, Smith DH. Natural gas production from hydrate decomposition by depressurization. Chemical Engineering Science 2001;56:5801-14.

[200] Ruppel C. Thermal state of the gas hydrate reservoir. Natural Gas Hydrate: Springer; 2003. p. 29-42.

[201] Zhao J, Zhu Z, Song Y, Liu W, Zhang Y, Wang D. Analyzing the process of gas production for natural gas hydrate using depressurization. Applied Energy 2015;142:125-34.

[202] Konno Y, Masuda Y, Hariguchi Y, Kurihara M, Ouchi H. Key factors for depressurization-induced gas production from oceanic methane hydrates. Energy \& Fuels 2010;24:1736-44.

[203] Seol Y, Kneafsey TJ. X-ray computed-tomography observations of water flow through anisotropic methane hydrate-bearing sand. Journal of Petroleum Science and Engineering 2009;66:121-32.

[204] Li B, Li XS, Li G, Jia JL, Feng JC. Measurements of water permeability in unconsolidated porous media with methane hydrate formation. Energies 2013;6:3622-36.

[205] Minagawa H, Ohmura R, Kamata Y, Nagao J, Ebinuma T, Narita H, et al. Water permeability of porous media containing methane hydrate as controlled by the methane-hydrate growth process: Natural gas hydrates-Energy resource potential and associated geologic hazards: AAPG Memoir 89; 2009.

[206] Jin Y, Hayashi J, Nagao J, Suzuki K, Minagawa H, Ebinuma T, et al. New method of assessing absolute permeability of natural methane hydrate sediments by microfocus X-ray computed tomography. Japanese journal of applied physics 2007;46:3159.

[207] Delli ML, Grozic JL. Experimental determination of permeability of porous media in the presence of gas hydrates. Journal of Petroleum Science and Engineering 2014;120:1-9.

[208] Kumar A, Maini B, Bishnoi P, Clarke M, Zatsepina O, Srinivasan S. Experimental determination of permeability in the presence of hydrates and its effect on the dissociation characteristics of gas hydrates in porous media. Journal of Petroleum Science and Engineering 2010;70:114-22.

[209] Kneafsey TJ, Seol Y, Gupta A, Tomutsa L. Permeability of laboratory-formed methane-hydrate-bearing sand: measurements and observations using X-ray Computed Tomography. SPE Journal 2011;16:78-94.

[210] Seol Y, Kneafsey TJ. Methane hydrate induced permeability modification for multiphase flow in unsaturated porous media. Journal of Geophysical Research: Solid Earth (1978-2012). 2011;116. 
[211] Ruan X, Yang M, Song Y, Liang H, Li Y. Numerical studies of hydrate dissociation and gas production behavior in porous media during depressurization process. Journal of Natural Gas Chemistry 2012;21:381-92.

[212] Kleinberg R, Flaum C, Griffin D, Brewer P, Malby G, Peltzer E, et al. Deep sea NMR: Methane hydrate growth habit in porous media and its relationship to hydraulic permeability, deposit accumulation, and submarine slope stability. Journal of Geophysical Research: Solid Earth (1978-2012). 2003;108.

[213] Ahn T, Lee J, Huh D-G, Kang JM. Experimental study on two-phase flow in artificial hydrate-bearing sediments. Geosystem Engineering 2005;8:101-4.

[214] Seol Y, Kneafsey TJ, Tomutsa L, Moridis GJ. Preliminary relative permeability estimates of methane hydrate-bearing sand. Lawrence Berkeley National Laboratory. 2006.

[215] Gupta A. Methane hydrate dissociation measurements and modeling: The role of heat transfer and reaction kinetics. Ph.D.Dissertation thesis, Colorado School of Mines, United States -- Colorado. 2007.

[216] Jaiswal NJ, Dandekar AY, Patil SL, Hunter RB, Collett TS. Relative permeability measurements of gas-water-hydrate systems. In Natural gas hydrates-Energy resource potential and associated geologic hazards, edited by A. J. T. Collett, C. Knapp, and R. Boswell, , pp. 723-733, AAPG.

[217] Johnson A, Patil S, Dandekar A. Experimental investigation of gas-water relative permeability for gas-hydrate-bearing sediments from the Mount Elbert Gas Hydrate Stratigraphic Test Well, Alaska North Slope. Marine and petroleum geology 2011;28:419-26.

[218] Liu X, Flemings PB. Capillary effects on hydrate stability in marine sediments. Journal of Geophysical Research: Solid Earth (1978-2012) 2011;116.

[219] Ghezzehei TA, Kneafsey TJ. Measurements of the capillary pressure-saturation relationship of methane hydrate bearing sediments. Offshore Technology Conference: Offshore Technology Conference; 2010.

[220] Jung J, Jang J, Santamarina J, Tsouris C, Phelps T, Rawn C. Gas production from hydrate-bearing sediments: the role of fine particles. Energy \& Fuels 2011;26:480-7.

[221] Hancock SH, Moridis GJ, Robertson A, Wilson S. Well design requirements for deepwater and arctic onshore gas hydrate production wells. Offshore Technology Conference: Offshore Technology Conference; 2010.

[222] Lee J, Ahn T, Lee JY, Kim SJ. Laboratory Test to Evaluate the Performance of Sand Control Screens During Hydrate Dissociation Process by Depressurization. Tenth ISOPE Ocean Mining and Gas Hydrates Symposium: International Society of Offshore and Polar Engineers; 2013.

[223] Stern I, Kirky S, Durham WB. Peculiarities of methane clathrate hydrate formation and solid-state deformation, including possible superheating of water ice. Science-AAAS-Weekly Paper Edition 1996;273:1843-7.

[224] Stern LA, Kirby SH, Durham WB. Polycrystalline methane hydrate: Synthesis from superheated ice, and low-temperature mechanical properties. Energy \& Fuels 1998;12:201-11. [225] Durham WB, Kirby SH, Stern LA, Zhang W. The strength and rheology of methane clathrate hydrate. Journal of Geophysical Research: Solid Earth (1978-2012). 2003;108.

[226] Hyodo M, Nakata Y, Yoshimoto N, Fukunaga M, Kubo K, Nanjo Y, et al. Triaxial compressive strength of methane hydrate. The Twelfth International Offshore and Polar 
Engineering Conference: International Society of Offshore and Polar Engineers; 2002.

[227] Nariai H, Yamane K, Aya I. Strength abnormarility of $\mathrm{CO}_{2}$ hydrate membrane at deep ocean storage site. Proceedings of the International Symposium "DEEP SEA \& CO22000. p. $1-2$.

[228] Ohmura R, Shigetomi T, Mori YH. Bending tests on clathrate hydrate single crystals. Philosophical Magazine A 2002;82:1725-40.

[229] Ning F, Yu Y, Kjelstrup S, Vlugt TJ, Glavatskiy K. Mechanical properties of clathrate hydrates: status and perspectives. Energy \& Environmental Science 2012;5:6779-95.

[230] Winters WJ, Pecher IA, Waite WF, Mason DH. Physical properties and rock physics models of sediment containing natural and laboratory-formed methane gas hydrate. American Mineralogist 2004;89:1221-7.

[231] Yun TS, Santamarina JC, Ruppel C. Mechanical properties of sand, silt, and clay containing tetrahydrofuran hydrate. Journal of Geophysical Research: Solid Earth (1978-2012). 2007;112.

[232] Waite WF, Winters WJ, Mason DH. Methane hydrate formation in partially water-saturated Ottawa sand. American Mineralogist 2004;89(8-9):1202-7.

[233] Winters WJ, Waite WF, Mason DH. Gilbert LY, Pecher IA. Methane gas hydrate effect on sediment acoustic and strength properties. Journal of Petroleum Science and Engineering 2007;56(1-3):127-35.

[234] Lu X, Wang L, Zhang X, Wang S, Yao H, Li Q. Instability of seabed and pipes induced by NGH dissociation. The Twentieth International Offshore and Polar Engineering Conference: International Society of Offshore and Polar Engineers; 2010.

[235] Sultan N, Cochonat P, Foucher J-P, Mienert J. Effect of gas hydrates melting on seafloor slope instability. Marine Geology 2004;213:379-401.

[236] Xu W, Germanovich LN. Excess pore pressure resulting from methane hydrate dissociation in marine sediments: A theoretical approach. Journal of Geophysical Research: Solid Earth (1978-2012). 2006;111.

[237] Miyazaki K, Masui A, Yamamoto Y, Ogata Y, Aoki K, Yamaguchi T. Investigation of Deformation Mechanism for Methane Hydrate Sediment based upon Mechanical Properties in Unloading and Reloading Process under Triaxial Compression. Eighth ISOPE Ocean Mining Symposium: International Society of Offshore and Polar Engineers; 2009.

[238] Winters W. Properties of samples containing natural gas hydrate from the JAPEX/JNOC/GSC Mallik 2L-38 gas hydrate research well, determined using Gas Hydrate And Sediment Test Laboratory Instrument (GHASTLI). Bulletin of the Geological Survey of Canada. 1999:241-50.

[239] Winters W, Waite W, Mason D, Kumar P. Physical properties of repressurized samples recovered during the 2006 national gas hydrate program expedition offshore India. 2008.

[240] Waite WF, Santamarina JC, Cortes DD, Dugan B, Espinoza D, Germaine J, et al. Physical properties of hydrate $\square$ bearing sediments. Reviews of Geophysics. 2009;47.

[241] Hyodo M, Nakata Y, Yoshimoto N, Ebinuma T. Basic research on the mechanical behavior of methane hydrate-sediments mixture. Soils and Foundations 2005;45:75-85.

[242] Hyodo M, Yoneda J, Yoshimoto N, Nakata Y. Mechanical and dissociation properties of methane hydrate-bearing sand in deep seabed. Soils and foundations 2013;53:299-314.

[243] Li Y, Song Y, Liu W, Yu F. Experimental research on the mechanical properties of 
methane hydrate-ice mixtures. Energies 2012;5:181-92.

[244] Li Y, Zhao H, Yu F, Song Y, Liu W, Li Q, et al. Investigation of the Stress-Strain and Strength Behaviors of Ice Containing Methane Hydrate. Journal of Cold Regions Engineering 2012;26:149-59.

[245] Miyazaki K, Masui A, Aoki K, Sakamoto Y, Yamaguchi T, Okubo S. Strain-rate dependence of triaxial compressive strength of artificial methane-hydrate-bearing sediment. International Journal of Offshore and Polar Engineering 2010;20.

[246] Yoneda J, Hyodo M, Nakata Y, Yoshimoto N. Triaxial shear characteristics of methane hydrate-bearing sediment in the deep seabed. Doboku Gakkai Ronbunshuu C/JSCE Journal of Geotechnical and Geoenvironmental Engineering 2010;66:742-56.

[247] Wu L, Grozic JL. Laboratory analysis of carbon dioxide hydrate-bearing sands. Journal of geotechnical and geoenvironmental engineering 2008;134:547-50.

[248] Hyodo M, Li Y, Yoneda J, Nakata Y, Yoshimoto N, Nishimura A. Effects of dissociation on the shear strength and deformation behavior of methane hydrate-bearing sediments. Marine and Petroleum Geology 2014;51:52-62.

[249] Hyodo M, Li Y, Yoneda J, Nakata Y, Yoshimoto N, Kajiyama S, et al. A comparative analysis of the mechanical behavior of carbon dioxide and methane hydrate-bearing sediments. American Mineralogist 2014;99:178-83.

[250] Hyodo M, Li Y, Yoneda J, Nakata Y, Yoshimoto N, Nishimura A, et al. Mechanical behavior of gas $\square$ saturated methane hydrate $\square$ bearing sediments. Journal of Geophysical Research: Solid Earth 2013;118:5185-94.

[251] Klar A, Soga K. Coupled deformation-flow analysis for methane hydrate production by depressurized wells. Proceedings of the 3rd Biot Conference on Poromechanics 2005.

[252] Ogisako E, Nishio S, Denda A, Oka F, Kimoto S. Simulation of triaxial compression tests on soil samples obtained from seabed ground in deep sea by elasto-viscoplastic constitutive equation. Seventh ISOPE Ocean Mining Symposium: International Society of Offshore and Polar Engineers; 2007.

[253] Kimoto S, Oka F, Fushita T, Fujiwaki M. A chemo-thermo-mechanically coupled numerical simulation of the subsurface ground deformations due to methane hydrate dissociation. Computers and Geotechnics 2007;34:216-28.

[254] Kimoto S, Oka F, Fushita T. A chemo-thermo-mechanically coupled analysis of ground deformation induced by gas hydrate dissociation. International Journal of Mechanical Sciences 2010;52:365-76.

[255] Li Yh, Song YC, Yu F, Liu WG, Zhao JF. Experimental study on mechanical properties of gas hydrate-bearing sediments using kaolin clay. China Ocean Engineering. 2011;25:113-22.

[256] Li YH, Song YC, Liu WG, Yu F, Wang R. A new strength criterion and constitutive model of gas hydrate-bearing sediments under high confining pressures. J Petrol Sci Eng. 2013;109:45-50.

[257] Li Y, Song Y, Liu W, Yu F, Wang R, Nie X. Analysis of mechanical properties and strength criteria of methane hydrate-bearing sediments. Int J Offshore Polar 2012;22(4), 290-296.

[258] Ng A, Klar A, Soga K. Coupled soil deformation-flow-thermal analysis of methane production in layered methane hydrate soils. Offshore Technology Conference: Offshore 
Technology Conference; 2008.

[259] Rutqvist, J., T. Grover, and G. J. Moridis (2008), Coupled Hydrological, Thermal and Geomechanical Analysis of Wellbore Stability in Hydrate-Bearing Sediments, in 2008 Offshore Technology Conference edited, Houston, Texas, U.S.A., 2008.

[260] Rutqvist J, Moridis G, Grover T, Silpngarmlert S, Collett T, Holdich S. Coupled multiphase fluid flow and wellbore stability analysis associated with gas production from oceanic hydrate-bearing sediments. Journal of Petroleum Science and Engineering 2012;92:65-81.

[261] Xu, E. M., S. Kenichi, and M. Zhou, L. (2014), Numerical simulation of wellbore behavior during methane hydrate gas production, paper presented at The 8th International Conference on Gas Hydrate (ICGH 8 - 2014), Beijing, China, July 28 - Aug 1, 2014.

[262] Handa Y. Compositions, enthalpies of dissociation, and heat capacities in the range 85 to $270 \mathrm{~K}$ for clathrate hydrates of methane, ethane, and propane, and enthalpy of dissociation of isobutane hydrate, as determined by a heat-flow calorimeter. The Journal of Chemical Thermodynamics 1986;18:915-21.

[263] Holder G, Angert PF, John V, Yen S. A Thermodynamic Evaluation of Thermal Recovery of Gas From Hydrates in the Earth (includes associated papers 11863 and 11924). Journal of Petroleum Technology 1982;34:1127-32.

[264] Kawamura T, Sakamoto Y, Ohtake M, Yamamoto Y, Haneda H, Yoon JH, et al. Dissociation behavior of hydrate core sample using thermodynamic inhibitor. International Journal of Offshore and Polar Engineering. Int J Offshore Polar. 2006;16:5-9.

[265] Ross MJ, Toczylkin LS. Hydrate dissociation pressures for methane or ethane in the presence of aqueous solutions of triethylene glycol. Journal of Chemical and Engineering Data 1992;37:488-91.

[266] Afzal W, Mohammadi AH, Richon D. Experimental measurements and predictions of dissociation conditions for methane, ethane, propane, and carbon dioxide simple hydrates in the presence of diethylene glycol aqueous solutions. Journal of Chemical \& Engineering Data 2008;53:663-6.

[267] Babaee S, Hashemi H, Javanmardi J, Eslamimanesh A, Mohammadi AH. Thermodynamic model for prediction of phase equilibria of clathrate hydrates of hydrogen with different alkanes, alkenes, alkynes, cycloalkanes or cycloalkene. Fluid Phase Equilibria 2012;336:71-8.

[268] Eslamimanesh A, Mohammadi AH, Richon D, Naidoo P, Ramjugernath D. Application of gas hydrate formation in separation processes: A review of experimental studies. The Journal of Chemical Thermodynamics 2012;46:62-71.

[269] Javanmardi J, Babaee S, Eslamimanesh A, Mohammadi AH. Experimental measurements and predictions of gas hydrate dissociation conditions in the presence of methanol and ethane-1, 2-diol aqueous solutions. Journal of Chemical \& Engineering Data 2012;57:1474-9.

[270] Mohammadi AH, Kraouti I, Richon D. Experimental data and predictions of dissociation conditions for methane, ethane, propane, and carbon dioxide simple hydrates in the presence of glycerol aqueous solutions. Industrial \& Engineering Chemistry Research 2008;47:8492-5.

[271] Mohammadi AH, Afzal W, Richon D. Experimental data and predictions of 
dissociation conditions for ethane and propane simple hydrates in the presence of methanol, ethylene glycol, and triethylene glycol aqueous solutions. Journal of Chemical \& Engineering Data 2008;53:683-6.

[272] Mohammadi AH, Afzal W, Richon D. Gas hydrates of methane, ethane, propane, and carbon dioxide in the presence of single $\mathrm{NaCl}, \mathrm{KCl}$, and $\mathrm{CaCl} 2$ aqueous solutions: Experimental measurements and predictions of dissociation conditions. The Journal of Chemical Thermodynamics 2008;40:1693-7.

[273] Mohammadi AH, Laurens S, Richon D. Experimental study of methane hydrate phase equilibrium in the presence of polyethylene glycol-400 aqueous solution. Journal of Chemical \& Engineering Data 2009;54:3118-20.

[274] Mohammadi AH, Richon D. Gas hydrate phase equilibrium in methane+ ethylene glycol, diethylene glycol, or triethylene glycol+ water system. Journal of Chemical \& Engineering Data 2011;56:4544-8.

[275] Mohammadi AH, Richon D. Estimating the hydrate safety margin in the presence of salt or organic inhibitor using refractive index data of aqueous solution. Industrial \& engineering chemistry research 2006;45:8207-12.

[276] Mohammadi AH, Richon D. Estimating the hydrate safety margin using surface tension data of salt aqueous solution. Industrial \& engineering chemistry research 2006;45:8154-7.

[277] Mohammadi AH, Richon D. Use of boiling point elevation data of aqueous solutions for estimating hydrate stability zone. Industrial \& engineering chemistry research 2007;46:987-9.

[278] Mohammadi AH, Richon D. Gas hydrate phase equilibrium in the presence of ethylene glycol or methanol aqueous solution. Industrial \& Engineering Chemistry Research 2010;49:8865-9.

[279] Mohammadi AH, Richon D. Phase equilibria of hydrogen sulfide and carbon dioxide simple hydrates in the presence of methanol, (methanol $+\mathrm{NaCl}$ ) and (ethylene glycol $+\mathrm{NaCl}$ ) aqueous solutions. The Journal of Chemical Thermodynamics 2012;44:26-30.

[280] Najibi H, Mohammadi AH, Tohidi B. Estimating the hydrate safety margin in the presence of salt and/or organic inhibitor using freezing point depression data of aqueous solutions. Industrial \& engineering chemistry research 2006;45:4441-6.

[281] Bishnoi P, Dholabhai PD. Equilibrium conditions for hydrate formation for a ternary mixture of methane, propane and carbon dioxide, and a natural gas mixture in the presence of electrolytes and methanol. Fluid Phase Equilibria 1999;158:821-7.

[282] Dholabhai PD, Parent JS, Bishnoi PR. Equilibrium conditions for hydrate formation from binary mixtures of methane and carbon dioxide in the presence of electrolytes, methanol and ethylene glycol. Fluid Phase Equilibria 1997;141:235-46.

[283] Mahadev KN, Bishnoi PR. Equilibrium conditions for the hydrogen sulfide hydrate formation in the presence of electrolytes and methanol. The Canadian Journal of Chemical Engineering 1999;77:718-22.

[284] Elgibaly A, Elkamel A. Optimal hydrate inhibition policies with the aid of neural networks. Energy \& fuels 1999;13:105-13.

[285] Kawamura T, Sakamoto Y, Ohtake M, Yamamoto Y, Komai T, Haneda H, et al. Dissociation behavior of pellet-shaped methane hydrate in ethylene glycol and silicone oil. Part 1: Dissociation above ice point. Industrial \& engineering chemistry research 
2006;45:360-4.

[286] Dong F, Zang X, Li D, Fan S, Liang D. Experimental investigation on propane hydrate dissociation by high concentration methanol and ethylene glycol solution injection. Energy \& Fuels 2009;23:1563-7.

[287] Fan S, Zhang Y, Tian G, Liang D, Li D. Natural gas hydrate dissociation by presence of ethylene glycol. Energy \& fuels 2006;20:324-6.

[288] Ohgaki K, Inoue Y. A Proposal for Gas-Storage on the Ocean-Floor Using Gas Hydrates. Kagaku Kogaku Ronbun 1991;17:1053-5.

[289] Goel N. In situ methane hydrate dissociation with carbon dioxide sequestration: Current knowledge and issues. Journal of Petroleum Science and Engineering 2006;51:169-84.

[290] Ohgaki K, Takano K, Sangawa H, Matsubara T, Nakano S. Methane exploitation by carbon dioxide from gas hydrates. Phase equilibria for $\mathrm{CO}_{2}-\mathrm{CH}_{4}$ mixed hydrate system. Journal of chemical engineering of Japan 1996;29:478-83.

[291] Qi Y, Ota M, Zhang H. Molecular dynamics simulation of replacement of CH 4 in hydrate with CO 2. Energy Conversion and Management 2011;52:2682-7.

[292] Seo Y, Lee S, Lee J. Experimental verification of methane replacement in gas hydrates by carbon dioxide. Chem Engineer Trans 2013;32:163-8.

[293] Deusner C, Bigalke N, Kossel E, Haeckel M. Methane production from gas hydrate deposits through injection of supercritical $\mathrm{CO}_{2}$. Energies 2012;5:2112-40.

[294] Park Y, Kim DY, Lee JW, Huh DG, Park KP, Lee J, et al. Sequestering carbon dioxide into complex structures of naturally occurring gas hydrates. P Natl Acad Sci USA 2006;103:12690-4.

[295] Koh DY, Kang H, Kim DO, Park J, Cha M, Lee H. Recovery of methane from gas hydrates intercalated within natural sediments using $\mathrm{CO}_{2}$ and a $\mathrm{CO}_{2} / \mathrm{N}_{2}$ gas mixture. Chem Sus Chem 2012;5:1443-8.

[296] Cranganu C. In-situ thermal stimulation of gas hydrates. Journal of Petroleum Science and Engineering 2009;65:76-80.

[297] Cranganu C. A method for producing natural gas from gas hydrate deposits. Proceedings of the AAPG Annual Convention 2005.

[298] Schicks JM, Spangenberg E, Giese R, Steinhauer B, Klump J, Luzi M. New approaches for the production of hydrocarbons from hydrate bearing sediments. Energies 2011;4:151-72.

[299] Schicks JM, Spangenberg E, Giese R, Luzi-Helbing M, Priegnitz M, Beeskow-Strauch B. A counter-current heat-exchange reactor for the thermal stimulation of hydrate-bearing sediments. Energies 2013;6:3002-16.

[300] Castaldi MJ, Zhou Y, Yegulalp TM. Down-hole combustion method for gas production from methane hydrates. Journal of Petroleum Science and Engineering 2007;56:176-85.

[301] Yousif M, Li P, Selim M, Sloan E. Depressurization of natural gas hydrates in Berea sandstone cores. Journal of inclusion phenomena and molecular recognition in chemistry 1990;8:71-88.

[302] Davidson D, Garg S, Ratcliffe C, Tse J, Gough S. Characterization of a clathrate hydrate of nitrogen trifluoride. Canadian journal of chemistry 1984;62:1229-35.

[303] John VT, Holder GD. Hydrates Of Methane + Normal-Butane Below the Ice Point. J 
Chem Eng Data 1982;27:18-21

[304] Dharma-Wardana M. The thermal conductivity of the ice polymorphs and the ice clathrates. The Journal of Physical Chemistry 1983;87:4185-90.

[305] Kneafsey TJ, Tomutsa L, Moridis GJ, Seol Y, Freifeld BM, Taylor CE, et al. Methane hydrate formation and dissociation in a partially saturated core-scale sand sample. J Petrol Sci Eng 2007;56:108-26.

[306] Zhou Y, Castaldi MJ, Yegulalp TM. Experimental Investigation of Methane Gas Production from Methane Hydrate. Ind Eng Chem Res 2009;48:3142-9.

[307] Phelps TJ, Peters DJ, Marshall SL, West OR, Liang LY, Blencoe JG, et al. A new experimental facility for investigating the formation and properties of gas hydrates under simulated seafloor conditions. Rev Sci Instrum 2001;72:1514-21.

[308] Su KH, Sun CY, Yang X, Chen GJ, Fan SS. Experimental investigation of methane hydrate decomposition by depressurizing in porous media with 3-Dimension device. J Nat Gas Chem 2010; 19:210-6.

[309] Yang X, Sun CY, Su KH, Yuan Q, Li QP, Chen GJ. A three-dimensional study on the formation and dissociation of methane hydrate in porous sediment by depressurization. Energy Convers Manag 2012;56:1-7.

[310] Circone S, Stern LA, Kirby SH, Pinkston JC, Durham WB. Methane hydrate dissociation rates at $0.1 \mathrm{MPa}$ and temperatures above $272 \mathrm{~K}$. Gas Hydrates: Challenges for the Future 2000;912:544-55.

[311] Sun CY, Chen GJ. Methane hydrate dissociation above $0{ }^{\circ} \mathrm{C}$ and below $0{ }^{\circ} \mathrm{C}$. Fluid Phase Equilib 2006;242:123-8.

[312] Lee J, Park S, Sung W. An experimental study on the productivity of dissociated gas from gas hydrate by depressurization scheme. Energy Convers Manage 2010;51:2510-5.

[313] Zhang Y, Li XS, Chen ZY, Wang Y, Ruan XK. Effect of hydrate saturation on the methane hydrate dissociation by depressurization in sediments in a cubic hydrate simulator. Ind Eng Chem Res 2015;54:2627-37.

[314] Li G, Li B, Li XS, Zhang Y, Wang Y. Experimental and numerical studies on gas from methane hydrate in porous media by depressurizationin pilot-scale hydrate simulator. Energy Fuels 2012;26(10):6300-10.

[315] Wang Y, Feng JC, Li XS, Zhang Y, Li G. Large scale experimental evaluation to methane hydrate dissociation below quadruple point in sandy sediment. Appl Energy 2015. In press.

[316] Feng JC, Wang Y, Li XS, Li G, Zhang Y, Chen ZY. Effect of horizontal and vertical well patterns on methane hydrate dissociation behaviors in pilot-scale hydrate simulator. Appl Energy 2015;145:69-79.

[317] Tang LG, Xiao R, Huang C, Feng ZP, Fan SS. Experimental investigation of production behavior of gas hydrate under thermal stimulation in unconsolidated sediment. Energy Fuel 2005;19:2402-7.

[318] Pang WX, Xu WY, Sun CY, Zhang CL, Chen GJ. Methane hydrate dissociation experiment in a middle-sized quiescent reactor using thermal method. Fuel. 2009;88:497-503. [319] Yang X, Sun CY, Yuan Q, Ma PC, Chen GJ. Experimental Study on Gas Production from Methane Hydrate-Bearing Sand by Hot-Water Cyclic Injection. Energy Fuel 2010;24:5912-20. 
[320] Katz DL, Cornell D, Poettmann FH, Vary JA, Elenbaas JR. Handbook of Natural Gas Engineering. New York, NY, USA: McGraw-Hill Book Inc.; 1959.

[321] Sira JH, Patil SL, Kamath VA. Study of hydrate dissociation by methanol and glycol injection. The SPE Annual Technical Conference and Exhibition. New Orleans, LA, USA1990.

[322] Yuan Q, Sun CY, Yang X, Ma PC, Ma ZW, Li QP, et al. Gas Production from Methane-Hydrate-Bearing Sands by Ethylene Glycol Injection Using a Three-Dimensional Reactor. Energy Fuels 2011;25:3108-15.

[323] Kamath VA, Godbole SP. Evaluation of Hot-Brine Stimulation Technique for Gas-Production from Natural-Gas Hydrates. J Pet Sci Technol 1987;39:1379-88.

[324] Qi YX, Wu WD, Liu YF, Xie YM, Chen X. The influence of $\mathrm{NaCl}$ ions on hydrate structure and thermodynamic equilibrium conditions of gas hydrates. Fluid Phase Equilib 2012;325:6-10.

[325] McGuire PL. Method for production of hydrocarbons from hydrates. USA: Thu United States of America as represented by the United States Department of Energy, Washington D.C.; 1984; p5.

[326] Atkinson S. Method for the recovery of hydrocarbons from hydrates. USA 2006.

[327] Kharrat M, Dalmazzone D. Experimental determination of stability conditions of methane hydrate in aqueous calcium chloride solutions using high pressure differential scanning calorimetry. J Chem Thermodyn 2003;35:1489-505.

[328] Yi LZ, Liang DQ. Decomposition mechanism of methane hydrate in brine solution by molecular dynamics simulation. The $8^{\text {th }}$ International Conference on Gas Hydrate Beijing, China, 2014.

[329] Lee J. Experimental Study on the Dissociation Behavior and Productivity of Gas Hydrate by Brine Injection Scheme in Porous Rock. Energy Fuels 2010;24:456-63.

[330] Ebinuma T. Method for dumping and disposing of carbon dioxide gas and apparatus therefor. E21B 36/00;E21B 43/24;E21B 43/40 ed: NKK Corporation, Tokyo, Japan; 1993.

[331] Yuan Q, Sun CY, Liu B, Wang X, Ma ZW, Ma QL, et al. Methane recovery from natural gas hydrate in porous sediment using pressurized liquid $\mathrm{CO}_{2}$. Energy Convers Manage 2013;67:257-64.

[332] White M, McGrail P. Designing a Pilot-Scale Experiment for the Production of Natural Gas Hydrates and Sequestration of $\mathrm{CO}_{2}$ in Class 1 Hydrate Accumulations. Greenhouse Gas Control Technologies 9. 2009;1:3099-106.

[333] Hirohama S, Shimoyama Y, Wakabayashi A, Tatsuta S, Nishida N. Conversion of $\mathrm{CH}_{4}$-hydrate to $\mathrm{CO}_{2}$-hydrate in liquid $\mathrm{CO}_{2}$. J Chem Eng Jpn 1996;29:1014-20.

[334] Lee H, Seo Y, Seo YT, Moudrakovski IL, Ripmeester JA. Recovering methane from solid methane hydrate with carbon dioxide. Angew Chem Int Edit 2003;42:5048-51.

[335] Zhou XT, Fan SS, Liang DQ, Du JW. Replacement of methane from quartz sand-bearing hydrate with carbon dioxide-in-water emulsion. Energy Fuels 2008;22:1759-64.

[336] Rice W. Hydrogen production from methane hydrate with sequestering of carbon dioxide. Int J Hydrogen Energy 2006;31:1955-63.

[337] Ota M, Abe Y, Watanabe M, Smith RL, Inomata H. Methane recovery from methane hydrate using pressurized $\mathrm{CO}_{2}$. Fluid Phase Equilib 2005;228:553-9.

[338] Ota M, Morohashi K, Abe Y, Watanabe M, Smith RL, Inomata H. Replacement of $\mathrm{CH}_{4}$ 
in the hydrate by use of liquid $\mathrm{CO}_{2}$. Energy Convers Manage 2005;46:1680-91.

[339] Zhou XT, Fan SS, Liang DQ, Du JW. Determination of appropriate condition on replacing methane from hydrate with carbon dioxide. Energy Convers Manage 2008;49:2124-9.

[340] Xu CG, Cai J, Lin FH, Chen ZY, Li XS. Raman analysis on methane production from natural gas hydrate by carbon dioxide-methane replacement. Energy 2015;79:111-6.

[341] Uchida T, Takeya S, Ebinuma $\mathrm{T}$, et al. Replacing Methane with $\mathrm{CO}_{2}$ in Clathrate Hydrate: Observations Using Raman Spectroscopy. In Proceedings of the Fifth International Conference on Greenhouse Gas Control Technologies, Cairns, Austrian, 2000.; Williams, DJ, Durie, RA, McMullan, P, Paulson, CAJ, Smith AY. CSIRO Publishing, Collingwood, Australia, 2001.

[342] Li ZZ, Guo XQ, Wang JB, Yang, LY. Experiment studies on $\mathrm{CH}_{4}$ recovery from hydrate using $\mathrm{CO}_{2}$ in different systems. Natu Gas Ind 2008;28:129-32.

[343] Yuan Q, Sun CY, Yang X, Ma PC, Ma ZW, Liu B, Ma QL, Yang LY, Chen GJ. Recovery of metane from hydrate reservoir with gaseous carbon dioxide using a three-dimensional middle-size reactor. Energy 2012;40:47-58.

[344] Zhang Y, Xiong LJ, Li XS, Chen ZY, Xu CG. Replacement of $\mathrm{CH}_{4}$ in hydrate in porous sediments with liquid $\mathrm{CO}_{2}$ injection. Chem Eng Technol 2014;37(12):2022-9.

[345] McGrail BP, Zhu T, Hunter RB, White MD, Patil SL, Kulkarni AS. A New Method for Enhanced Production of Gas Hydrate with $\mathrm{CO}_{2}$. In Proceedings of the AAPG Hedberg Conference on Gas Hydrates: Energy Resource Potential and Associated Geologic Hazards, Vancouver, Canada, 12-16 September 2004.

[346] Zhang W, Wang Z, Li WQ, Li WY, He DW. Research progress in the enhanced replacing methane out of gas hydrate by carbon dioxide emulsion. Nat Gas Chem Eng 2009;34:59-63.

[347] Cha MJ, Shin K, Lee H, Moudrakovski IL, Ripmeester JA, Seo Y. Kinetics of Methane Hydrate Replacement with Carbon Dioxide and Nitrogen Gas Mixture Using in Situ NMR Spectroscopy. Environ Sci Technol 2015;49:1964-71.

[348] Lu HL, Seo YT, Lee JW, Moudrakovski I, Ripmeester JA, Chapman NR, et al. Complex gas hydrate from the Cascadia margin. Nature 2007;445:303-6.

[349] Shin K, Park Y, Cha MJ, Park KP, Huh DG, Lee J, et al. Swapping phenomena occurring in deep-sea gas hydrates. Energy Fuels 2008;22:3160-3.

[350] Feng JC, Wang Y, Li XS, Li G, Chen ZY. Production behaviors and heat transfer characteristics of methane hydrate dissociation by depressurization in conjunction with warm water stimulation with dual horizontal wells. Energy 2015;79:315-24.

[351] Feng JC, Wang Y, Li XS, Chen ZY, Li G, Zhang Y. Investigation into optimization condition of thermal stimulation for hydrate dissociation in the sandy reservoir. Appl Energ 2015;154:995-1003.

[352] Song YC, Cheng CX, Zhao JF, Zhu ZH, Liu WG, Yang MJ, et al. Evaluation of gas production from methane hydrates using depressurization, thermal stimulation and combined methods. Appl Energ 2015;145:265-77.

[353] Loh M, Too JL, Falser S, Linga P, Khoo BC, Palmer A. Gas production from methane hydrates in a dual wellbore system. Energy Fuels 2015;29:35-42.

[354] Li S, Zheng R, Xu X, Chen Y. Dissociation of Methane Hydrate by Hot Brine. Petrol 
Sci Technol. 2015;33:671-7.

[355] Yuan Q, Sun CY, Wang XH, Zeng XY, Yang X, Liu B, et al. Experimental study of gas production from hydrate dissociation with continuous injection mode using a three-dimensional quiescent reactor. Fuel 2013;106:417-24.

[356] Lv QN, Li XS, Chen ZY, Feng JC. Phase equilibrium and dissociation enthalpies for hydrates of various water-insoluble organic promoters with methane. J Chem Eng Data 2013;58:3249-53.

[357] Chen ZY, Li QP, Yan ZY, Yan KF, Zeng ZY, Li XS. Phase equilibrium and dissociation enthalpies for cyclopentane + methane hydrates in $\mathrm{NaCl}$ aqueous solutions. J Chem Eng Data 2010;55:4444-9.

[358] Li L, Lv QN, Li XS, Feng JC, Chen ZY. Phase equilibrium and dissociation enthalpies of trimethyleneide + methane hydrates in brine water systems. J Chem Eng Data 2014;59:3717-22.

[359] Lv QN, Li L, Li XS, Chen ZY. Formation kinetics of cyclopentane + methane hydrates in brine water systems and Raman Spectroscopic analysis. Energy Fuels In press.

[360] Lv QN, Li XS, Xu CG, Chen ZY. Experimental investigation of the formation of cyclopentane + methane hydrate in a novel and large-size bubble column reactor. Ind Eng Chem Res 2012;51:5967-75.

[361] Chen XR, Li XS, Chen ZY, Zhang Y, Yan KF, Lv QN. Experimental Investigation into the Combustion Characteristics of Propane Hydrates in Porous Media. Energies 2015;8:1242-55.

[362] Misyura SY. Effect of heat transfer on the kinetics of methane hydrate dissociation. Chem Phys Lett 2013;583:34-37.

[363] Fitzgerald GC, Castaldi MJ, Zhou Y. Large scale reactor details and results for the formation and decomposition of methane hydrates via thermal stimulation dissociation. $\mathrm{J}$ Petrol Sci Eng 2012;94-95:19-27.

[364] Holder GD, Angert PF, Godbole SP. Simulation of Gas Production from a Reservoir Containing Both Gas Hydrates and Free Natural Gas. SPE 11105 presented at 1982 SPE Annual Technical Conference and Exhibition. 1982. New Orleans, Louisiana.

[365] Burshears M, O'Brien TJ, Malone RD. A Multi-Phase Multi-Dimensional,Variable Composition Simulation of Gas Production From a Conventional Gas Reservoir in Contact with Hydrates. paper SPE 15246 presented at the 1986 SPE Unconventional Gas Technology Symposium. 1986: 18-21.

[366] Holder GD, Angert PF, Godbole SP. Simulation of Gas Production from a Reservoir Containing Both Gas Hydrates and Free Natural Gas. SPE 11105 presented at 1982 SPE Annual Technical Conference and Exhibition. 1982. New Orleans, Louisiana.

[367] Makogon YF. Hydrates of hydrocarbons. Tulsa, OK: Penn Well, 1997.

[368] Tsypkin GG. Regimes of Dissociation of Gas Hydrates Coexisting with a Gas in Natural Strata. J Eng Phys Thermophys 2001;74(5):1083-9.

[369] Zhang KN, Moridis GJ, Wu YS. A domain decomposition approach for large-scale simulations of flow processes in hydrate-bearing geologic media. the 6th International Conference on Gas Hydrate (ICGH-2008). Vancouver, Canada 2008.

[370] White MD, Oostrom M, Rockhold ML, Rosing M. Scalable modeling of carbon tetrachloride migration at the hanford site using the STOMP simulator. Vadose Zone $\mathrm{J}$ 
2008;7:654-66.

[371] Oostrom M, White MD, Lenhard RJ, Van Geel PJ, Wietsma TW. A comparison of models describing residual NAPL formation in the vadose zone. Vadose Zone $\mathrm{J}$ 2005;4:163-74.

[372] White MD, Oostrom M, Lenhard RJ. A practical model for mobile, residual, and entrapped NAPL in water-wet porous media. Ground Water. 2004;42:734-46.

[373] Oostrom M, White MD, Brusseau ML. Theoretical estimation of free and entrapped nonwetting-wetting fluid interfacial areas in porous media. Adv Water Resour 2001;24:887-98.

[374] White MD, Oostrom M. Modeling surfactant-enhanced nonaqueous-phase liquid remediation of porous media. Soil Sci 1998;163:931-40.

[375] Schroth MH, Istok JD, Selker JS, Oostrom M, White MD. Multifluid flow in bedded porous media: laboratory experiments and numerical simulations. Adv Water Resour 1998;22:169-83.

[376] White MD, Oostrom M, Lenhard RJ. Modeling Fluid-Flow and Transport in Variably Saturated Porous-Media with the Stomp Simulator .1. Nonvolatile 3-Phase Model Description. Adv Water Resour. 1995;18:353-64.

[377] Wilder JW, Moridis GJ, Wilson SJ, Kurihara M, White MD, Masuda Y, et al. An International Effort to Compare Gas Hydrate Reservoir Simulators. The 6th International Conference on Gas Hydrates (ICGH 2008). Vancouver, British Columbia, Canada2008.

[378] Temma N, Sakamoto Y, Komai T, Yamaguchi T, Zyvoloski G, Pawar R. Numerical simulation of gas hydrate dissociation in artificial sediment. Proceedings of the Sixteenth (2006) International Offshore and Polar Engineering Conference, Vol 1. 2006:299-303.

[379] Pawar RJ, Zyvoloski GA, Tenma N, Sakamoto Y, Komai T. Numerical simulation of laboratory experiments on methane hydrate dissociation. Proceedings of the Fifteenth (2005) International Offshore and Polar Engineering Conference, Vol 1. 2005:379-85.

[380] Liu Y, Strumendo M, Arastoopour H. Numerical simulation of methane production from a methane hydrate formation. Ind Eng Chem Res 2008;47:2817-28.

[381] Gamwo IK, Liu Y. Mathematical Modeling and Numerical Simulation of Methane Production in a Hydrate Reservoir. Ind Eng Chem Res 2010;49:5231-45.

[382] Ruan XK, Song YC, Zhao JF, Liang HF, Yang MJ, Li YH. Numerical Simulation of Methane Production from Hydrates Induced by Different Depressurizing Approaches. Energies 2012;5:438-58.

[383] Bai YH, Li QP, Zhao Y, Li XF, Du Y. The Experimental and Numerical Studies on Gas Production from Hydrate Reservoir by Depressurization. Transport Porous Med 2009;79:443-68.

[384] Su Z, He Y, Wu NY, Zhang KN, Moridis GJ. Evaluation on gas production potential from laminar hydrate deposits in Shenhu Area of South China Sea through depressurization using vertical wells. J Petrol Sci Eng 2012;86-87:87-98.

[385] Su Z, Moridis GJ, Zhang KN, Wu NY. A huff-and-puff production of gas hydrate deposits in Shenhu area of South China Sea through a vertical well. J Petrol Sci Eng 2012;86-87:54-61.

[386] Li G, Li XS, Zhang KN, Moridis GJ. Numerical simulation of gas production from hydrate accumulations using a single horizontal well in Shenhu Area, South China Sea. 
Chinese J Geophys-Ch 2011;54:2325-37.

[387] Janicki G, Schluter S, Henning T, Deerberg G. Simulation of subsea gas hydrate exploitation. Energy Procedia 2014;57:8.

[388] Myshakin EM, Gaddipati M, Rose K, Anderson BJ. Numerical simulations of depressurization-induced gas production from gas hydrate reservoirs at the Walker Ridge 313 site, northern Gulf of Mexico. Mar Petrol Geol 2012;34:169-85.

[389] Moridis GJ, Collett TS, Dallimore SR, Inoue T, Mroz T. Analysis and interpretation of the thermal test of gas hydrate dissociation in the JAPEX/JNOC/GSC et al. Mallik 5L-38 gas hydrate production research well. GSC Bulletin.585:21.

[390] Kurihara M, Masuda Y, Narita H, Dallimore SR, Wright F. Analysis of the JOGMEC/NRCAN/AURORA Mallik gas hydrate production test through numerical simulation. The 6th International Conference on Gas Hydrates (ICGH-2008). Vancouver, British Columbia, Canada2008. p13.

[391] Takahashi H, Fercho E, Dallimore SR. Drilling and operations overview of the Mallik 2002 Production Research Well Program. GSC Bulletin. 2005;585.

[392] Li G, Li XS, Li B, Wang Y. Methane Hydrate Dissociation using Inverted Five-Spot Water Flooding Method in Cubic Hydrate Simulator. Energy 2014;64:298-306.

[393] Makogon YF, Omelchenko RY. Commercial gas production from Messoyakha deposit in hydrate conditions. J Nat Gas Sci Eng 2013;11:1-6.

[394] Dallimore SR, Collett TS, Uchida T, Weber M, Takahashi H, Mroz T. Overview of Gas Hydrate Research at the Mallik Field in the Mackenzie Delta, Northwest Territories, Canada. p39.

[395] Kurihara M, Sato A, Funatsu K, Ouchi H, Yamamoto K, Ebinuma T, et al. Analysis of Production Data for 2007/2008 Mallik Gas Hydrate Production Tests in Canada. The CPS/SPE International Oil \& Gas Conference and Exhibition in China Beijing, China 2010. [396] Anderson BJ, Kurihara M, White MD, Moridis GJ, Wilson SJ, Pooladi-Darvish M, et al. Regional long-term production modeling from a single well test, Mount Elbert Gas Hydrate Stratigraphic Test Well, Alaska North Slope. Mar Petrol Geol 2011;28:493-501.

[397] Hauge LP, Birkedal KA, Ersland G, Graue A. Methane Production from Natural Gas Hydrates by $\mathrm{CO}_{2}$ Replacement - Review of Lab Experimental and Field Trial. The SPE Bergen One Day Seminar. Grieghallen, Bergen, Norway 2014.

[398] Schoderbek D, Farrell H, Hester K, Howard J, Silpngarmlert S. ConocoPhillips gas hydrate production test final technical report. United States Department of Energy 2013.

[399] Wang PK, Zhu YH, Lu ZQ, Huang X, Pang SJ, Zhang S. Gas hydrate stability zone migration occurred in the Qilian mountain permafrost, Qinghai, Northwest China: Evidences from pyrite morphology and pyrite sulfur isotope. Cold Reg Sci Technol 2014;98:8-17.

[400] Sun YH, Li B, Guo W, Lu XS, Zhang YQ, Li K, et al. Comparative analysis of the production trial and numerical simulations of gas production from multilayer hydrate deposits in the Qilian Mountain permafrost. J Nat Gas Sci Eng 2014;21:456-66.

[401] Yamamoto K. Overview and introduction: Pressure core-sampling and analysis in the 2012 - 2013 MH21 offshore test of gas production from methane hydrate in teh eastern Nankai Trough. Mar Petrol Geol. 2015:14.

[402] Lu SM. A global survey of gas hydrate development and reserves: specifically in the marine field. Renew Sustain Energy Rev. 2015;41:7. 
[403] Trehu AM, Ruppel C, Holland M, Dickens GR, Torres M, Collett TS, et al. Gas hydrates in marine sediments - lessons from scientific ocean drilling. Oceanography 2006;19:124.

[404] Kennett JP, Cannariato KG, Hendy IL, Behl RJ. Methane Hydrates in Quaternary Climate Change: The Clathrate Gun Hypothesis. Special Publications Series 2002.

[405] Reeburgh WS. Oceanic methane biogeochemistry. Chem Rev 2007;107:486-513.

[406] Hester KC, Dunk RM, White SN, Brewer PG, Peltzer ET, Sloan ED. Gas hydrate measurements at Hydrate Ridge using Raman spectroscopy. Geochim Cosmochim Ac 2007;71:2947-59.

[407] Kirkwood WJ, Peltzer ET, Brewer PG. In situ ocean acidification environmental observations: MBARI's cabled observatory technology for controlled studies of changing ocean pH. 2007 Symposium on Underwater Technology and Workshop on Scientific Use of Submarine Cables and Related Technologies, Vols 1 and 2. 2007:627-33.

[408] Nagakubo S, Arata N, Yabe I, Kobayashi H. Methane hydrate development and environmental impacts: environmental studies in phase 2 of Japan's methane hydrate R\&D program. J Jpn Assoc Pet Technol 2011;76:10.

[409] Paull CK, Dillon WP. Natural Gas Hydrates: Occurrence, Distribution and Detection, Geophysical Monograph Series, Am. Washington DC: Geophysical Union; 2001.

[410] Milkov AV, Sassen R. Economic geology of offshore gas hydrate accumulations and provinces. Mar Petrol Geol 2002;19:1-11.

[411] Milkov AV, Sassen R. Economic geology of the Gulf of Mexico and the Blake Ridge gas hydrate provinces. Transactions Gulf Coast Association of Geological Societies 2001;51:10.

[412] Sassen R, Joye S, Sweet ST, DeFreitas DA, Milkov AV, MacDonald IR. Thermogenic gas hydrates and hydrocarbon gases in complex chemosynthetic communities, Gulf of Mexico continental slope. Org Geochem 1999;30:485-97.

[413] Dopke LK, Requate T. The Economics of exploiting gas hydrates. Energy Ecnomics 2014;42:355-64.

[414] Walsh MR, Hancock SH, Wilson SJ, Patil SL, Moridis GJ, Boswell R, et al. Premilinary report on the commercial viability of gas production from natural gas hydrates. Energy Economics 2009;31:9.

[415] Hancock S, Okazawa T. A preliminary investigation on the economics of onshore gas hydrate production. The 7th Annual Conference on Unconventional Gas. Calgary, Alberta 2005.

[416] Hancock S. Gas hydrates: commercial sooner than expected. CERI 2008 Natural Gas Conference. Calgary, Alberta, Canada 2008.

[417] Moridis GJ, Reagan M. Strategies for Production from Oceanic Class 3 Hydrate Accumulations. OTC. 2007;18865.

[418] Milkov AV, Sassen R. Estimate of gas hydrate resource, northwestern Gulf of Mexico continental slope. Mar Geol 2001;179:13.

[419] Pflaum RC, Brooks JM, Cox HB, Kennicutt MC, Sheu DD. Molecular and isotopic analysis of core gases and gas hydrates, DSDP Leg 96. In: Bouma AH, Coleman JM, Meyer AW, editors. Initial reports of the DEEP Sea Drilling Project, 96. Washigton DC, U.S.1986. p. 781-4. 
[420] Sassen K, Mace GG, Wang Z, Poellot MR. Continental stratus clouds: A case study using coordinated remote sensing and aircraft measurements. J Atmos Sci 1999;56:2345-58. [421] Suess E, Torres ME, Bohrmann G, Collier RW, Greinert J, Linke P, et al. Gas hydrate destabilization: enhanced dewatering, benthic material turnover and large methane plumes at the Cascadia convergent margin. Earth Planet Sc Lett 1999;170:1-15.

[422] Trehu AM, Torres ME, Moore GF, Suess E, Bohrmann G. Temporal and spatial evolution of a gas hydrate-bearing accretionary ridge on the Oregon continental margin. Geology 1999;27:939-42.

[423] Bogdanov YA, Sagalevitch AM, Vogt PR, Mienert Y, Sundvor E, Krane K, et al. The Haakon Mosby mud volcano in the Norwegian Sea: Results of comprehensive investigations with submersibles. Okeanologiya 1999;39:412-9.

[424] Ginsburg GD, Milkov AV, Soloviev VA, Egorov AV, Cherkashev GA, Vogt PR, et al. Gas hydrate accumulation at the Hakon Mosby Mud Volcano. Geo-Mar Lett 1999;19:57-67.

[425] Dickens GR, Paull CK, Wallace P. Direct measurement of in situ methane quantities in a large gas-hydrate reservoir. Nature 1997;385:426-8.

[426] Minai Y, Matsumoto R, Tominaga T. Geochemistry of Deep-Sea Sediments from the Nankai Trough, the Japan Trench, and Adjacent Regions. Initial Rep Deep Sea. 1986;87:643-57. 


\section{FIGURE Captions}

Figure 1. Types of NGH reservoirs

Figure 2. Sketch diagram of Classes 1, 2, and 3 hydrate reservoirs

Figure 3. Schematic diagram of gas production methods

Figure 4. Conceptual depiction of the warm brine in situ gas production with a dual horizontal wells system

Figure 5. World map showing the locations of natural gas hydrate deposits on-shore (within and beneath permafrost), and off-shore

(within a few $100 \mathrm{~m}$ of the seafloor on continental slopes, in deep seas and lakes): (courtesy K. Kvenvolden, Nov. 2005)

Figure 6. Wells application in Messoyakha field

Figure 7. Estimation of gas and water production in 2007 winter test

Figure 8. Estimation of gas and water production in 2008 winter test

Figure 9. The designation of the production field test well in the QTPP

Figure 10. Schematics of the wells for the Nankai Trough produciton test

Figure 11.A scheme sample for classifying the resource/reserve of NGH

\section{TABLE Captions}

Table 1. Content overview

Table 2. The simulation Zone and simulation scheme

Table 3. Main geological, technological, and economic characteristics of gas hydrate accumulations and provinces 


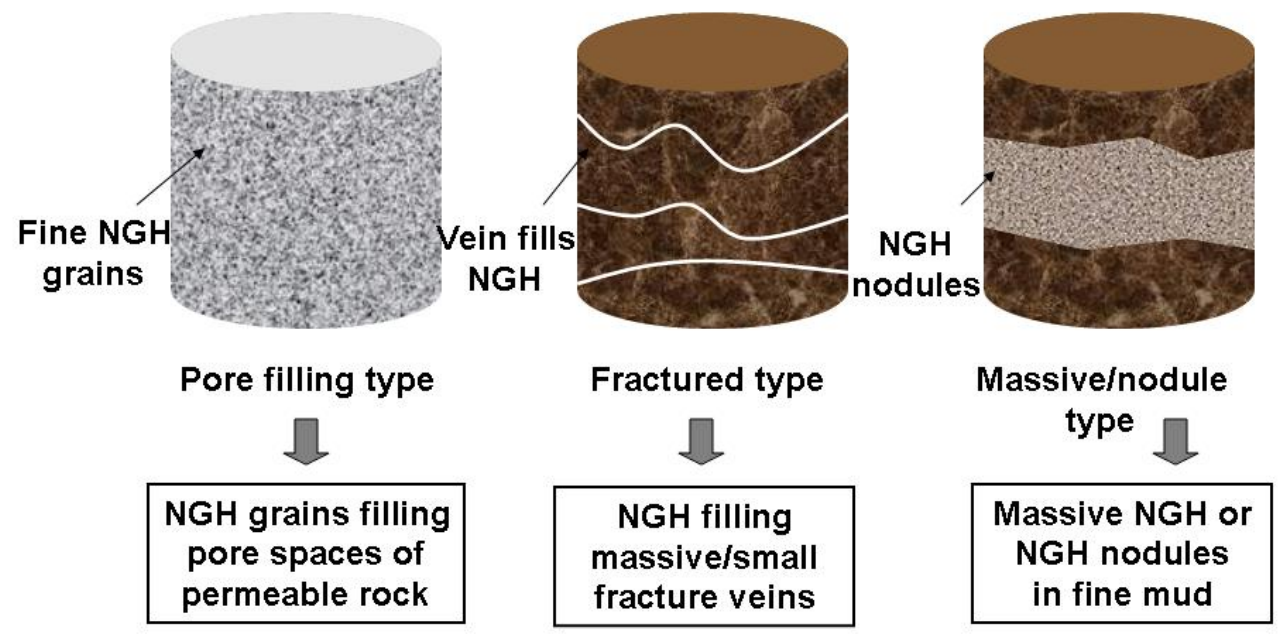

Figure 1. Types of NGH reservoirs

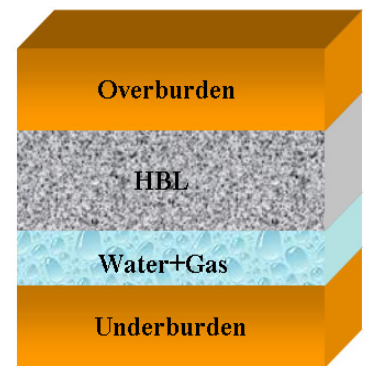

Class 1

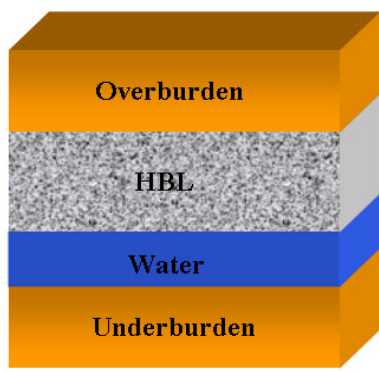

Class 2

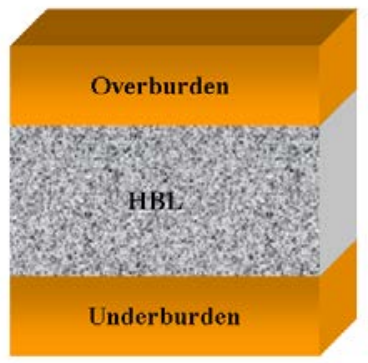

Class 3

Figuire 2. Sketch diagram of Classes 1, 2, and 3 hydrate reservoirs 


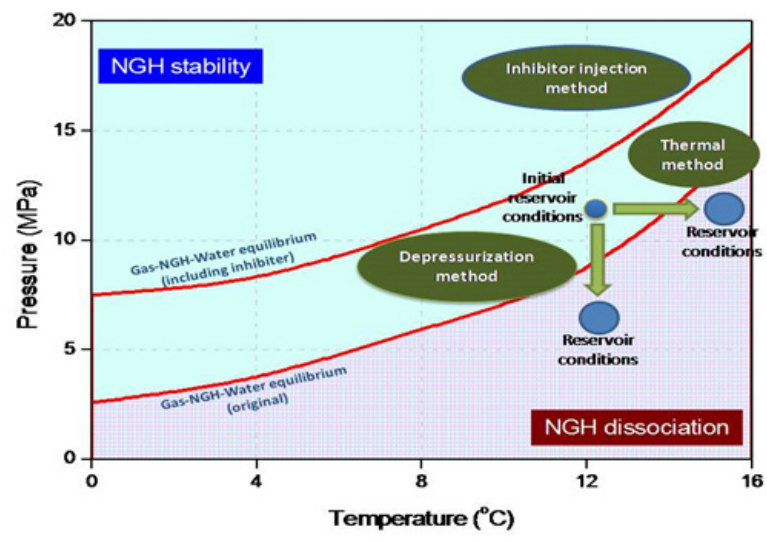

Figure 3. Schematic diagram of gas production methods 


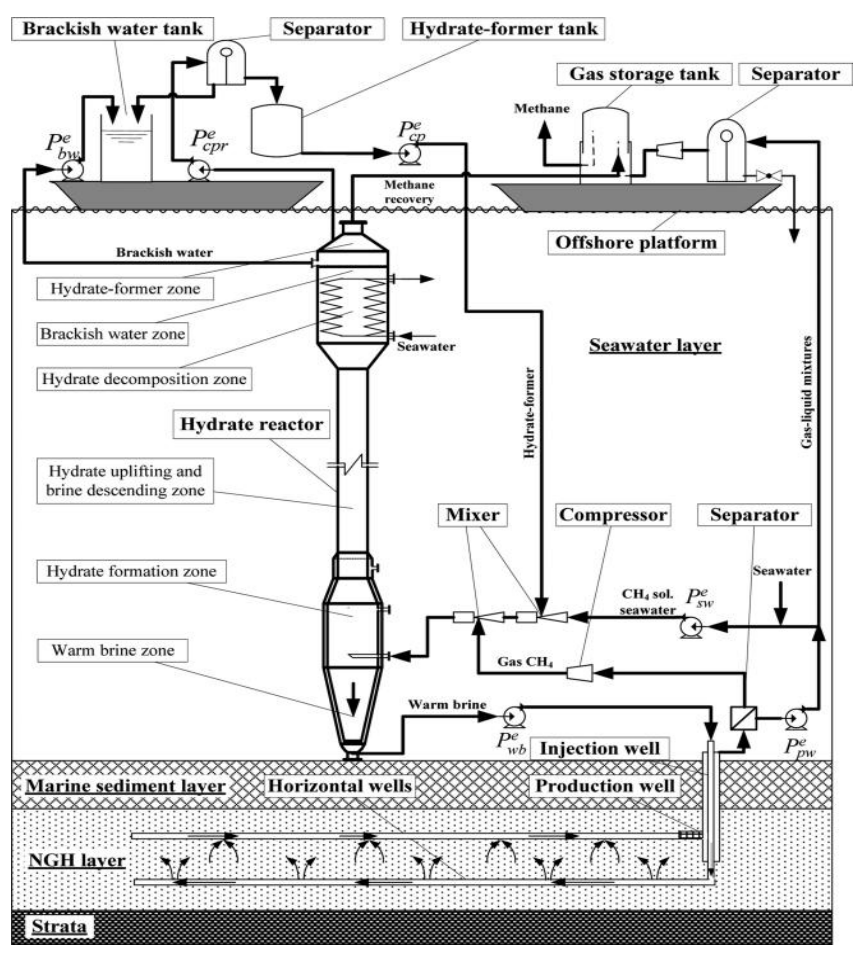

Figure 4. Conceptual depiction of the warm brine in situ gas production with a dual horizontal wells system

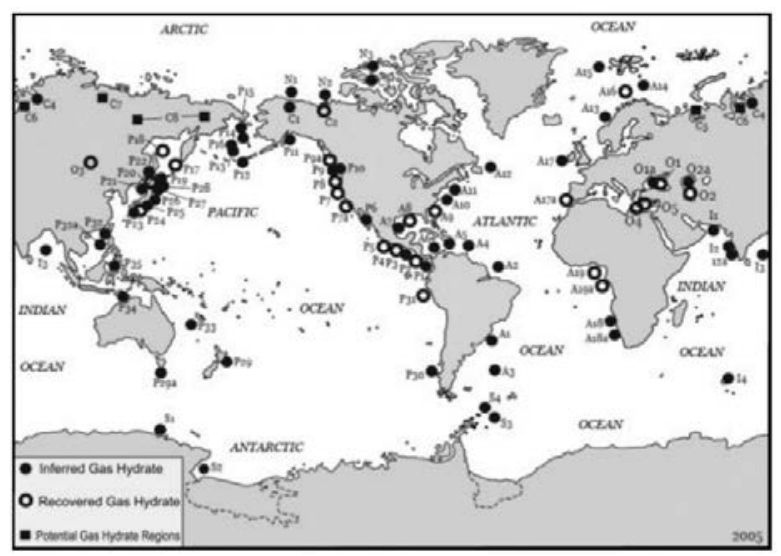

Figure 5. World map showing the locations of natural gas hydrate deposits on-shore

(within and beneath permafrost), and off-shore

(within a few $100 \mathrm{~m}$ of the seafloor on continental slopes, in deep seas and lakes):

(courtesy K. Kvenvolden, Nov. 2005). 


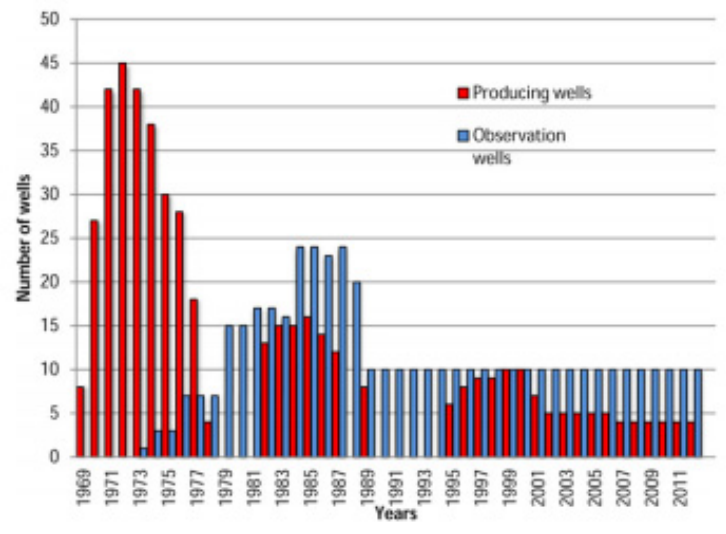

Figure 6. Wells application in Messoyakha field
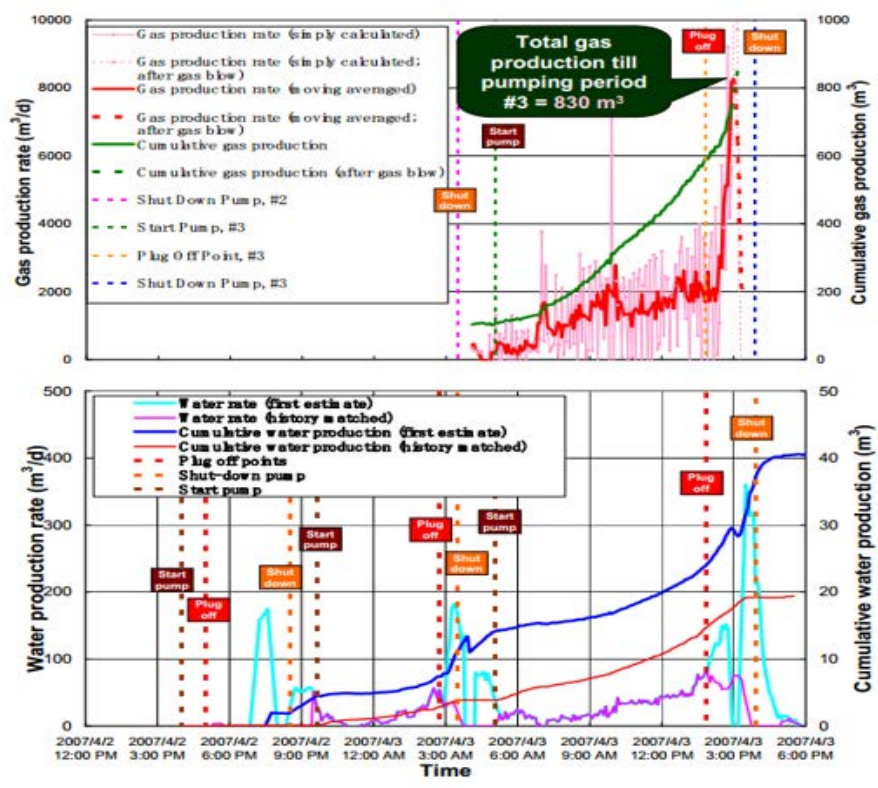

Figure 7. Estimation of gas and water production in 2007 winter test. 


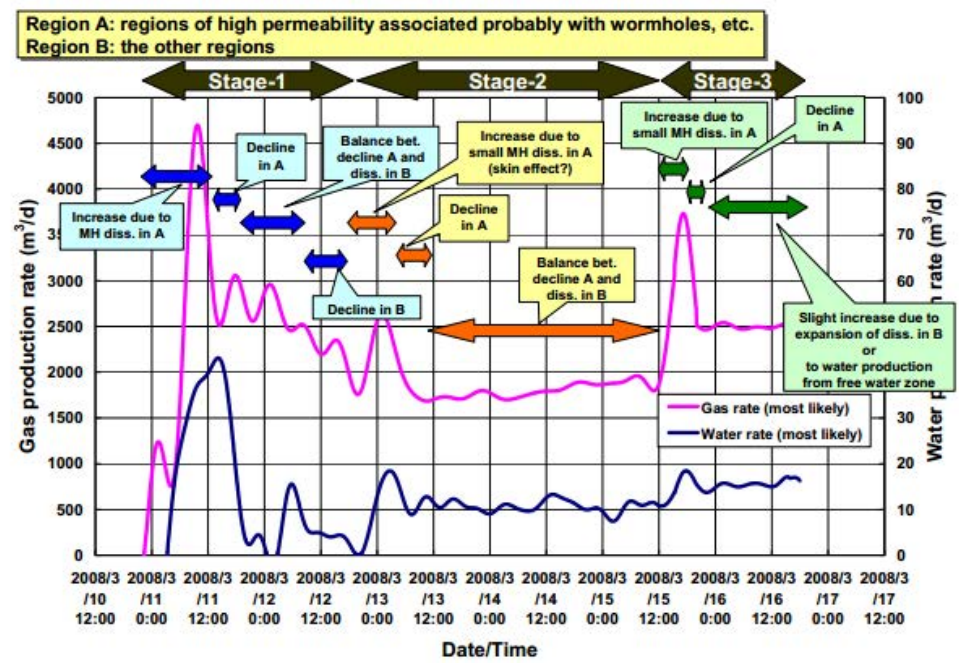

Figure 8. Estimation of gas and water production in 2008 winter test

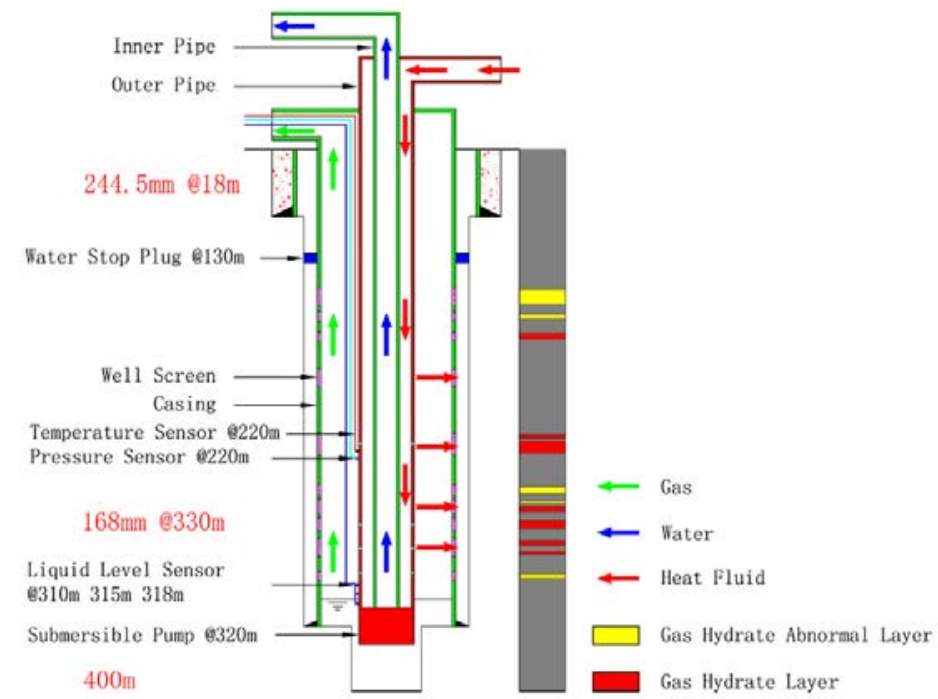

Figure 9. The designation of the production field test well in the QTPP 


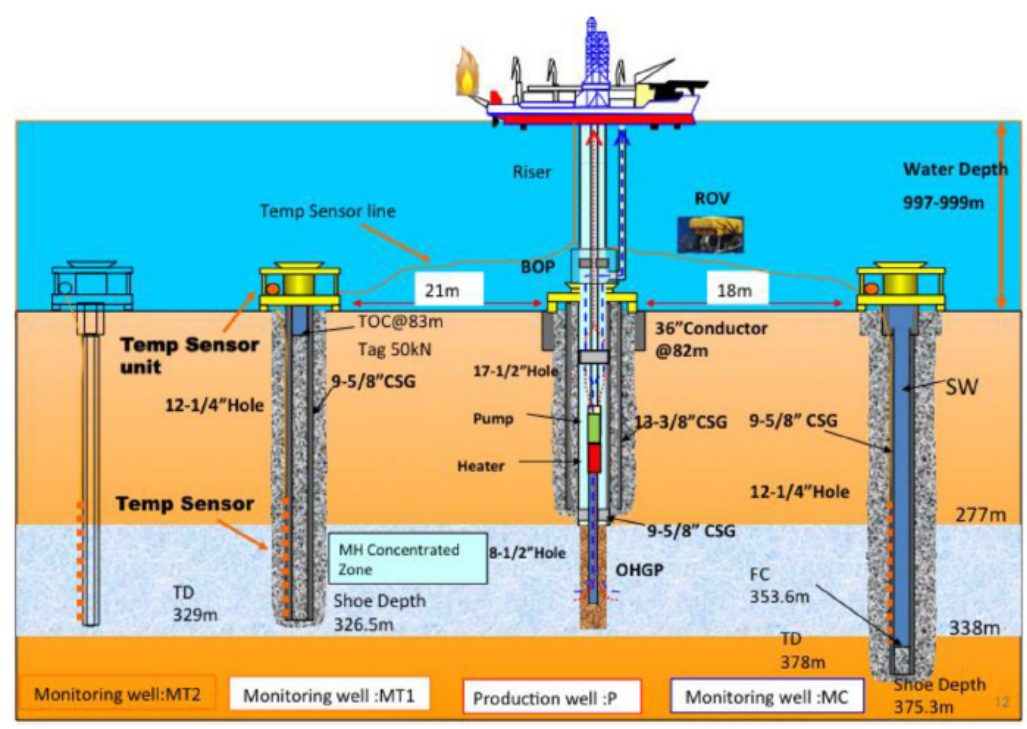

Figure 10. Schematics of the wells for the Nankai Trough produciton test

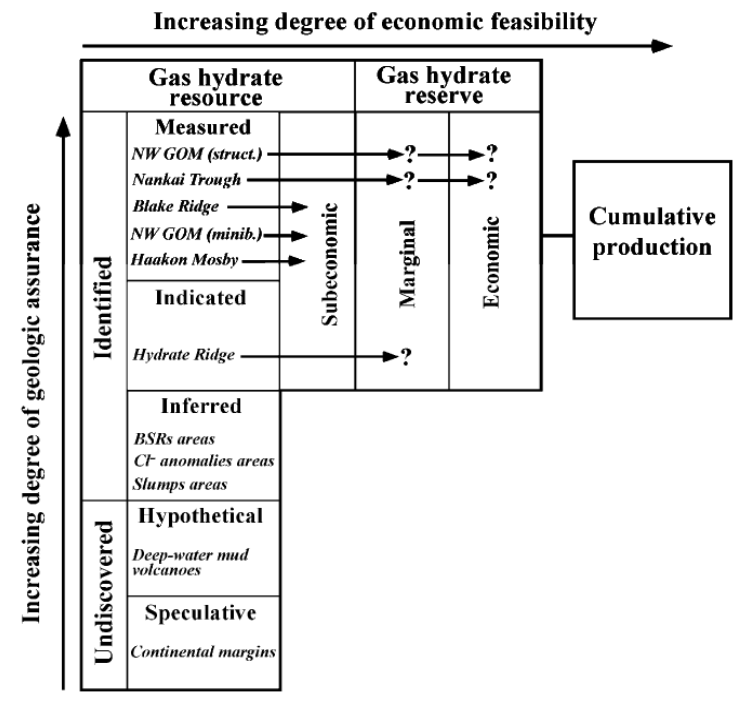

Figure 11. A scheme sample for classifying the resource/reserve of NGH 
Table 1. The simulation Zone and simulation scheme.

\begin{tabular}{|c|c|c|c|c|c|}
\hline Item & Zone \#1 & Zone \#2 & Zone \#3 & Zone \#4 & Zone \#5 \\
\hline $\begin{array}{l}\text { Properties } \\
\text { and } \\
\text { Characterist } \\
\text { ics }\end{array}$ & $\begin{array}{l}\text { Thickness: } 20 \mathrm{~m} \\
\text { Depth: to }-1108.4 \\
\mathrm{~m} \\
\text { Initial } \\
\text { Temperature:13.1 } \\
8 \square \\
\text { Pressure: } 10.8 \\
\mathrm{MPa} \\
\mathrm{S}_{\mathrm{H}}: 0.8 \\
\mathrm{~S}_{\mathrm{W}}: 0.2 \\
\mathrm{~A} \text { free gas zone } \\
\text { underlying }\end{array}$ & $\begin{array}{l}\text { Thickness: } 15 \mathrm{~m} \\
\text { Depth: }-899 \text { to } \\
-915 \mathrm{~m} \\
\text { Initial } \\
\text { Temperature: } \\
7.5 \square \\
\text { Pressure: } \quad 9.0 \\
\mathrm{MPa} \\
\mathrm{S}_{\mathrm{H}}: 0.5 \\
\mathrm{~S}_{\mathrm{W}}: 1.0 \\
\text { Impermeable } \\
\text { flow boundaries } \\
\text { An aquifer } \\
\text { underlying }\end{array}$ & $\begin{array}{l}\text { Thickness: } 10 \mathrm{~m} \\
\text { Depth: }-1081 \text { to } \\
-1091 \mathrm{~m} \\
\text { Initial } \\
\text { Temperature: } \\
12.8 \\
\text { Pressure: } 10.74 \\
\mathrm{MPa} \\
\mathrm{S}_{\mathrm{H}}: 0.8 \\
\mathrm{~S}_{\mathrm{W}}: 1.0 \\
\text { Impermeable } \\
\text { boundaries } \\
\text { No gas or water } \\
\text { underlying }\end{array}$ & $\begin{array}{l}\text { Thickness: } 10 \mathrm{~m} \\
\text { Depth: }-1007 \quad \text { to } \\
-1017 \mathrm{~m} \\
\text { Initial } \\
\text { Temperature: } \\
10.5 \square \\
\text { Pressure: } \quad 10.0 \\
\mathrm{MPa} \\
\mathrm{S}_{\mathrm{H}}: 0.5 \\
\text { Impermeable } \\
\text { boundaries } \\
\text { No gas or water } \\
\text { underlying }\end{array}$ & $\begin{array}{l}\text { Thickness: } 10 \mathrm{~m} \\
\text { Depth:-905 to -915 m } \\
\text { Initial Temperature: } \\
7.5 \square \\
\text { Pressure: } 8.9 \mathrm{MPa} \\
\mathrm{S}_{\mathrm{H}}: 0.8 \\
\text { Impermeable } \\
\text { boundaries } \\
\text { No gas or water } \\
\text { underlying }\end{array}$ \\
\hline Scheme 1 & $\begin{array}{l}\text { Depressurization, } \\
\text { Single vertical } \\
\text { well }\end{array}$ & $\begin{array}{l}\text { Depressurization, } \\
\text { Single vertical } \\
\text { well }\end{array}$ & $\begin{array}{l}\text { Thermal } \\
\text { stimulation, } \\
\text { Single vertical } \\
\text { well }\end{array}$ & $\begin{array}{l}\text { Thermal } \\
\text { stimulation, Single } \\
\text { vertical well }\end{array}$ & $\begin{array}{l}\text { Thermal stimulation, } \\
\text { Single vertical well }\end{array}$ \\
\hline Scheme 2 & $\begin{array}{l}\text { Depressurization, } \\
\text { Single horizontal } \\
\text { well }\end{array}$ & & & & \\
\hline Scheme 3 & $\begin{array}{l}\text { Depressurization } \\
\text { and thermal } \\
\text { stimulation, } \\
\text { Vertical two-well } \\
\text { system, } \\
\mathrm{Q}_{\mathrm{i}}=\mathrm{Q}_{\mathrm{p}}=1.67 \times 10^{-3} \\
\mathrm{~kg} / \mathrm{s}\end{array}$ & & & & \\
\hline Scheme 4 & $\begin{array}{l}\text { Depressurization } \\
\text { and thermal } \\
\text { stimulation, } \\
\text { Vertical two-well } \\
\text { system, } \\
\mathrm{Q}_{\mathrm{i}}=8.35 \times 10^{-4} \\
\mathrm{~kg} / \mathrm{s} \\
\mathrm{Q}_{\mathrm{p}}=2.51 \times 10^{-3} \\
\mathrm{~kg} / \mathrm{s} \\
\mathrm{Q}_{\mathrm{p}}-\mathrm{Q}_{\mathrm{i}}=1.67 \times 10^{-3} \\
\mathrm{~kg} / \mathrm{s}\end{array}$ & & & & \\
\hline
\end{tabular}


Table 2. Main geological, technological, and economic characteristics of gas hydrate accumulations and provinces

\begin{tabular}{|c|c|c|c|c|c|c|}
\hline \multirow[t]{3}{*}{ Characteristics } & \multicolumn{3}{|c|}{ Structural accumulations/provinces } & \multicolumn{3}{|c|}{ Stratigraphic accumulations/provinces } \\
\hline & Northern Gulf & Hydrate & Haakon & Northern & Blake & Nankai \\
\hline & of Mexico ${ }^{\mathrm{a}}$ & Ridge $^{b}$ & $\begin{array}{l}\text { Mosby mud } \\
\text { volcano }^{c}\end{array}$ & $\begin{array}{l}\text { Gulf of } \\
\text { Mexico }^{\mathrm{a}}\end{array}$ & Ridge $^{d}$ & Trough $^{\mathrm{e}}$ \\
\hline Water depth (m) & $440-2500$ & $700-1000$ & $1250-1260$ & $615-2500$ & $\begin{array}{l}1000-400 \\
0\end{array}$ & $700-3500$ \\
\hline Area extent $\left(\mathrm{km}^{2}\right)$ & 23000 & 375 & 1.8 & 22500 & 2600 & 3200 \\
\hline $\begin{array}{l}\text { Subsurface depth of } \\
\text { gas hydrate } \\
\text { occurrence (m) }\end{array}$ & $\begin{array}{l}0-1900 \text { (data } \\
\text { from cores and } \\
\text { modeling) }\end{array}$ & $\begin{array}{l}0-200 \text { (data } \\
\text { from cores } \\
\text { and BSR) }\end{array}$ & $\begin{array}{l}0-160 \text { (data } \\
\text { from cores and } \\
\text { modeling) }\end{array}$ & $\begin{array}{l}20-1500 \\
\text { (data from } \\
\text { one well and } \\
\text { modeling) }\end{array}$ & $\begin{array}{l}58-620 \\
\text { (data } \\
\text { from } 18 \\
\text { wells and } \\
\text { BSR) }\end{array}$ & $\begin{array}{l}50-500 \text { (data } \\
\text { from one well } \\
\text { and BSR) }\end{array}$ \\
\hline Gas hydrate origin & \multicolumn{3}{|c|}{$\begin{array}{l}\text { From thermogenic, bacterial, and mixed gas } \\
\text { rapidly migrated from depth below }\end{array}$} & \multicolumn{3}{|c|}{$\begin{array}{l}\text { Mainly from bacterial methane generated in } \\
\text { situ or slowly supplied from depth below }\end{array}$} \\
\hline $\begin{array}{l}\text { Gas hydrate } \\
\text { concentration } \\
(\mathrm{vol} \%)\end{array}$ & $\begin{array}{l}\text { Average } 20- \\
30, \text { up to } 100\end{array}$ & $\begin{array}{l}\text { Up to } 20- \\
60\end{array}$ & Up to 25 & Up to $1-2$ & $\begin{array}{l}\text { Average } \\
2, \text { up to } \\
14\end{array}$ & $\begin{array}{l}\text { Average 10, up } \\
\text { to } 30\end{array}$ \\
\hline Resource $\left(\mathrm{m}^{3}\right)$ & $8-11 \times 10^{12}$ & $\begin{array}{l}\text { Not } \\
\text { reported }\end{array}$ & $3 \times 10^{8}$ & $2-3 \times 10^{12}$ & $2.8 \times 10^{13}$ & Up to $6 \times 10^{13}$ \\
\hline $\begin{array}{l}\text { Average resource } \\
\text { density }\left(\mathrm{m}^{3} / \mathrm{km}^{2}\right)\end{array}$ & $4-5 \times 10^{8}$ & $\begin{array}{l}\text { Not } \\
\text { reported }\end{array}$ & $1.7 \times 10^{8}$ & $1 \times 10^{8}$ & $12 \times 10^{8}$ & $\begin{array}{l}\text { Up to } \\
18.4 \times 10^{8}\end{array}$ \\
\hline Permeability & High (fracture) & $\begin{array}{l}\text { High } \\
\text { (fracture) }\end{array}$ & High (fracture) & Low (matrix) & $\begin{array}{l}\text { Low } \\
\text { (matrix) }\end{array}$ & $\begin{array}{l}\text { Low to high } \\
\text { (matrix) }\end{array}$ \\
\hline Recovery factor & High & High & High & Low & Low & Low to high \\
\hline Development costs & Low & $\begin{array}{l}\text { Low to } \\
\text { average }\end{array}$ & $\begin{array}{l}\text { Average to } \\
\text { high }\end{array}$ & High & High & High \\
\hline Production costs & Low & Low & Low & High & High & $\begin{array}{l}\text { Average to } \\
\text { high }\end{array}$ \\
\hline Infrastructure & $\begin{array}{l}\text { Well } \\
\text { developed }\end{array}$ & None & None & $\begin{array}{l}\text { Well } \\
\text { developed }\end{array}$ & None & None \\
\hline Economic potential & High & $\begin{array}{l}\text { Average to } \\
\text { high }\end{array}$ & Low & Low & Low & $\begin{array}{l}\text { Average to } \\
\text { high }\end{array}$ \\
\hline
\end{tabular}

Remark: ${ }^{\mathrm{a}}[412,418-420]^{\mathrm{b}}[421,422]^{\mathrm{c}}[423,424]{ }^{\mathrm{d}}[425]^{\mathrm{e}}[81,113,426]$ 